\title{
FLORA Y VEGETACIÓN DEL PARAJE NATURAL DESFILADERO DE LOS GAITANES Y SU ENTORNO (MÁLAGA, ESPAÑA)
}

\author{
Andrés V. PÉREZ LATORRE*, Federico CASIMIRO-SORIGUER SOLANAS, \\ José GARCÍA SÁNCHEZ y Baltasar CABEZUDO \\ Dpto. de Biología Vegetal. Facultad de Ciencias. Universidad de Málaga. 29071 Málaga. \\ *Autor para correspondencia: avperez@uma.es
}

Recibido el 4 de septiembre de 2014, aceptado para su publicación el 31 de octubre de 2014

RESUMEN. Flora y vegetación del Paraje Natural Desfiladero de los Gaitanes y su entorno (Málaga, España). En el presente trabajo se realiza un catálogo de la flora, de las comunidades vegetales y su dinamismo sucesional y del paisaje vegetal de las Sierras que forman parte del Paraje Natural y Lugar de Importancia Comunitaria del Desfiladero de los Gaitanes (Málaga, Andalucía, España). El macrobioclima es de tipo mediterráneo con termotipos termo y mesomediterráneo y ombrotipos seco y subhúmedo. El área de estudio está compuesta geológicamente por materiales calizo-dolomíticos, arcillosos y calcareníticos, con geomorfología montañosa y altitudes entre 100 a $1200 \mathrm{~m}$. y se encuentra en la provincia fitogeográfica Bética (región Mediterránea), con zonas en los sectores Antequerano (sierras calizo-dolomíticas) y Malacitano-Axarquiense (sierras calcareníticas). El catálogo florístico se compone de 586 taxones, destacando endemismos de los sectores, como Echium albicans subsp. fruticescens o Saxifraga reuteriana, y 12 especies amenazadas, destacando Hippocrepis tavera-mendozae y Scrophularia viciosoi, ambos CR y también endemismos. Se han catalogado 50 comunidades y asociaciones vegetales, entre las que destacan como novedades sintaxonómicas los lastonares de Helictotricho arundani-Festucetum capillifoliae stat. nov., los matorrales de Genisto equisetiformis-Cytisetum fontanesii lectotipificada en este trabajo y las subasociaciones de matorral sobre dolomías Genisto speciosae-Ulicetum parviflorii lavanduletosum lanatae lectotipificada en este trabajo y el sabinar con pino carrasco de Asparago horridi-Juniperetum turbinatae pinetosum halepensis subass. nova. El dinamismo sucesional se resume en dos series climatófilas termo y mesomediterráneas de Quercus rotundifolia y una serie edafoxerófila termo-mesomediterránea de Juniperus turbinata. Existen también dos series edafohigrófilas (de Fraxinus angustifolia y de Nerium oleander). En los frecuentes hábitats rupícolas se describen 6 complejos topogénicos (entre ellos uno con Rupicapnos africana subsp. decipiens) y 3 edafogénicos (entre ellos uno con Festuca mediterranea). En el Parque existen 7 grandes unidades de paisaje zonopotencial, caracterizados en gran medida por la presencia de Juniperus turbinata.

Palabras clave. Comunidades vegetales, Sierra de Huma, Sierra de Almorchón, Sierra del Valle de Abdalajís, subsector Torcalense, Andalucía, Península Ibérica.

Financiado con la aportación económica de la Junta de Andalucía al grupo de investigación RNM 115 de la Universidad de Málaga. 
ABSTRACT. Vegetation and flora of the Paraje Natural Desfiladero de los Gaitanes and its surroundings (Malaga, Spain). In this paper, catalogues of flora and plant communities are performed and successional dynamism and vegetation landscape are described for the Natural Area and Site of European Importance Desfiladero de los Gaitanes (Malaga, Andalusia, Spain). The macrobioclimate is Mediterranean, with termo- and mesomediterranean thermotypes (vegetation belts) and dry and sub-humid ombrotypes. The study area is geologically composed of limestone-dolomite, clay and calcareous sanstone; geomorphology is mountainous with altitudes of $100-1200 \mathrm{~m}$. and it is placed in the Baetica phytogeographical province (Mediterranean region), with areas included in the Antequerano sector (limestone-dolomite mountains) and Malacitano-Axarquiense (calcareous sandstone mountains). The floristic catalogue consists of 586 taxa, highlighting endemism of the sectors such as Echium albicans subsp. fruticescens or Saxifraga reuteriana, and 12 threatened species, highlighting Hippocrepis tavera-mendozae and Scrophularia viciosoi both CR and also endemism. We have listed 50 plant communities and associations, among which stand out as new syntaxa the lastonares of Helictotricho arundani-Festucetum capillifoliae stat. nov., scrubs of Genisto equisetiformis-Cytisetum fontanesii lectotypus in this work and subassociations as scrubs on dolomites Genisto speciosae-Ulicetum parviflorii lavanduletosum lanatae lectotypus in this work and the juniper shrublands with Aleppo pine Asparago horridi-Juniperetum turbinatae pinetosum halepensis subass. nova. The successional dynamics is summarized in two climatophilous thermo and mesomediterranean vegetation series of Quercus rotundifolia and one thermo-mesomediterranean edafoxerophilous series of Juniperus turbinata. There are also two edaphohigrophilous series, one with Fraxinus angustifolia and other with Nerium oleander. In the frequent rocky places, 6 topogenous vegetation complexes (including one with Rupicapnos africana subsp. decipiens) and 3 edaphogenous (including one with Festuca mediterraneanea) are described. In the natural area, there are 7 major units of zonopotential landscape, characterized largely by the presence of Juniperus turbinata.

Key words. Plant communities, Sierra de Huma, Sierra de Almorchón, Sierra del Valle de Abdalajís, Torcalense phytogeographical subsector, Andalusia, Iberian Peninsula.

\section{INTRODUCCIÓN Y OBJETIVOS}

Dentro del hot-spot de fitodiversidad mediterránea en las Cordilleras Béticas (Andalucía, España) (Médail \& Quézel, 1999; Blanca et al., 2011), se localiza una de las zonas botánicas mas interesantes de la provincia de Málaga. Se trata del entorno del denominado Desfiladero de los Gaitanes, que incluye el propio desfiladero y la totalidad o parte de las sierras de la Pizarra, Huma, Llana y Abdalajís. El interés de este territorio viene avalado por su protección legal bajo el paraguas de distintas figuras de espacios protegidos a nivel regional, estatal y europeo. El Paraje Natural Desfiladero de los Gaitanes fue declarado como tal en 1984 (Ley 2/1984 de 18 de Julio), en 2002 es declarado como ZEPA y en 2014 (Decreto 222/2013 de la Junta de Andalucía) es declarado como ZEC. El resto del territorio estudiado se incluye en el LIC denominado Sierra de Abdalajís y la Encantada Sur, declarado como tal por decisión de la Comisión Europea (19 de julio de 2013) y propuesto como ZEC en la Resolución de 25 de Febrero de 2014 (BOJA de 19 de marzo de 2014). Sobre este territorio, o en su área fitogeográfica, se han realizado algunos trabajos de índole florística (Guerra, 1982; Plaza Arregui et al., 2001) y fitosociológica (Asensi et al., 2005; Pérez Latorre et al., 2008, 2009) siendo necesario un estudio completo de flora y vegetación exclusivo, que pueda servir para futuros planes de gestión y conservación.

El objetivo de este trabajo es la realización de un estudio de la vegetación de la zona (fitosociología y series de vegetación) y un catálogo florístico con un análisis de las especies mas significativas localizadas en la zona. 


\section{MATERIAL Y MÉTODOS}

\section{Área de estudio}

\section{Geografía}

El Paraje Natural Desfiladero de los Gaitanes tiene una extensión de 2.016 Ha y sus hitos mas importantes son: el Desfiladero de los Gaitanes (El Chorro), Sierra de la Pizarra / Sierra del Almorchón con 663 m y la Sierra de Huma con $1191 \mathrm{~m}$, pertenecientes a los términos municipales de Álora, Ardales y Antequera. El LIC Sierra de Abdalajís y la Encantada Sur, tiene una extensión de 2775 Ha y sus hitos mas importantes son: Sierra Llana con $881 \mathrm{~m}$, Sierra del Valle de Abdalajís con 1186 m y Sierra de la Pizarra con 663 m (Bobastro/ Encantada Sur), pertenecientes a los terminos municipales de Antequera, Ardales y Campillos (fig. 1).

\section{Litología y edafología}

Los materiales litológicos (IGME, 1990) y suelos (Balsera, 1989) se reparten por la zona de estudio a modo de dos grandes teselas, que utilizaremos posteriormente para asignar la corología de la flora y vegetación en el área de estudio:

1. Las sierras de El Chorro y Almorchón son muy homogéneas, compuestas por calcarenitas y conglomerados (macrotesela Pizarreña). Los suelos corresponden mayoritariamente a litosoles, lo que va a condicionar de modo drástico la vegetación.

2. El conjunto de las Sierras de Huma, Llana y Valle del Abdalajís (macrotesela de

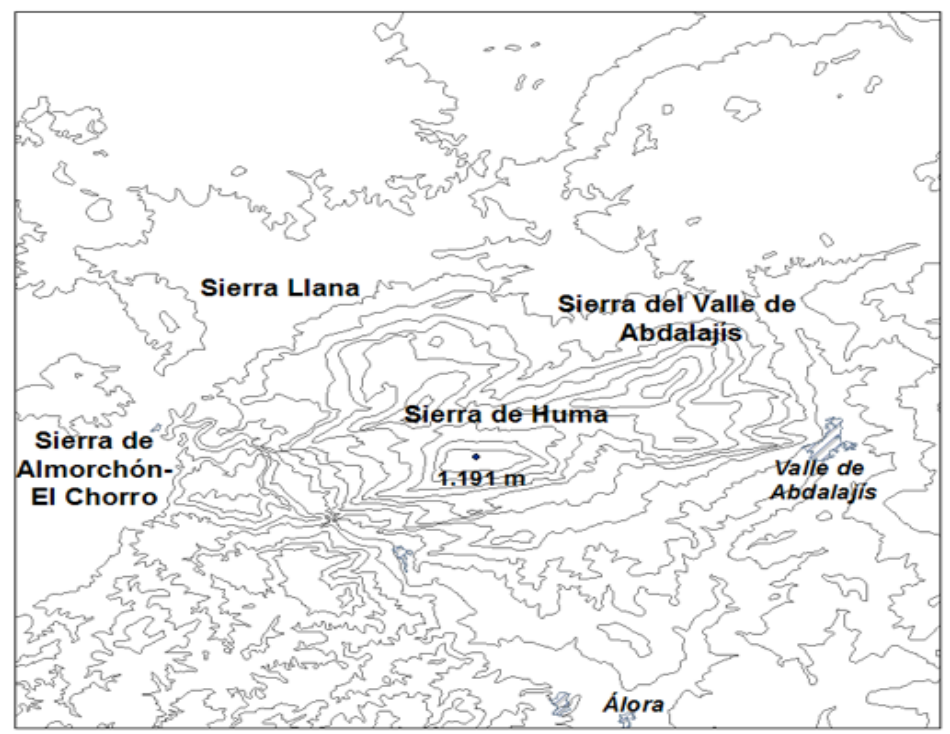

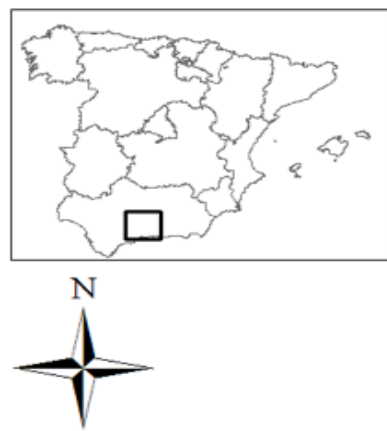

Leyenda

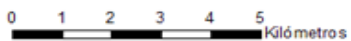

Figura 1. Localización y fitogeografía del área de estudio en el sur de la Península Ibérica (Andalucía, provincia de Málaga). Sierra de Almorchón y El Chorro (distrito Pizarreño del sector Malacitano-Axarquiense). Sierra de Huma, Sierra Llana y Sierra del Valle de Abdalajís (unidad de Abdalajís del subsector Torcalense, sector Antequerano). Location and phytogeography of the study area in the south of the Iberian Peninsula (Andalusia, Malaga province). Sierra de Almorchon and El Chorro (Pizarreño district, Malacitano-Axarquiense sector). Sierra de Huma, Sierra Llana and Sierra del Valle de Abdalajís (Abdalajís unit, Torcalense subsector, Antequerano sector). 


\begin{tabular}{lcccccc}
\hline Estación & altitud & $\mathrm{P}$ & $\mathrm{T}$ & $\mathrm{Itc}$ & Io & Ic \\
\hline Bobadilla* & 380 & 470 & 17,2 & 358 & 2,3 & 17,2 \\
El Chorro* & 225 & 494 & 16,3 & 355 & 2,5 & 15 \\
Gobantes** & 400 & 522 & 16,7 & 347 & 2,6 & 16,8 \\
\hline
\end{tabular}

Tabla 1. Datos climatológicos de la zona estudiada. P: precipitación media anual. T: temperatura media anual. Itc: índice de termicidad compensado. Io: índice ombrotérmico. Ic: índice de continentalidad simple. Datos: * Rivas Martínez (2007); ** De León (1989).

Abdalajís) presenta dolomías y calizas oolíticas, margocalizas rosadas "capas rojas", coluviones recientes de cantos con arenas y arcillas, margas y margocalizas, calizas nodulosas, margoareniscas, canchales de bloques y cantos de calizas y deslizamientos en masa de margas y bloques calcáreos.

Los suelos se corresponden con cambisoles cálcicos en la base de las sierras, mayoritariamente cultivados, y luvisoles crómicos y rendsinas en montaña, con gran abundancia de litosoles en las extensas zonas rocosas.

Es destacable la práctica inexistencia de materiales silíceos en el área de estudio, lo que puede influir por tanto en la ausencia de flora y vegetación silicícola o acidófila.

\section{Clima y bioclimatología}

Para la caracterización bioclimática de la zona estudiada nos hemos basado en los conceptos de termotipo (piso bioclimático) y ombrotipo (Rivas Martínez, 1987). Los datos climatológicos se han obtenido de De León (1989) y Rivas Martínez (2007). La clasificación macrobioclimática está basada en los conceptos de Rivas Martínez (op. cit.).

En función de las estaciones meteorologicas de la zona de estudio (tab. 1), el macrobioclima del territorio se define como mediterráneo pluviestacional oceánico (Rivas Martínez, 2007). La mayor parte del mismo se incluye en el piso bioclimático (termotipo) termomediterráneo superior con ombrotipo seco (hasta 800 m.). Sin embargo, la existencia de sinfitoindicadores como los piornales de Erinacea anthyllis, los matorrales con Lavandula lanata, pastizales de Viola demetria o los lastonares de Festuca capillifolia (entre otros) apuntan a la existencia del piso bioclimático mesomediterráneo, al menos en sus horizontes inferior (hasta $1000 \mathrm{~m}$.) y medio (hasta $1200 \mathrm{~m}$.) que alcanzarían las cumbres de Sierra Llana, Sierra de de Huma y Sierra del Valle de Abdalajís (macrotesela de Abdalajís). La macrotesela Pizarreña queda en su totalidad en el piso termomediterráneo superior. En cuanto al ombrotipo, aunque la mayor parte del territorio esté bajo el dominio del ombrotipo seco inferior, las estaciones meteorológicas se encuentran a muy baja altitud, por lo que, por efecto orográfico las lluvias deben de aumentar y en zonas medias debe dominar el ombrotipo seco superior. También en base a la aparición de fitoindicadores en zonas altas (Sierra de Huma), como algunos fanerófitos caducifolios y acompañantes herbáceos (Crataegus monogyna, Rosa agrestis., Pistacia terebinthus, Helleborus foetidus) y vegetación rupícola ombrófila (Saxifraga reuteriana), sería posible la existencia del ombrotipo subhúmedo inferior a partir de la aparición conjunta de dichos fitoindicadores (1000 m.). En cuanto a la continentalidad, la cara norte de las sierras muestran un Ic semejante al de zonas interiores de la Serranía de Ronda (Pérez Latorre et al., 2012) y a las caras sur que dan al térmico Valle del Guadalhorce. 


\section{Fitogeografía}

La sectorización fitogeográfica se basa fundamentalmente en la propuesta de Nieto Caldera et al. (1991) y Pérez Latorre \& Cabezudo (2002) para la provincia de Málaga, de Pérez Latorre et al. (2009) para el subsector Torcalense y de Pérez Latorre et al. (2008) e Hidalgo y Pérez Latorre (2013) para el sector Malacitano-Axarquiense y el Valle del Guadalhorce. Para las unidades superiores se ha seguido la sectorización propuesta por Galán de Mera et al. (2003). Los límites de las distintas unidades fitogeográficas se determinan en base a bioindicadores florísticos, comunidades, series de vegetación, paisaje vegetal, bioclimatología, geología y uso del territorio.

Según Pérez Latorre et al. (2009) la macrotesela calizo-dolomítica del territorio forma parte la unidad fitogeográfica de Abdalajís dentro del subsector Torcalense (sector Antequerano), cuya influencia se extiende hasta la sierra de Loja. Es posible que esta influencia llegue hasta las Subbéticas cordobesas, ya que Gómez Mercado et al. (1994) mencionan esta posible relación y la inexistencia de indicadores subbéticos en esa zona sudeste de la provincia de Córdoba, con el contrapunto de la existencia de algunos indicadores antequerano-torcalenses como Saxifraga reuteriana e Hippocrepis taveramendozae (Blanca et al., 2011). La macrotesela de las calcarenitas miocénicas se incluye según Asensi et al. (2005) en el distrito Anticariense (sector Rondeño), mientras que Pérez Latorre et al. (2008) mencionan un distrito Pizarreño (sector Malacitano-Axarquiense) que incluye los resaltes calizos y calcareníticos del Valle del Guadalhorce, en el que finalmente optamos por incluir esta macrotesela, ajena así tanto al sector Rondeño como al Antequerano sensu Pérez Latorre \& Cabezudo (2002).

La zona de estudio queda encuadrada en el siguiente esquema fitogeográfico:

Reino Holártico
Región Mediterránea

Subregión Mediterránea Occidental

Superprovincia Iberomarroquí Atlántica

Provincia Bética

A. Sector Antequerano [p.p. Sector Rondeño sensu Rivas Martínez et al. (2007)]

Subsector Torcalense [p.p. Distrito Anticariense sensu Rivas Martínez et al. (2007)]

Unidad de Abdalajís: Sierras de Huma, Llana y Valle de Abdalajís (algunos bioindicadores en el territorio: Saxifraga reuteriana, Scrophularia viciosoi; algunos sinfitoindicadores: Genisto speciosaeUlicetum parviflorii, Biscutello-Saxifragetum reuterianae)

B. Sector Malacitano-Axarquiense [p.p. Sector Granadino-Almijarense sensu Rivas Martínez et al. (2007)]

Subsector Malacitano [p.p. Distrito Axarquiense sensu Rivas Martínez et al. (2007)]

Distrito Pizarreño: Sierras de El Chorro, Almorchón, Bobastro (algunos bioindicadores en el territorio: Echium albicans subsp. fruticescens, Linaria salzmanii var. salzmanii; algunos sinfitoindicadores: Arenario arundanae-Linarietum salzmanii, Asparago horridi-Juniperetum turbinatae pinetosum halepensis subass. nova).

\section{Metodología}

El estudio de campo (recolecciones florísticas e inventarios de vegetación) se ha realizado durante los años 2012 y 2013 en todo el territorio del Paraje Natural y alrededores. Se ha recolectado material de todas las especies incluidas en los inventarios fitosociológicos y de otras especies de interés para la caracterización florística del territorio (endemismos, amenazadas, raras, singulares, etc.). Para la identificación del material recolectado se han seguido básicamente las obras "Flora Vascular de Andalucía Oriental" 
(Blanca et al., 2011) y "Flora Iberica" (Castroviejo et al., 1986-2014). Todos los pliegos se han depositado e informatizado en el Herbario MGC de la Universidad de Málaga.

Las unidades de vegetación se han descrito en base a la metodología fitosociológica de Braun-Blanquet (1979), Gehú \& Rivas Martínez (1981) y Schuhwerk (1990). Los inventarios se encuentran georeferenciados en teselas ecológicamente homogéneas de tamaño estimado mediante el cálculo del área mínima. La vegetación del territorio ha sufrido antropización en gran parte, lo que da lugar a comunidades fragmentarias, descritas como comunidades basales (BC), (Foucault, 1981; Dierschke, 1993). Para las nuevas propuestas nomenclaturales sintaxonómicas se ha consultado el Código Internacional de Nomenclatura Fitosociológica (Weber et al., 2000). Los diferentes estadíos dinámicos de la vegetación han sido analizados, en general, según la metodología sinfitosociológica bidireccional, aunque estimamos que existe un dinamismo horizontal "en red" (Pérez Latorre et al., 2012). Asumimos las propuestas tipológicas de Vigo (1998) para los complejos edafogénicos y topogénicos y de Pérez Latorre et al. (2004, 2008) respecto a la zonopotencialidad de los territorios y teselas, la sinfenosucesión y la vegetación criptoclimácica. El esquema sintaxonómico sigue el orden de las grandes unidades ecológicas y sintaxonómicas propuestas por Rivas Martínez et al. (2011).

\section{RESULTADOS Y DISCUSIÓN}

\section{Flora}

Se han identificado un total de 585 taxones (especies y subespecies). Todas vienen reseñadas en el catálogo florístico (Anexo I) donde hemos volcado la información en base a tres unidades características de la zona estudiada: Bobastro / Almorchón (distrito Pizarreño) con 228 especies
$(30$ SUF4128086750, radiopunto $=2100 \mathrm{~m})$, Sierras Llana / Huma (unidad de Abdalajís) con 424 especies (30SUF4429389568, radiopunto= $2200 \mathrm{~m})$ y Sierra del Valle de Abdalajís (unidad de Abdalajís) con 235 especies (30SUF4732590345, radiopunto $=2000$ $\mathrm{m})$. Los datos de todo el material estudiado (identificación, georeferenciación, ecología, etc.) han sido incorporados a la base de datos GBIF (Global Biodiversity Information Facility).

Entre todas las especies del catálogo florístico (Anexo I) hemos considerado en este apartado aquellas especies de interés en función de su grado de amenaza, distribución muy restringida en el territorio estudiado o por ser endemismos locales. La secuencia de datos sobre cada taxón es: nombre y autores, pliegos MGC, distribución general, abundancia en el área de estudio, biotipo, comportamiento ecológico, sintaxones principales en que aparece y categorías de amenaza si hubiere.

\section{Arenaria arundana Gallego}

Málaga. Ardales. Sierra del Almorchón. Cerro por encima del arroyo Granado. 30SUF4086. 300 m. 15/03/2013. Calcarenitas. Leg.: B. Cabezudo \& F. Soriguer. MGC 76347; Ardales. Montes alrededor del Caminito del Rey. 26/03/1993. Calizas. Leg.: B. Cabezudo, A. Flores \& P. Navas. MGC 35996

Bética. Rara. Terófito erecto. Pastizales sobre suelos pedregosos. Arenario arundanae-Linarietum salzmanii.

\section{Astragalus bourgaeanus Coss}

Málaga. Antequera. Sierra de Huma. Vertiente Oeste. Carril de Puerto Pizarro al cortijo del Madroño. 30SUF4389. 850 m. 12/04/2013. Leg.: B. Cabezudo, J. García-Sánchez \& F. Soriguer. MGC 76578.

Íbero-magrebí. Muy rara. Hemicriptófito rosulado. Matorrales y pastizales sobre suelos calizos. Genisto cinereae-Ulicetum parviflorii.

Athamanta vayredana (Font Quer) C. Pardo Málaga. Ardales. Desfiladero de los Gaitanes. 30SUF4287. 02/06/2005. Leg.: B. Díez Garretas \& A. Asensi. MGC 61779; Álora. Entre El Chorro 
y Bobastro. 30SUF4286085615 (Rp: 750 m.) 21/06/1986. Paredones. Leg.: B. Cabezudo \& R. Suau. MGC 20691.

Íbero-magrebí. Rara. Hemicriptófito escaposo. Rupícola en paredones calizos. Athamantetum vayredanae. VU (B2ab(i,ii,iv,v)).

Avenula gervaisii subsp. arundana C. Romero Zarco Málaga. Antequera. Sierra de Huma. Puerto Pizarro. 30SUF4389. 870 m. 06/06/2013. Matorrales. Calizo-dolomías. Leg.: B. Cabezudo, A. V. Pérez Latorre \& F. Soriguer. MGC 77778; Antequera. Sierra del Valle de Abdalajís. Carril de subida al Cortijo de la Rejanada. Alrededores del «salto de levante de parapente». 30SUF4688. $750 \mathrm{~m}$. 24/05/2013. Matorrales. Calizas. Leg.: A. V. Pérez Latorre \& F. Soriguer. MGC 77479.

Bético-rifeña. Rara. Hemicriptófito cespitoso. Matorrales sobre calizas y dolomías. Genisto cinereae-Ulicetum parviflorii.

Campanula cabezudoi Cano-Maq. \& Talavera

Málaga. Antequera. Sierra de Huma. Vertiente Norte. Desde el Cortijo de Campano Chico hasta la cumbre de Huma. 30SUF4505488542 (Rp: 500 m). 1070 m. 06/06/2013. Calizas. Leg.: B. Cabezudo, A. V. Pérez Latorre \& F. Soriguer. MGC 77720; Antequera. Sierra del Valle de Abdalajís. Cresta Oeste de la Sierra. Desde la cumbre al cortijo de la Rejanada. 30SUF4684989595 (Rp: 534 m). 1018 m. 24/05/2013. Calizas. Leg.: A. V. Pérez Latorre \& F. Soriguer. MGC 77467; Antequera. Sierra Llana. Tajo de los Cabritos. "El Metecaña". 30SUF4291. 700 m. 17/05/2013. Calizo-dolomías. Leg.: B. Cabezudo \& F. Soriguer. MGC 77336.

Endemismo bético. Rara. Terófito erecto. Pastizales sobre gleras móviles y roquedos. Violo demetriae-Jonopsidietum prolongoi. VU (B2ac(i,ii,iii,iv)).

\section{Centaurea boissieri DC. subsp. boissieri}

Málaga. Antequera. Sierra de Huma. Vertiente Norte. Desde el Cortijo de Campano Chico hasta la cumbre de Huma. 30SUF4505488542 (Rp: 500 m). 1070 m. 06/06/2013. Calizas. Leg.: B. Cabezudo, A. V. Pérez Latorre \& F. Soriguer. MGC 77697; Antequera. Sierra de Huma. Vertiente Oeste. 30SUF4388. 925 m. 17/05/2013. Calizo-dolomías. Leg.: B. Cabezudo \& F. Soriguer. MGC 77367; Antequera. Sierra de Huma. Vertiente Oeste. Entre el carril superior y la cumbre. 30SUF4382888374 (Rp: $233 \mathrm{~m}) .1005$ m. 30/05/2013. Calizas y dolomías. Leg.: B. Cabezudo, A. V. Pérez Latorre, N. Hidalgo \& F. Soriguer. MGC 77590.

Endemismo bético. Rara. Hemicriptófito reptante. Matorrales y lastonares sobre gleras fijas. Comunidad de Centaurea boissieri y Andryala ramosissima.

\section{Cistus ladanifer subsp. africanus Dans}

Málaga. Ardales. Sierra del Almorchón. Entre el pico del Convento y los Altos del Almorchón. 30SUF4087. 631 m. 21/03/2013. Pinar-sabinar y matorral sobre suelos desarrollados. Calcarenitas. Leg.: B. Cabezudo \& F. Soriguer. MGC 76409.

Íbero-magrebí. Muy rara. Nanofanerófito perennifolio. Matorrales y pinares. Comunidad de Cistus monspeliensis BC.

Cytisus malacitanus subsp. moleroi (Fern. Casas)

Á. Lora \& al.

Málaga. Antequera. Sierra Llana. Pista forestal desde los Tajos del Cabrero a la casa forestal de Cerro Pardo. 30SUF4190. 550 m. 25/01/2013. Calizas. Leg.: B. Cabezudo, A. V. Pérez Latorre \& F. Soriguer. MGC 76256; Campillos. Cercanías presa Guadalhorce-Guadalteba. 400 m. 29/02/2004. Leg.: A. V. Pérez Latorre. MGC 57796; Entre los términos municipales de Campillos y Ardales. Desde la Fuente del Carrizo a los altos de Cuevas Pardas. 30SUF4089. $450 \mathrm{~m}$. 12/04/2013. Zona rocosa con sabinar-pinar y pastizales. Sobre suelos arenosos. Calcarenitas. Leg.: B. Cabezudo, J. García-Sánchez \& F. Soriguer. MGC 76664; Ardales. Sierra del Almorchón. Carretera MA-444, poco antes del cruce a Bobastro. 30SUF4086. 300 m. 15/03/2013. Matorral abierto en zona rocosa. Calcarenitas. Leg.: B. Cabezudo \& F. Soriguer. MGC 76344.

Endemismo antequerano. Muy rara. Caméfito genistoide. Matorrales. Saturejo micranthaeThymbrion capitati.

\section{Echium albicans subsp. fruticescens (Coincy) Valdés}

Málaga. Entre los términos municipales de Campillos y Ardales. Desde la Fuente del Carrizo a los altos de Cuevas Pardas. 30SUF4089. 450 m. 12/04/2013. Calcarenitas. Leg.: B. Cabezudo, J. García-Sánchez \& F. Soriguer. MGC 76664; Ardales. Sierra del Almorchón. Carretera MA-444, 
poco antes del cruce a Bobastro. 30SUF4086. 300 m. 15/03/2013. Calcarenitas. Leg.: B. Cabezudo \& F. Soriguer. MGC 76344.

Endemismo pizarreño. Ocasional. Hemicriptófito erecto. Matorrales sobre suelos arenosos. Comunidad de Echium albicans subsp. fruticescens.

Erodium recoderii Ariault \& Guittonneau

Málaga. Álora. Tajos del Estudiante. Vereda a la Escalera Árabe. 30SUF4487. 600 m. 15/03/2013. Orientación sur. Tajos calizos verticales. Leg.: B. Cabezudo \& F. Soriguer. MGC 76305; Antequera. Sierra del Valle de Abdalajís. Pista desde el Valle de Abdalajís al cortijo de la Rejanada. 30SUF4788. 600 m. 15/03/2013. Calizas. Leg.: B. Cabezudo \& F. Soriguer. MGC 76363; Álora. El Chorro. Las Frontales. Subida al cortijo Can Pedrero por la «Escalera Árabe». 30SUF4487. $600 \mathrm{msnm}$. 27/03/2010. Rupícola. Calizas. Leg.: F. Soriguer. MGC 71246;

Endemismo bético. Rara. Terófito reptante. Rupícolas en grandes fisuras y pastizales sobre gleras. Comunidad de Hippocrepis tavera-mendozae. VU (D2).

Hedera hibernica (G. Kirchn.) Bean

Málaga. Antequera. Sierra del Valle de Abdalajís. Vaguada entre el Cortijo de la Rejanada y el pico de la Capilla. 30SUF4789. $900 \mathrm{~m}$. 24/05/2013. Torcal. Calizas. Leg.: A. V. Pérez Latorre \& F. Soriguer. MGC 77539.

Mediterránea occidental. Muy rara. Fanerófito trepador. Roquedos y canchales. Asplenietea trichomanis.

Helianthemum sanguineum (Lag.) Lag. ex Dunal Málaga. Ardales. Sierra del Almorchón. Entre el pico del Convento y los Altos del Almorchón. 30SUF4087. 631 m. 21/03/2013. Pastizales. Calcarenitas. Leg.: B. Cabezudo \& F. Soriguer. MGC 76375.

Íbero-magrebí. Rara. Terófito fasciculado. Pastizales terofíticos. Arenario arundanaeLinarietum salzmanii.

Helictotrichon filifolium (Lag.) Henrard. subsp. arundanum Romero Zarco

Málaga. Antequera. Sierra Llana. Tajos del Cortijo de Puerto Pizarro. 30SUF4342389216 (Rp:
273 m). 950 m. 30/05/2013. Rupícolas. Calizas. Leg.: B. Cabezudo, A. V. Pérez Latorre, N. Hidalgo \& F. Soriguer. MGC 77656; Antequera. Sierra del Valle de Abdalajís. Cara Norte. Alrededores del «despegue Norte de parapente». 30SUF4790. 775 m. 23/04/2013. Zona muy rocosa, lapiaces, gleras y tajos verticales. Calizas. Leg.: B. Cabezudo, A. V. Pérez Latorre \& F. Soriguer. MGC 77042; Antequera. Sierra del Valle de Abdalajís. Cresta Oeste de la Sierra. Desde la cumbre al cortijo de la Rejanada. 30SUF4684989595 (Rp: 534 m). 1018 m. 24/05/2013. Calizas. Leg.: A. V. Pérez Latorre \& F. Soriguer. MGC 77456; Antequera. Sierra del Valle de Abdalajís. Pico de la Capilla. Zona cacuminal. 30SUF4789. 1100 m. 24/05/2013. Orientación Noroeste. Roquedos. Calizas. Leg.: A. V. Pérez Latorre \& F. Soriguer. MGC 77492.

Endemismo bético. Ocasional. Hemicriptófito cespitoso. Lastonares y matorrales sobre lapiaces. Helictotricho arundani-Festucetum capillifoliae. VU (B2ab(i,ii,iii,iv,v)).

Hippocrepis tavera-mendozae Talavera \& E. Domínguez

Málaga. Antequera. Sierra Llana. Tajos del Cortijo de Puerto Pizarro. 30SUF4342389216 (Rp: 273 m). 950 m. 30/05/2013. Rupícolas. Calizas. Leg.: B. Cabezudo, A. V. Pérez Latorre, N. Hidalgo \& F. Soriguer. MGC 77659; Álora. Tajos del Estudiante. Vereda a la Escalera Árabe. 30SUF4487. $600 \mathrm{~m}$. 15/03/2013. Orientación sur. Tajos calizos verticales. Leg.: B. Cabezudo \& F. Soriguer. MGC 76303; Ardales. Desfiladero de los Gaitanes. 30SUF4069087025 (Rp: 1250 m.). 450 m. 09/06/1998. Calizas. Rupícola. Leg.: B. Cabezudo. MGC 46661

Endemismo antequerano. Muy rara. Caméfito pulvinular. Grietas de roquedos calizos. Comunidad de Hippocrepis tavera-mendozae. CR(B1ab(iii,iv,v) $+2 \mathrm{ab}(\mathrm{iii}, \mathrm{iv}, \mathrm{v}) ; \mathrm{C} 2 \mathrm{a}(\mathrm{i} . \mathrm{ii}) ; \mathrm{D})$.

\section{Juniperus turbinata Guss}

Málaga. Valle de Abdalajís. Sierra del Valle. 30SUF4673391793 (Rp: 2500 m.) 02/1990. Leg.: B. Cabezudo et J. M. Nieto. MGC 27400; Antequera. Sierra Llana. Tajos del Cortijo de Puerto Pizarro. 30SUF4342389216 (Rp: 273 m.). 950 m. 30/05/2013. Rupícolas. Calizas. Leg.: B. Cabezudo, A. V. Pérez Latorre, N. Hidalgo \& F. Soriguer. MGC 77661; Antequera. Sierra Llana. Zona superior y tajo 
de Ballesteros. 30SUF4490. 975 m. 17/05/2013. Tajos verticales y torcal. Calizas. Leg.: B. Cabezudo \& F. Soriguer. MGC 77392; Antequera. Sierra de Huma. Vertiente Oeste. 30SUF4388. 925 m. 17/05/2013. Matorrales en ladera pedregosa de fuerte pendiente. Calizo-dolomías. Leg.: B. Cabezudo \& F. Soriguer. MGC 77373; Antequera. Sierra Llana. Pista forestal desde los Tajos del Cabrero a la casa forestal de Cerro Pardo. 30SUF4190. 550 m. 25/01/2013. Matorrales. Calizas. Leg.: B. Cabezudo, A. V. Pérez Latorre \& F. Soriguer. MGC 76260; Ardales. Sierra del Almorchón. Carretera de subida al embalse superior del Tajo de la Encantada. 30SUF4085. 375 m. 25/01/2013. Calcarenitas. Leg.: B. Cabezudo, A. V. Pérez Latorre \& F. Soriguer. MGC 76266; Ardales. Cerro Almorchón. 30SUF4058587730 (Rp: 1200 m.) 09/02/2001. Calcarenitas. Leg.: B. Cabezudo et A. V. Pérez Latorre. MGC 47977; Campillos. Cerro Pardo. Zona superior. Orientación Sur. 30SUF4089. 550 m. 12/04/2013. Calcarenitas. Leg.: B. Cabezudo, J. García-Sánchez \& F. Soriguer. MGC 76621; Ardales. Sierra del Almorchón. Entre el pico del Convento y los Altos del Almorchón. 30SUF4087. $631 \mathrm{~m}$. 21/03/2013. Calcarenitas. Leg.: B. Cabezudo \& F. Soriguer. MGC 76407.

Mediterránea occidental. Frecuente. Nanofanerófito siempreverde. Formaciones arbustivas. Asparago horridi-Juniperetum turbinatae. VU (B2ab(i,ii,iii,iv,v))

Lepidium calycotrichum subsp. anticarium Valdés Berm. \& G. López

Málaga. Antequera. Sierra del Valle de Abdalajís. Pico de la Capilla. Zona cacuminal. 30SUF4789. 1100 m. 24/05/2013. Orientación Noroeste. Roquedos. Calizas. Leg.: A. V. Pérez Latorre \& F. Soriguer. MGC 77499.

Endemismo antequerano. Muy rara. Hemicriptófito cespitoso. Roquedos calizos. Biscutello frutescentis-Saxifragetum reuterianae. VU (B1ab(iii,v)+2ab(iii,v)).

\section{Linaria salzmannii Boiss var. salzmannii}

Málaga. Ardales. Mesa de Villaverde. Antigua ciudad de Bobastro. 30SUF4185. 600 m. 15/03/2013. Calcarenitas. Leg.: B. Cabezudo \& F. Soriguer. MGC 76334; Ardales. Sierra del Almorchón. Carretera MA-444, poco antes del cruce a Bobastro. 30SUF4086. $300 \mathrm{~m}$. 15/03/2013. Calcarenitas. Leg.: B. Cabezudo \& F. Soriguer. MGC 76342;
Ardales. Sierra del Almorchón. Cerro por encima del arroyo Granado. 30SUF4086. 300 m. 15/03/2013. Calcarenitas. Leg.: B. Cabezudo \& F. Soriguer. MGC 76351.

Endemismo pizarreño. Rara. Terófito erecto. Pastizales terofíticos sobre arenas. Arenario arundanae-Linarietum salzmannii.

\section{Lythrum thymifolia $\mathrm{L}$}

Málaga. Antequera. Sierra de Huma. Puerto Pizarro. 30SUF4389. 870 m. 06/06/2013. Arcillas. Leg.: B. Cabezudo, A. V. Pérez Latorre \& F. Soriguer. MGC 77762.

Circunmediterránea. Muy rara. Terófito erecto. Herbazales sobre suelos con encharcamiento temporal. Ranunculo macrophylli-Juncetum inflexi.

\section{Omphalodes commutata G. López}

Málaga. Antequera. Sierra de Huma. Vertiente Norte. Desde el Cortijo de Campano Chico hasta la cumbre de Huma. 30SUF4505488542 (Rp: 500 m). 1070 m. 06/06/2013. Calizas. Leg.: B. Cabezudo, A. V. Pérez Latorre \& F. Soriguer. MGC 77716; Antequera. Sierra Llana. Tajos del Cortijo de Puerto Pizarro. 30SUF4342389216 (Rp: 273 m). 950 m. 30/05/2013. Base de acantilados. Calizas. Leg.: B. Cabezudo, A. V. Pérez Latorre, N. Hidalgo \& F. Soriguer. MGC 77625; Antequera. Sierra del Valle de Abdalajís. Cara Norte. Alrededores del «despegue Norte de parapente». 30SUF4790. 775 m. 23/04/2013. Lapiaces y gleras. Calizas. Leg.: B. Cabezudo, A. V. Pérez Latorre \& F. Soriguer. MGC 77026; Antequera. Sierra Llana. Tajo de los Cabritos. «El Metecaña». 30SUF4291. 700 m. 17/05/2013. Gleras de fuertes pendientes. Calizo-dolomías. Leg.: B. Cabezudo \& F. Soriguer. MGC 77328.

Bética. Rara. Terófito erecto. Pastizales sobre gleras móviles y zonas rocosas. Violo demetriaeJonpsidietum prolongoi $\mathrm{VU}(\mathrm{B} 1 \mathrm{ab}(\mathrm{i}, \mathrm{ii}, \mathrm{iii}, \mathrm{iv}, \mathrm{i})+2 \mathrm{ab}$ $(\mathrm{i}, \mathrm{ii}, \mathrm{iii}, \mathrm{iv}, \mathrm{v}))$

\section{Petrorhagia saxifraga (L.) Link}

Málaga. Antequera. Sierra de Huma. Vertiente Norte. Desde el Cortijo de Campano Chico hasta la cumbre de Huma. 30SUF4505488542 (Rp: 500 m.). 1070 m. 06/06/2013. Pastizales sobre gleras móviles y zona rocosa. Calizas. Leg.: B. Cabezudo, A. V. Pérez Latorre \& F. Soriguer. MGC 77739; Antequera. Sierra de Huma. Vertiente Oeste. Tajos superiores por debajo de la cumbre. 30SUF4388. $1050 \mathrm{~m}$. 
30/05/2013. Rupícolas. Calizas. Leg.: B. Cabezudo, A. V. Pérez Latorre, N. Hidalgo \& F. Soriguer. MGC 77609; Antequera. Sierra Llana. Tajos del Cortijo de Puerto Pizarro. 30SUF4342389216 (Rp: 273 m). 950 m. 30/05/2013. Rupícolas. Calizas. Leg.: B. Cabezudo, A. V. Pérez Latorre, N. Hidalgo \& F. Soriguer. MGC 77665.

Euroasiática. Rara. Hemicritófito cespitoso. Pastizales rupícolas. Biscutello frutescentisSaxifragetum reuterianae. DD (LRA).

Rupicapnos africana subsp. decipiens (Pugsley) Maire in Jahand. \& Maire

Málaga. Ardales. Mesa de Villaverde. Bobastro. Final de carretera MA-448. 30SUF4285. $600 \mathrm{~m}$. 15/03/2013. Rupícola. En covachas excavadas en calcarenitas. Leg.: B. Cabezudo \& F. Soriguer. MGC 76328; Campillos. Cerro Pardo. Carril de la cantera al tajo de los Cabritos. 30SUF4090. 400 m. 12/04/2013. Sabinar denso en ladera umbría. Calcarenitas. Leg.: B. Cabezudo, J. García-Sánchez \& F. Soriguer. MGC 76553; Antequera. Sierra de Huma. Vertiente Oeste. Tajos superiores por debajo de la cumbre. 30SUF4388. 1050 m. 30/05/2013. Rupícolas. Calizas. Leg.: B. Cabezudo, A. V. Pérez Latorre, N. Hidalgo \& F. Soriguer. MGC 77605; Antequera. Sierra Llana. Tajos del Cortijo de Puerto Pizarro. 30SUF4342389216 (Rp: 273 m). 950 m. 30/05/2013. Rupícolas. Calizas. Leg.: B. Cabezudo, A. V. Pérez Latorre, N. Hidalgo \& F. Soriguer. MGC 77660; Antequera. Sierra Llana. Cortijo de las Cabreras. Tajos del Pozo de la Mona. 30SUF4391. $550 \mathrm{~m}$. 19/04/2013. Rupícolas. Tajos verticales. Calizas. Leg.: B. Cabezudo \& F. Soriguer. MGC 76847.

Bético-magrebí. Ocasional. Caméfito pulvinular. Rupicola espeluncícola (calizas y areniscas). Rupicapnetum decipientis. EN (B2ab(ii,iii,iv)c(ii)).

\section{Saxifraga reuteriana Boiss}

Málaga. Antequera. Sierra de Huma. Vertiente Norte. Desde el Cortijo de Campano Chico hasta la cumbre de Huma. 30SUF4505488542 (Rp: 500 m). 1070 m. 06/06/2013. Rupícolas. Calizas. Leg.: B. Cabezudo, A. V. Pérez Latorre \& F. Soriguer. MGC 77751; Antequera. Sierra de Huma. Vertiente Oeste. Tajos superiores por debajo de la cumbre. 30SUF4388. 1050 m. 30/05/2013. Rupícolas. Calizas. Leg.: B. Cabezudo, A. V. Pérez Latorre, N. Hidalgo \& F. Soriguer. MGC 77603; Antequera.
Sierra Llana. Cara Noroeste. Tajos del Cortijo del Arpa. Tajos del Buenasombra. 30SUF4190. $625 \mathrm{~m}$. 23/04/2013. Rupícolas y subrupícolas en la base de cantiles calizos. Leg.: B. Cabezudo, A. V. Pérez Latorre \& F. Soriguer. MGC 76993; Antequera. Sierra Llana. Cortijo de las Cabreras. Tajos del Pozo de la Mona. 30SUF4391. 550 m. 19/04/2013. Rupícolas. Tajos verticales. Calizas. Leg.: B. Cabezudo \& F. Soriguer. MGC 76851; Antequera. Sierra Llana. Final de la pista forestal. 30SUF4390. 800 m. 17/05/2013. Rupícolas. Torcas calizas. Leg.: B. Cabezudo \& F. Soriguer. MGC 77427; Antequera. Sierra Llana. Tajo de los Cabritos. «El Metecaña». 30SUF4291. 700 m. 17/05/2013. Rupícolas. Calizas. Leg.: B. Cabezudo \& F. Soriguer. MGC 77318.

Endemismo antequerano. Rara. Caméfito pulvinular. Roquedos calizos. Biscutello frutescentisSaxifragetum reuterianae. $\mathrm{VU}(\mathrm{B} 1 \mathrm{ab}(\mathrm{i}, \mathrm{ii}, \mathrm{iii}, \mathrm{iv}, \mathrm{v})+2 \mathrm{a}$ b(i,ii,iii,iv,V))

Scrophularia viciosoi A. Ortega Olivencia et J. A. Devesa Alcaraz

Málaga. Álora. Sierra de Huma. Camino El Chorro-Valle de Abdalajís. 30SUF4688. $680 \mathrm{~m}$. 01/05/2002. Sustrato calizo. Márgenes de zonas cultivadas. Leg.: D. Navas et S. Trías. MGC 44278.

Endemismo torcalense. Muy rara. Hemicriptófito rizomatoso. Matorrales en zonas pedregosas y borde de cultivos. CR(B1ab(ii,iii,v))

\section{Sideritis reverchonii Willk}

Málaga. Antequera. Sierra del Valle de Abdalajís. Cara Norte. Pista de subida al «despegue norte de parapente». 30SUF4891. 625 m. 23/04/2013. Matorrales. Margocalizas rosadas (capas rojas). Leg.: B. Cabezudo, A. V. Pérez Latorre \& F. Soriguer. MGC 76978; Antequera. Sierra Llana. Final de la pista forestal. 30SUF4390. $800 \mathrm{~m}$. 17/05/2013. Mosaico de matorrales y pastizales. Calizas. Leg.: B. Cabezudo \& F. Soriguer. MGC 77408; Antequera. Sierra Llana. Tajo de los Cabritos. «El Metecaña». 30SUF4291. 700 m. 17/05/2013. Mosaico de matorrales y pastizales sobre gleras y fuertes pendientes. Calizo-dolomías. Leg.: B. Cabezudo \& F. Soriguer. MGC 77326; Antequera. Alrededores del Cerro del Águila. Entrando por el cortijo de Carallana. 30SUF4793. 450 m. 19/04/2013. Matorrales y pastizales. Calizas/margas y yesos. Leg.: B. Cabezudo \& F. Soriguer. MGC 76890; Valle de Abdalajís. Valle de Abdalajís. 30SUF5156789924 
(Rp: 3100 m.). 10/12/1995. Leg.: Velasco, Artacho, Enriquez, Santillana \& Nieto. MGC 41023

Endemismo rondeño, antequerano y malacitano-axarquiense. Rara. Caméfito sufruticoso. Matorrales. Saturejo micranthae-Thymbrion capitati. EN (B2ab(I,II,III,IV,V);D)

\section{Novedades y comentarios sintaxonómicos}

Se incluyen en este apartado los comentarios y descripciones de las asociaciones de interés presentes en el territorio estudiado, con un número que corresponde al que se les asigna en el esquema sintaxonómico. El conjunto de todas las comunidades y asociaciones localizadas en la zona estudiada se resumen en el esquema sintaxonómico.

\section{Comunidad de Carex hispida e Iris pseudacorus}

Formaciones herbáceas megafórbicas y edafohigrófilas, caracterizadas por Carex hispida e Iris pseudacorus, acompañadas de Lythrum salicaria y Typha domingensis. Se desarrollan en aguas lentas con suelos limosos encharcados debido al agua embalsada en toda la zona de los pantanos de El Chorro. Estas comunidades son escasas en la provincia de Málaga. (Asensi \& Nieto, 1981; Pérez Latorre, 2010).

Localidad. Málaga. Ardales. Embalse del Gaitanejo. 30SUF4088. Orientación: Inclinación: $0^{\circ}$. Área: $100 \mathrm{~m}^{2}$. Litología: limos. Altitud: $300 \mathrm{~m}$. Altura vegetación: $160 \mathrm{~cm}$. Cobertura vegetación: $100 \%$. Características de comunidad: Carex hispida 4, Iris pseudacorus 3. Características de unidades superiores: Lythrum salicaria 3, Typha domingensis 2 . Compañeras: Equisetum telmateia 1, Scirpoides holoschoenus 2, Dorycnium rectum 2.

\section{Biscutello frutescentis-Saxifragetum} reuterianae Socorro \& Marín Calderón 1983 saxifragetosum reuterianae [Tabla 2]
Vegetación rupícola basófila, umbrófila, que se desarrolla en grietas de acantilados verticales orientados al norte, en el piso mesomediterráneo de las Sierras de Huma, Llana y del Valle de Abdalajís (subsector Torcalense, unidad de Abdalajís). Está caracterizada por el endemismo torcalense Saxifraga reuteriana, aunque en el área de estudio no se ha localizado a Biscutella frutescens, al igual que en otras zonas del subsector Torcalense (Pérez Latorre et al., 2009). Tampoco se ha localizado la variante termófila propuesta por Pérez Latorre et al. (op. cit.) para las unidades más orientales del subsector, aunque sí a Erodium cheilanthifolium, de la variante orófila, a más de $1100 \mathrm{~m}$. de altitud. En algunos inventarios aparece Petrorrhagia saxifraga, que caracteriza una variante local de la unidad de Abdalajís, ausente de las zonas central y oriental de dicho subsector.

\section{Athamantetum vayredanae $\mathrm{M}$. López \&}

Esteve in M. López, Marín, Molero Mesa

\& Esteve 1982 nom. mut. propos. [Tabla 3]

(Seselietum vayredani M. López \& Esteve in M. López, Marín, Molero \& Esteve 1982, art. 45; Syn. Chaenorhino villosae-Campanuletum mollis Rivas Goday 1953 athamantetosum vayredanae Pérez Latorre y Cabezudo in Pérez Latorre et al. 1998) [El nombre aceptado en Flora Vascular de Andalucía Oriental y Flora Iberica es el de Athamanta vayredana (Font Quer) C. Pardo]

\section{var. con Rupicapnos africana}

Asociación rupícola muy restringida a determinadas sierras béticas litorales muy térmicas y secas. En la sierra de Almijara, A. vayredana se acompaña de Sarcocapnos enneaphylla en el Athamanto vayredanaeSarcocapnetum enneaphyllae (Pérez Latorre et $a l ., 2004)$, mientras que en Sierra de las Nieves, en una ecología desviante, lo hace de Centaurea clementei (Pérez Latorre et al., 1998). A modo de vicariancia ecológica con esas dos zonas, en el área de estudio existe una variante de paredes 
Tabla 2

\begin{tabular}{|c|c|c|c|c|c|c|c|c|c|}
\hline \multicolumn{10}{|c|}{$\begin{array}{l}\text { 5. Biscutello frutescentis-Saxifragetum reuterianae Socorro \& Marín Calderón } 1983 \\
\text { (Campanulion velutinae, Asplenietalia petrarchae, Asplenietea trichomanis) }\end{array}$} \\
\hline INVENTARIO N ${ }^{\circ}$ & 1 & 2 & 3 & 4 & 5 & 6 & 7 & 8 & 9 \\
\hline Orientación & $\mathrm{NE}$ & $\mathrm{N}$ & $\mathrm{N}$ & $\mathrm{N}$ & $\mathrm{O}$ & NO & $\mathrm{N}$ & $\mathrm{N}$ & $\mathrm{N}$ \\
\hline Inclinación $\left({ }^{\circ}\right)$ & 90 & 80 & 90 & 90 & 90 & 80 & 80 & 80 & 90 \\
\hline Área $\left(\mathrm{m}^{2}\right)$ & 15 & 20 & 4 & 10 & 24 & 20 & 7 & 12 & 100 \\
\hline Litología & Cal & $\mathrm{Cal}$ & $\mathrm{Cal}$ & Cal & Cal & Cal & Cal & Cal & $\mathrm{Cal}$ \\
\hline Altitud (m) & 500 & 820 & 1100 & 1100 & 1010 & 1010 & 1090 & 1180 & 1000 \\
\hline Altura vegetación (cm) & 15 & 20 & 10 & 25 & 20 & 20 & 10 & 25 & 15 \\
\hline Cobertura vegetación (\%) & 25 & 25 & 50 & 60 & 25 & 20 & 40 & 15 & 10 \\
\hline \multicolumn{10}{|c|}{ Características y territoriales de asociación } \\
\hline Saxifraga reuteriana & 2 & 1 & + & 3 & + & 1 & 2 & 1 & 1 \\
\hline Lepidium calycotrichum subsp. anticarium & - & - & - & + & - & - & - & - & - \\
\hline Erodium cheilanthifolium & - & - & - & - & - & - & - & 1 & - \\
\hline Petrorrhagia saxifraga & - & - & - & - & + & - & 1 & + & - \\
\hline \multicolumn{10}{|l|}{ Características de unidades superiores } \\
\hline Silene andryalifolia & + & 1 & 1 & 3 & 1 & 2 & - & - & 1 \\
\hline Ceterach officinarum & + & - & + & - & - & + & + & + & - \\
\hline Crepis albida & - & - & 2 & - & 1 & 1 & 2 & - & - \\
\hline Linaria anticaria & - & 1 & - & 2 & 1 & - & - & - & + \\
\hline Melica minuta & - & + & + & - & + & + & - & - & - \\
\hline Asplenium trichomanes & - & + & - & - & - & - & + & - & - \\
\hline Campanula mollis & + & + & - & - & - & - & - & - & - \\
\hline Phagnalon rupestre & - & - & - & - & + & - & - & - & - \\
\hline \multicolumn{10}{|l|}{ Compañeras } \\
\hline Stachys circinata & 1 & - & + & + & + & 1 & 2 & - & 1 \\
\hline Scabiosa turolensis & - & + & 3 & - & + & 1 & 1 & + & - \\
\hline Cerastium boissieri & - & + & + & 1 & - & - & + & + & - \\
\hline Chaenorhinum villosum & - & 1 & - & - & 1 & - & 1 & + & + \\
\hline Galium lucidum & - & - & + & + & + & + & - & - & + \\
\hline Umbilicus rupestris & + & - & - & + & - & + & + & - & + \\
\hline Hyoseris radiata & - & 1 & + & - & 1 & + & - & - & - \\
\hline Ranunculus blepharicarpos & - & + & 1 & - & - & + & - & + & - \\
\hline Anthemis tuberculata & - & - & - & + & + & + & - & - & - \\
\hline Mucizonia hispida & + & - & - & + & + & - & - & - & - \\
\hline Muscari atlanticum & - & - & + & - & - & + & - & + & - \\
\hline Sedum dasyphyllum & + & + & - & - & + & - & - & - & - \\
\hline Lactuca tenerrima & + & - & - & - & + & - & - & - & - \\
\hline Lobularia maritima & + & 1 & - & - & - & - & - & - & - \\
\hline Rhamnus myrtifolius & - & - & - & - & 2 & - & + & - & - \\
\hline Veronica cymbalaria & + & - & - & + & - & - & - & - & - \\
\hline
\end{tabular}

Otras compañeras. En 1: Polypodium interjectum 1, Centranthus macrosiphon,+ Fumaria macrosepala + , Lapiedra martinezii + , Mercurialis ambigua + , Phagnalon saxatile + , Sonchus tenerrimus + . En 2: Fumaria rupestris +, Polypodium cambricum 1. En 3: Campanula cabezudoi +, Conopodium thalictrifolium +, Saxifraga tridactylites +, Viola demetria +. En 4: Bunium macuca +, Geranium lucidum +, Musgo pleurocárpico 3, Líquenes 4. En 5: Sedum acre +. En 6: Armeria villosa subsp. longiaristata 1, Helictotrichon filifolium subsp. arundanum 1, Smyrnium olusatrum +. En 7: Hedera helix +.

Localidades. 1. Málaga. Antequera. Sierra Llana. Tajos del Cortijo del Arpa, "El Buenasombra". 30SUF4190. 2. Málaga. Antequera. Sierra del Valle de Abdalajís. Proximidades del "despegue norte". 30SUF4790. 3. Málaga. Antequera. Sierra del Valle de Abdalajís. La Capilla, cara noroeste. 30SUF4789. 4. Málaga. Antequera. Sierra del Valle de Abdalajís. La Capilla, cara norte. 30SUF4789. 5 y 6. Málaga. Antequera. Sierra de Huma, vertiente oeste. Tajos de la cumbre. 30SUF4388. 7 y 8. Málaga. Antequera. Sierra de Huma. Vertiente norte, entre el Cortijo Campano Chico y la cumbre de Huma. 30SUF4588. 9. Málaga. Antequera. Sierra Llana. Tajo de Ballesteros. 30SUF4490. Cal: calizas. 
extraplomadas (El Chorro) con Rupicapnos africana, ya reconocida por López et al. (1982) (Pérez Latorre et al., 1995).

7. Comunidad de Hippocrepis tavera-mendozae [Tabla 4]

Vegetación rupícola, edafoxerófila y heliófila, en grietas cercanas a la verticalidad, calcícola y termomediterránea, propia de la zona de El Chorro y Sierra Llana (subsector Torcalense, unidad de Abdalajís). Está caracterizada por el endemismo antequerano Hippocrepis tavera-mendozae, que se acompaña de especies notables como Rupicapnos africana subsp. decipiens y Erocium recoderi (endemismo bético-occidental). Por la altitud a que se desarrolla y la presencia de especies como Silene andryalifolia o Putoria calabrica optamos por incluirla en Campanulion velutinae. Es posible la existencia de esta comunidad en Sierra Alcaide (sur de Córdoba) por la presencia de H. tavera-mendozae (Blanca et al., 2011).
10. Rupicapnetum decipientis Pérez Latorre, Cabezudo \& Nieto 1995 [Tabla 5]

Vegetación rupícola que se desarrolla en extraplomos tanto calizos en las sierras Llana y de Huma (unidad de Abdalajís, subsector Torcalense) como calcareníticos en El Chorro, Almorchón y Bobastro (unidad Pizarreña, subsector Malacitano). Está caracterizada básicamente por Rupicapnos africana subsp. decipiens, que se acompaña de otras especies rupícolas nitrófilas. En las sierras calizas son compañeras diferenciales Stachys circinata, Fumaria rupestris y Silene andryalifolia, entre otras. En las sierras estudiadas alcanza el piso mesomediterráneo (invs. 8, 9 y 10) lo que no es frecuente para la asociación.

\section{Comunidad de Centaurea boissieri y Andryala ramosissima}

Vegetación herbácea perenne, propia de taludes dolomíticos en el piso mesomediterráneo inferior de la Sierra de Huma y que llega más empobrecida a algunos canchales de la Sierra

Tabla 3

6. Athamantetum vayredanae M. López \& Esteve in M. López, Marín, Molero \& Esteve 1982 nom. mut. propos., var. con Rupicapnos africana

(Campanulion velutinae, Asplenietalia petrarchae, Asplenietea trichomanis)

\begin{tabular}{|c|c|c|c|c|}
\hline INVENTARIO N ${ }^{\circ}$ & 1 & 2 & 3 & 4 \\
\hline Orientación & $\mathrm{E}$ & E & NE & $\mathrm{NE}$ \\
\hline Inclinación $\left({ }^{\circ}\right)$ & 100 & 90 & 100 & 90 \\
\hline Área $\left(m^{2}\right)$ & 10 & 10 & 25 & 25 \\
\hline Litología & Cal & Cal & Cal & Cal \\
\hline Altitud (m) & 500 & 500 & 300 & 300 \\
\hline Altura vegetación (cm) & 30 & 50 & 30 & 30 \\
\hline Cobertura vegetación (\%) & 5 & 10 & 10 & 20 \\
\hline $\begin{array}{l}\text { Característica de asociación } \\
\text { Athamanta vayredana } \\
\text { Diferencial de variante }\end{array}$ & 1 & 1 & 3 & 2 \\
\hline Rupicapnos africana subsp. decipiens & + & - & 1 & - \\
\hline
\end{tabular}

Características de unidades superiores. En 3: Campanula mollis + . En 4: Petrorhagia saxifraga + , Melica minuta 1.

Compañeras. En 2: Rhamnus myrtifolia 1, Lavatera maritima +. En 4: Bupleurum gibraltaricum 3, Chaenorhinum villosum + .

Localidades. 1 y 2. Málaga. Ardales. Tajos del Almorchón. 30SUF4188. 3 y 4. Málaga. Ardales. Desfiladero de los Gaitanes. Caminito del Rey a su paso por el segundo cañón. 30SUF4188. Cal: calizas. 
Tabla 4

7. Comunidad de Hippocrepis tavera-mendozae (Campanulion velutinae, Asplenietalia petrarchae, Asplenietea trichomanis)

\begin{tabular}{lcc} 
INVENTARIO N & 1 & 2 \\
Orientación & $\mathrm{E}$ & $\mathrm{S}$ \\
Inclinación $\left.^{\circ}{ }^{\circ}\right)$ & 90 & 80 \\
${\text { Área }\left(\mathrm{m}^{2}\right)}^{\text {Litología }}$ & 20 & 25 \\
Altitud (m) & $\mathrm{Cal}$ & $\mathrm{Cal}$ \\
Altura vegetación (cm) & 600 & 929 \\
Cobertura vegetación $(\%)$ & 15 & 20 \\
Características de comunidad & 15 & 25 \\
Hippocrepis tavera-mendozae & 1 & \\
Petrorhagia saxifraga & - & 1 \\
Erodium recoderii & + & - \\
Putoria calabrica & + & - \\
Rupicapnos africana & & \\
$\quad$ subsp. decipiens & + & - \\
Características de unidades superiores & \\
Melica minuta & 1 & + \\
Ceterach officinarum & + & - \\
Crepis albida & - & + \\
Silene andryalifolia & - & 1 \\
Compañeras & & \\
Galium lucidum subsp. lucidum & 1 & 1 \\
Lavatera maritima & 1 & 1 \\
Rhamnus myrtifolius & + & + \\
\hline
\end{tabular}

Otras compañeras. En 1: Crambe filiformis +, Geranium purpureum +, Lapiedra martinezii +, Ruta angustifolia + , Sedum sediforme 1. En 2: Ballota hirsuta 1, Hyoseris radiata + , Lactuca tenerrima + , Scabiosa turolensis + , Sonchus tenerrimus + , Stachys circinata + , Teucrium similatum + .

Localidades. 1. Málaga. Álora. Tajos del Estudiante, vereda a la "Escalera Arabe". 30SUF4487. 2. Málaga. Antequera. Sierra Llana. Tajos del Cortijo de Puerto Pizarro. 30SUF4389. Cal: calizas.

del Valle de Abdalajís. Se trata de formaciones muy escasas, ya que el hábitat también lo es. En su composición dominan los dolomitófitos (Mota et al., 2008) Andryala ragusina var. ramosissima, Echium albicans subsp. albicans y Centaurea boissieri subsp. boissieri con especies propias del piso mesomediterráneo y superiores como Teucrium similatum y Ptilostemon hispanicus. Se trata de la única representación de la alianza Andryalo-Crambion filiformis en las zonas occidental y central del subsector Torcalense (Asensi et al., 2005; Pérez Latorre et al., 2009), ya que en la oriental existe una comunidad de Andryala ramosissima $\mathrm{BC}$ con la que podría estar relacionada (Pérez Latorre et al., op. cit.).

Localidad: Málaga. Antequera. Sierra de Huma. Vertiente oeste, pista superior. 30SUF4388. Orientación: O. Inclinación: $50^{\circ}$. Área: $20 \mathrm{~m}^{2}$. Litología: dolomías. Altitud: $873 \mathrm{~m}$. Altura vegetación: $50 \mathrm{~cm}$. Cobertura vegetación: $80 \%$. Características de comunidad: Andryala ragusina var. ramosissima 4, Echium albicans subsp. albicans 1, Centaurea boissieri subsp. boissieri +. Compañeras: Arrhenaterum baeticum 1, Asperula hirsuta 1, Biscutella laxa + , Convolvulus lanuginosus 1, Dactylis glomerata subsp. hispanica 1, Helianthemun origanifolium +, Helichrysum stoecha + , Koeleria vallesiana + , Micromeria graeca 1 , Ptilostemon hispanicus 1, Teucrium similatum + , Thymus mastichina + .

15. Comunidad de Echium albicans subsp. fruticescens [Tabla 6]

Vegetación herbácea perenne de taludes y roquedos originados en las molasas y calcarenitas del distrito Pizarreño. La comunidad es muy pobre en especies características pero está caracterizada por el endemismo pizarreño Echium albicans subsp. fruticescens, que se acompaña de especies propias de hábitats rupícolas como Campanula mollis o Putoria calabrica y de otras del matorral circundante (Saturejo malacitanae-Coridothymetum capitati). El área de esta comunidad se continúa en las vecinas sierras de Álora y Pizarra, en la misma unidad fitogeográfica, donde habían sido catalogadas como poblaciones de Echium albicans y Andryala ramosissima a modo de un incipiente (o basal) Andryalo-Crambion filiformis (Pérez Latorre et al., 2008). 
Tabla 5

10. Rupicapnetum decipientis Pérez Latorre, Cabezudo \& Nieto 1995

(Rupicapnion africanae, Sarcocapnetalia enneaphyllae, Petrocoptido-Sarcocapnetea enneaphyllae)

\begin{tabular}{|c|c|c|c|c|c|c|c|c|c|c|}
\hline INVENTARIO N ${ }^{\circ}$ & 1 & 2 & 3 & 4 & 5 & 6 & 7 & 8 & 9 & 10 \\
\hline Orientación & $\mathrm{N}$ & $\mathrm{N}$ & $\mathrm{NE}$ & SE & NO & NO & $\mathrm{N}$ & $\mathrm{S}$ & $\mathrm{O}$ & $\mathrm{N}$ \\
\hline Inclinación $\left({ }^{\circ}\right)$ & 90 & 90 & 90 & 120 & 120 & 90 & 110 & 95 & 100 & 100 \\
\hline Área $\left(m^{2}\right)$ & 4 & 10 & 2 & 4 & 4 & 6 & 15 & 6 & 15 & 10 \\
\hline Litología & Car & Car & Car & Car & $\mathrm{Cal}$ & Cal & Cal & $\mathrm{Cal}$ & $\mathrm{Cad}$ & $\mathrm{Cal}$ \\
\hline Altitud (m) & 600 & 600 & 600 & 530 & 550 & 550 & 500 & 929 & 1010 & 700 \\
\hline Altura vegetación $(\mathrm{cm})$ & 5 & 10 & 10 & 5 & 10 & 10 & 10 & 5 & 15 & 5 \\
\hline Cobertura vegetación (\%) & 5 & 5 & 25 & 5 & 15 & 5 & 15 & 10 & 10 & 5 \\
\hline $\begin{array}{l}\text { Característica de asociación } \\
\text { Rupicapnos africana subsp. decipiens }\end{array}$ & 1 & 1 & 2 & 1 & 2 & + & 1 & 1 & 1 & 1 \\
\hline Compañeras & & & & & & & & & & \\
\hline Chaenorhinum villosum & 1 & - & 1 & - & - & - & - & - & + & - \\
\hline Parietaria judaica & - & 1 & 1 & - & - & - & - & - & - & + \\
\hline Umbilicus rupestris & - & + & - & - & + & + & - & - & - & - \\
\hline Campanula erinus & - & + & + & - & - & - & - & - & - & - \\
\hline Campanula mollis & - & - & - & - & + & + & - & - & - & - \\
\hline Cheilanthes acrostica & - & - & + & - & - & - & - & + & - & - \\
\hline Fumaria rupestris & - & - & - & - & + & + & - & - & - & - \\
\hline Lobularia maritima & - & + & + & - & - & - & - & - & - & - \\
\hline Saxifraga reuteriana & - & - & - & - & + & - & - & - & - & + \\
\hline Sedum album & - & + & + & - & - & - & - & - & - & - \\
\hline Silene andryalifolia & - & - & - & - & + & 1 & - & - & - & - \\
\hline Sonchus oleraceus & - & - & - & - & + & + & - & - & - & - \\
\hline Stachys circinata & - & - & - & - & - & + & + & - & - & - \\
\hline
\end{tabular}

Otras compañeras. En 5: Mercurialis ambigua +. En 6: Lapiedra martinezii +, Ficus carica + , Linaria anticaria + . En 9: Rhamnus myrtifolius + .

Localidad. 1 y 2. Málaga. Ardales. Mesa de Villaverde. Final de la carretera. 30S UF42853. Málaga. Ardales. Mesa de villaverde. Antigua ciudad de Bobastro. 30SUF 4185. 4. Málaga. Ardales. Mesa de Villaverde. Entre la Iglesia de Bobastro y el embalse superior. 30SUF4184. 5 y 6. Málaga. Antequera. Sierra Llana.Tajos del "Pozo de la Mona". 30SUF4391. 7. Málaga. Antequera. Sierra Llana. Tajos del Cortijo del Arpa, "El Buenasombra". 30SUF4190. 8. Málaga. Antequera. Sierra Llana. 30SUF4291. 9. Málaga. Antequera. Sierra de Huma. Tajos de la cumbre vertiente oeste. 30SUF4388. 10. Málaga. Antequera. Sierra Llana. Tajos del "Metecaña". 30SUF4291. Car: calcarenitas. Cal: calizas. Cad: calizo-dolomías.

20. Arenario arundanae-Linarietum salzmannii Asensi, Díez-Garretas \& Esteve 1979 corr. Rivas-Martínez, Asensi, Molero \& F. Valle 1991 [Tabla 7]

Pastizales anuales efímeros, que se desarrollan a principios de primavera en rellanos arenosos sobre las calcarenitas y molasas del distrito Pizarreño. Esta asociación incluye en su composición florística el endemismo pizarreño Linaria salzmannii var. salzmannii y el endemismo de la provincia de Málaga y zonas limítrofes Arenaria arundana. Hacia los restantes afloramientos miocénicos del Valle del Guadalhorce (Hachos de Álora y de Pizarra, Sierra de Cártama) la asociación va perdiendo sus especies características (Hidalgo \& Pérez Latorre, 2013).

\section{Comunidad de Arenaria modesta y Chaenorhinum rubrifolium [Tabla 8]}

Comunidad terofítica dolomitícola de gleras muy xéricas, propia del piso mesomediterráneo en la Sierra de Huma. Se trata de la única representación, hasta el presente trabajo, de la 
Tabla 6

\begin{tabular}{|c|c|c|c|}
\hline \multicolumn{4}{|c|}{$\begin{array}{c}\text { 15. Comunidad de Echium albicans } \\
\text { subsp. fruticescens } \\
\text { (Melico-Phagnalion intermedii, } \\
\text { Phagnalo-Rumicetalia indurati, Phagnalo- } \\
\text { Rumicetea indurati) }\end{array}$} \\
\hline INVENTARIO Nº & 1 & 2 & 3 \\
\hline Orientación & SE & $\mathrm{S}$ & $\mathrm{S}$ \\
\hline Inclinación $\left({ }^{\circ}\right)$ & 40 & - & 30 \\
\hline Área $\left(\mathrm{m}^{2}\right)$ & 20 & 20 & 20 \\
\hline Litología & Car & Car & Car \\
\hline Altitud (m) & 300 & 550 & 500 \\
\hline Altura vegetación $(\mathrm{cm})$ & 40 & 50 & 50 \\
\hline Cobertura vegetación (\%) & 15 & 10 & 10 \\
\hline \multicolumn{4}{|c|}{$\begin{array}{l}\text { Características de comunidad } \\
\text { Echium albicans }\end{array}$} \\
\hline subsp. fruticescens & 1 & 1 & 1 \\
\hline Crambe filiformis & + & - & - \\
\hline \multicolumn{4}{|l|}{ Compañeras } \\
\hline Ononis natrix & 1 & 1 & 1 \\
\hline Rosmarinus officinalis & + & + & + \\
\hline Chaenorhinum villosum & + & + & + \\
\hline Macrochloa tenacissima & + & + & + \\
\hline Juniperus turbinata & + & + & + \\
\hline Fumana ericoides & - & + & + \\
\hline Helianthemun syriacum & - & + & + \\
\hline Teucrium similatum & - & + & + \\
\hline Pinus halepensis & - & + & + \\
\hline Phagnalon sordidum & - & + & + \\
\hline Putoria calabrica & - & + & + \\
\hline Anthyllis cytisoides & - & + & + \\
\hline Campanula mollis & - & + & + \\
\hline
\end{tabular}

Otras compañeras. En 1: Alkanna tinctoria + , Lavandula stoechas 1, Linaria salzmannii +, Thymbra capitata + , Thymus mastichina + . En 3: Cheilanthes acrostica + , Cistus clusii + , Reichardia tingitana + , Sedum sediforme + .

Localidades. 1. Málaga. Ardales. Sierra del Almorchón, por encima del cruce a Bobastro. 30SUF4086. 2 y 3. Málaga. Campillos. Cerro Pardo. 30SUF4089. Car: calcarenitas.

alianza Omphalodion commutatae en todo el subsector Torcalense (Asensi et al., 2005; Pérez Latorre et al., 2009).

\section{Sedo caespitosii-Crassuletum tillaeae} Rivas Goday 1958

poetosum bulbosae Pérez Latorre \& Cabezudo in Pérez Latorre et al. 2008
Nanopastizales crasos y efímeros, que cubren superficies muy pequeñas sobre calcarenitas del distrito Pizarreño (subsector Malacitano). Esta subasociación tiene origen en prácticas de majadeo y fue descrita para Los Montes de Málaga (subsector Axarquiense, Pérez Latorre et al., 2008) habiéndose inventariado en la zona de estudio, ampliando así su área de distribución.

Localidad: Málaga. Ardales. Mesa de Villaverde. 30SUF4285. Orientación: NE. Inclinación: $0^{\circ}$. Área: $2 \mathrm{~m}^{2}$. Litología: calcarenitas. Altitud: $600 \mathrm{~m}$. Altura vegetación: 3 $\mathrm{cm}$. Cobertura vegetación: 70\%. Características y diferenciales de asociación: Crassula tillaea 1, Sedum caespitosum + . Diferenciales de subasociación: Erodium cicutarium +, Paronychia argentea + . Características de unidades superiores: Filago pygmaea subsp. pygmaea + , Campanula erinus + . Compañeras: Sedum mucizonia 1.

\section{Violo demetriae-Jonopsidietum prolongoi} Asensi, Díez-Garretas \& Esteve 1979

var. con Campanula cabezudoi sensu Pérez Latorre et al. (2012) [Tabla 9]

Nanopastizales efímeros mesomediterráneos basófilos que se desarrollan sobre litosuelos en las sierras del Valle de Abdalajís y Huma (unidad de Abdalajís, subsector Torcalense). Al igual que en las Sierras Blanquilla y Prieta, aparece como una variante con Campanula cabezudoi, especie ausente de los inventarios de Sierra de las Nieves (Cabezudo et al., 1998; Pérez Latorre et al., 2012) y de los tomados en el resto del subsector Torcalense (Pérez Latorre et al., 2009).

\section{Comunidad de Brachypodium phoenicoides \\ BC}

Herbazales graminoides de talla elevada, caracterizados por Brachypodium phoenicoides, característicos de suelos que permanecen húmedos toda la primavera, teniendo por tanto ciertas características edafohigrófilas, aunque 
Tabla 7

20. Arenario arundanae-Linarietum salzmannii Asensi, Díez-Garretas \& Esteve 1979 corr. RivasMartínez, Asensi, Molero \& F. Valle 1991

(Omphalodion commutatae, Trachynietalia distachyae, Helianthemetea guttati)

\begin{tabular}{|c|c|c|c|c|c|}
\hline INVENTARIO N ${ }^{\circ}$ & 1 & 2 & 3 & 4 & 5 \\
\hline Orientación & - & - & - & - & $\mathrm{S}$ \\
\hline Inclinación $\left({ }^{\circ}\right)$ & - & - & - & - & - \\
\hline Área $\left(m^{2}\right)$ & 1 & 1 & 1 & 1 & 2 \\
\hline Litología & Car & Car & Car & Car & Car \\
\hline Altitud (m) & 300 & 300 & 300 & 300 & 550 \\
\hline Altura vegetación (cm) & 10 & 10 & 10 & 10 & 15 \\
\hline Cobertura $(\%)$ & 90 & 70 & 90 & 100 & 10 \\
\hline \multicolumn{6}{|c|}{ Características y diferenciales de asociación } \\
\hline Arenaria arundana & + & 1 & + & + & 2 \\
\hline \multicolumn{6}{|c|}{ Características de unidades superiores } \\
\hline Hypochaeris glabra & + & 2 & 1 & 1 & 1 \\
\hline Prolongoa hispanica & 2 & 2 & 3 & 1 & 1 \\
\hline Asterolinom linum-stellatum & + & + & - & 1 & + \\
\hline Silene colorata & 2 & 2 & 3 & 2 & - \\
\hline Tuberaria guttata & 1 & 1 & + & + & - \\
\hline Iberis pectinata & - & + & - & 1 & - \\
\hline
\end{tabular}

Otras características de unidades superiores. En 3: Erodium laciniatum + . En 5: Campanula erinus + , Crupina crupinastrum +, Filago pygmaea + , Jasione blepharodon + , Lomelosia stellata + , Plantago bellardii 1, Rumex bucephalophorus subsp. gallicus 1.

\section{Compañeras}

Calendula arvensis

Medicago polymorpha

Misopates orontium

\begin{tabular}{lllll}
- & + & + & + & - \\
1 & - & + & - & 1 \\
+ & - & + & - & + \\
\hline
\end{tabular}

Otras compañeras. En 1: Dipcadi serotinum + . En 3: Reichardia tingitana +. En 4: Muscari atlanticum 1. En 5: Vulpia ciliata subsp. ciliata 1.

Localidades. 1-4. Málaga. Ardales. Sierra del Almorchón. Cerros por encima del Ayo. Granado. 30SUF4086. 5. Málaga. Campillos. Cerro Pardo. 30SUF4089. Car: calcarenitas.

finalmente culminan el desarrollo con el suelo más seco en el verano. En el área de estudio solo han sido localizados sobre suelos arcillosos en el piso mesomediterráneo con ombrotipo subhúmedo, en microhábitats que favorecen el acúmulo de agua. Hasta el momento solo se habían descrito estas comunidades de $B$. phoenicoides en el Parque Natural de TejedaAlmijara y Alhama (Pérez Latorre et al., 2004) para la provincia de Málaga y alrededores, también en hábitats similares.

Localidad. Málaga. Antequera. Sierra de Huma. Por encima del cortijo de Campano
Chico. 30SUF4588. Orientación: -. Inclinación: $0^{\circ}$. Área: $20 \mathrm{~m}^{2}$. Litología: arcillas y calizas. Altitud: $1000 \mathrm{~m}$. Altura vegetación: $45 \mathrm{~cm}$. Cobertura vegetación: $100 \%$. Característica de comunidad: Brachypodium phoenicoides 5. Características de unidades superiores: Galium verum + , Melica magnolii + . Compañeras: Achillea ageratum + , Aegilops geniculata 1, Arrhenaterum album 1, Avena barbata +, Avenula bromoides subsp. bromoides +, Cerastium boissieri + , Dactylis glomerata subsp. hispanica 2, Elymus repens subsp. repens + , Hypochaeris radicata 1 , Linum 
setaceum +, Melica minuta + , Ornithogalum narbonense + , Phalaris coerulescens + , Stachys germanica + , Ulex parviflorus 1 .

\section{Comunidad de Poa bulbosa y Erodium cicutarium [Tabla 10]}

Majadales de escasa extensión, caracterizados por Poa bulbosa, Erodium cicutarium y Trifolium scabrum, desarrollados sobre las calcarenitas del distrito Pizarreño (subsector Malacitano) en suelos arenosos con presencia de pastoreo ovino y cierto pisoteo. Estos majadales difieren de los existentes en los territorios torcalenses adyacentes, desarrollados sobre suelos arcillosos calizos y caracterizados en ese caso por Erodium primulaceum (Pérez Latorre et al., 2009).

\section{Comunidad de Celtica gigantea}

Comunidad gramidoide de talla elevada, caracterizada por Celtica gigantea y el endemismo Helictotrichon filifolium subsp. arundanum. Se desarrolla en el piso mesomediterráneo de la sierra de Huma (unidad de Abdalajís), sobre gleras semimóviles con fuerte inclinación y en cuya composición litológica aparece la dolomía. Estas formaciones podrían estar relacionadas ecológicamente con las de C. gigantea detectadas en las Sierras Prieta y Blanquilla (sector Rondeño) (Pérez Latorre et al., 2012) o constituir una variante de los lastonares de Helictotricho arundaniFestucetum capillioliae stat. nov. descritos más adelante.

Localidad. Málaga. Antequera. Sierra de Huma. Vertiente oeste, entre la pista superior y los tajos de la cumbre. 30SUF4388. Orientación: O. Inclinación: $45^{\circ}$. Área: $100 \mathrm{~m}^{2}$. Litología: calizas y dolomías. Altitud: $980 \mathrm{~m}$. Altura vegetación: $200 \mathrm{~cm}$. Cobertura vegetación: 50\%. Características de comunidad: Celtica gigantea 3, Helictotrichon filifolium subsp. arundanum + . Característica de unidades superiores: Brachypodium retusum 1. Compañeras: Cerastium boissieri +, Helianthemun
Tabla 8

\section{Comunidad de Arenaria modesta y Chaenorhinum rubrifolium}

(Omphalodion commutatae, Trachynietalia distachyae, Helianthemetea guttati)

\begin{tabular}{lcc}
\hline INVENTARIO N $^{\circ}$ & 1 & 2 \\
Orientación & $\mathrm{O}$ & $\mathrm{NE}$ \\
Inclinación $\left(^{\circ}\right)$ & 25 & 5 \\
Área $\left(\mathrm{m}^{2}\right)$ & 8 & 4 \\
Litología & $\mathrm{Cad}$ & $\mathrm{Cad}$ \\
Altitud (m) & 880 & 1100 \\
Altura vegetación (cm) & 5 & 5 \\
Cobertura vegetación $(\%)$ & 35 & 20 \\
Características de comunidad & & \\
$\begin{array}{l}\text { Arenaria modesta } \\
\quad \text { subsp. modesta }\end{array}$ & & \\
$\begin{array}{l}\text { Chaenorhinum rubrifolium } \\
\text { subsp. rubrifolium }\end{array}$ & 1 & 1 \\
$\begin{array}{l}\text { Características de unidades superiores } \\
\text { Asterolinom linum-stellatum } \\
\text { Trachynia distachya }\end{array}$ & + & + \\
& + & +
\end{tabular}

Otras características. En 1: Narduroides salzmanii 2, Bombycilaena discolor + , Linum strictum + , Euphorbia exigua +, Catapodium rigidum +, Crucianella angustifolia + , Crupina crupinastrum 1, Helianthemum aegyptiacum +, Hippocrepis ciliata + , Polygala monspeliaca + , Xeranthemum inapertum +. En 2: Rumex bucephalophorus subsp. gallicus 1, Minuartia montana + , Petrorrhagia nanteuilii + , Vulpia unilateralis + .

\section{Compañeras}

Stoibrax dichotomum

Valantia hispida

$\begin{array}{ll}+ & + \\ 1 & +\end{array}$

Otras compañeras. En 1: Aegilops geniculata 1, Anagallis arvensis + , Filago pyramidata 1, Galium minutulum + , Linum setaceum + , Trifolium scabrum + . En 2: Bromus rubens 1, Cerastium glomeratum + , Lagurus ovatus + , Leontodon longirrostris + .

Localidades. 1. Málaga. Antequera. Sierra de Huma. Vertiente oeste, entre la pista superior y los tajos de la cumbre. 30SUF4387. 2. Málaga. Antequera. Sierra de Huma. Vertiente norte, entre el Cortijo Campano Chico y la cumbre de Huma. 30SUF4588. Cad: calizas-dolomías.

appeninum subsp. cavanillesanium + , Melica minuta + , Ptilostemon hispanicus + , Santolina canescens + , Teucrium similatum 1, Thymus baeticus 1, Ulex parviflorus 1. 
Tabla 9

24. Violo demetriae-Jonopsidietum prolongoi Asensi, Díez-Garretas \& Esteve 1979 var. con Campanula cabezudoi sensu Pérez Latorre et al. (2012) (Trachynion distachyae, Trachynietalia distachyae, Helianthemetea guttati)

\begin{tabular}{|c|c|c|c|c|}
\hline INVENTARIO N & 1 & 2 & 3 & 4 \\
\hline Orientación & $\mathrm{N}$ & $\mathrm{N}$ & $\mathrm{N}$ & $\mathrm{N}$ \\
\hline Inclinación $\left({ }^{\circ}\right)$ & 60 & - & 45 & 50 \\
\hline Área $\left(\mathrm{m}^{2}\right)$ & 5 & 1 & 100 & 4 \\
\hline Litología & Cal & Cal & Cal & $\mathrm{Cal}$ \\
\hline Altitud (m) & 838 & 1100 & 990 & 1100 \\
\hline Altura vegetación (cm) & 10 & 5 & 10 & 10 \\
\hline Cobertura vegetación (\%) & 80 & 40 & 15 & 40 \\
\hline \multicolumn{5}{|c|}{ Características y diferenciales de asociación } \\
\hline Viola demetria & 3 & + & + & 2 \\
\hline Senecio minutus & 1 & - & - & + \\
\hline Jonopsidium prolongoi & + & - & - & - \\
\hline \multicolumn{5}{|l|}{ Diferencial de variante } \\
\hline Campanula cabezudoi & - & 1 & + & 1 \\
\hline \multicolumn{5}{|c|}{ Características de unidades superiores } \\
\hline Omphalodes commutata & + & - & 1 & 2 \\
\hline Euphorbia exigua & + & - & - & + \\
\hline Linaria oblongifolia & + & - & + & - \\
\hline
\end{tabular}

Otras características de unidades superiores. En 1: Trachynia distachya + , Asterolinon linum-stellatum +. En 2: Saxifraga tridactylites 1, Arabis verna +, Erophila verna +, Cerastium semidecandrum +. En 4: Trifolium campestre 1.

\section{Compañeras}

Conopodium thalictrifolium

Geranium purpureum

Papaver hybridum

Thlaspi perfoliatum

Veronica cymbalaria

$\begin{array}{llll}+ & - & 1 & + \\ - & - & 1 & 1 \\ - & - & + & + \\ + & - & - & + \\ - & + & + & -\end{array}$

Otras compañeras. En 1: Fumaria rupestris 1, Lamarckia aurea + , Muscari atlanticum 1, Rhagadiolus stellatus 1, Silene secundiflora + . En 2: Musgo pleurocárpico 2, Sherardia arvensis + . En 3: Arrhenatherum album + , Cerastium boissieri + , Fumaria macrosepala 1 , Hedera helix + , Scandix pecten-veneris + , Silene commutata +, Vulpia ciliata +. En 4: Anagallis arvensis +, Cynosorus echinatus 1, Galium minutulum +, Melilotus sulcatus + .

Localidades. 1. Málaga. Antequera. Sierra del Valle de Abdalajís. Proximidades del "despegue norte". 30SUF4790. 2. Málaga. Antequera. Sierra del Valle de Abdalajís. La Capilla. 30SUF4789. 3 y 4. Málaga. Antequera. Sierra de Huma. Vertiente norte, entre el Cortijo Campano Chico y la cumbre de Huma. 30SUF4588. Cal: calizas.

\section{Helictotricho arundani-Festucetum} capillifoliae stat. nov. [Tabla 11]

[Festuco scariosae-Helictotrichetum arundani Asensi, Díez Garretas \& Martín Osorio 1993 festucetosum capillifoliae Pérez Latorre \& Cabezudo in Pérez Latorre, CasimiroSoriguer, Gavira \& Cabezudo in Acta Bot.
Malacitana 37: 114, Tab. 8, 2012]

Los lastonares meso-supramediterráneos con Helictotrichon filifolium subsp. arundanum y Festuca capillifolia fueron descritos para las Sierras Prieta y Blanquilla como una subasociación del Festuco scariosaeHelictotrichetum arundani Asensi, Díez 
Garretas \& Martín Osorio 1993 (sector Rondeño) por Pérez Latorre et al. (2012). En dicha descripción se ponía de manifiesto la notable ausencia de Festuca scariosa en los inventarios de toda la Serranía de Ronda oriental, desde Sierra de las Nieves hacia el este. Esta ausencia y la presencia constante de las dos especies anteriormente citadas se ha corroborado en los lastonares del área de estudio, lo que nos lleva a proponer el cambio de estatus a asociación, con ampliación de su área de distribución hacia la unidad de Abdalajís (subsector Torcalense) y su sinecología al termotipo mesomediterráneo medio y ombrotipo subhúmedo. Estos lastonares se desarrollan en el área de estudio solo en las umbrías con roquedos de fuerte inclinación y pequeños pedregales, sobre calizas y dolomías de las sierras de Huma y el Valle del Abdalajís, en el piso mesomediterráneo, y constituyen un tipo de vegetación edafoxerófila permanente.

\section{Comunidad de Festuca mediterranea BC}

(Comunidad de Festuca arundinacea BC sensu Pérez Latorre et al., 2012)

[La revisión del material de $F$. arundinacea Schreb. de la zona de las Sierras Prieta y Blanquilla ha llevado a su inclusión en $F$. mediterranea (K. Richt.) Rouy]

Pastizales graminoides perennes, edafohigrófilos, desarrollados sobre suelos vérticos margosos, dominados por Festuca mediterranea, que se desarrollan en el piso mesomediterráneo entre las sierras de Huma y el Valle de Abdalajís (subsector Torcalense). Al igual que ocurre en las cercanas Sierras Prieta y Blanquilla (Pérez Latorre et al., 2012; sector Rondeño), debido a la escasa altitud, la ausencia de características no permite incluir estas formaciones en el Elymo repentisPhalaridetum coerulescentis (Pérez Latorre et al., 1998) presente en otras zonas orientales del subsector Torcalense (Pérez Latorre et al., 2009), aunque sí en la alianza Gaudinio fragilisHordeion bulbosi.
Tabla 10

\begin{tabular}{|c|c|c|}
\hline $\begin{array}{r}\text { 30. Comunidad de Poa } \\
\text { y Erodium cicutari } \\
\text { (Plantaginion serrariae, Poet } \\
\text { Poetea bulbosae }\end{array}$ & busa & \\
\hline INVENTARIO N ${ }^{\circ}$ & 1 & 2 \\
\hline Orientación & $\mathrm{N}$ & $\mathrm{N}$ \\
\hline Inclinación $\left({ }^{\circ}\right)$ & - & - \\
\hline Área $\left(\mathrm{m}^{2}\right)$ & 2 & 2 \\
\hline Litología & Car & Car \\
\hline Altitud (m) & 600 & 600 \\
\hline Altura vegetación (cm) & 5 & 5 \\
\hline Cobertura vegetación $(\%)$ & 60 & 90 \\
\hline Características de comunidad & & \\
\hline Poa bulbosa & 2 & 3 \\
\hline Erodium cicutarium & 2 & 1 \\
\hline Características de unidades sup & ores & \\
\hline Trifolium scabrum & 2 & + \\
\hline Compañeras & & \\
\hline Calendula arvensis & + & + \\
\hline Filago pygmaea subsp. pygmaea & + & + \\
\hline Helianthemun salicifolium & + & 1 \\
\hline Leontodon longirrostris & + & + \\
\hline Medicago polymorpha & 1 & 1 \\
\hline Plantago lagopus & + & + \\
\hline Silene decipiens & + & + \\
\hline
\end{tabular}

Otras compañeras. En 1: Sedum caespitosum + , Crassula tillaea + . En 2: Hirschfeldia incana +, Salvia verbenaca + .

Localidades. 1 y 2. Málaga. Ardales. Mesa de Villaverde, proximidades del mirador. 30SUF4285. Car: calcarenitas.

Localidades. Málaga. Antequera. Sierra del Valle de Abdalajís. Cortijo de la Rejanada. 30SUF4688. Orientación: S. Inclinación: 5․ Área: $200 \mathrm{~m}^{2}$. Litología: margas. Altitud: $865 \mathrm{~m}$. Altura vegetación: $150 \mathrm{~cm}$. Cobertura vegetación: $100 \%$. Características de comunidad: Festuca mediterranea 4. Características de unidades superiores: Gaudinia fragilis +, Hordeum bulbosum +, Scilla peruviana +, Carex flacca +, Ranunculus macrophyllus +, Phalaris coerulescens 1, Trifolium fragiferum 2, Trifolium squamosum 1. Compañeras: Allium roseum +, Anagallis arvensis +, Carex hispida 3, Crepis vesicaria subsp. taraxacifolia 1, Cynara cardunculus 1, Dactylis glomerata + , 
Galactites tomentosa +, Juncus acutiflorus 1, Juncus articulatus subsp. articulatus + , Juncus bufonius 1, Leontodon tuberosus 1, Mentha pulegium + , Oenanthe globulosa + , Ophrys tenthredinifera + , Ornithogalum narbonense + , Plantago serraria 1, Ranunculus ficaria + , Rumex crispus + , Trifolium campestre 1 .

\section{Comunidad de Cistus monspeliensis BC} Jaguarzal silicícola, dominado por caméfitos y nanofanerófitos, que aparece puntualmente en algunas zonas del distrito Pizarreño (Almorchón, Bobastro) donde el suelo es más arenoso. Constituye la única representación de vegetación acidófila del área de estudio, con especies como Cistus ladanifer o Lavandula stoechas.

Localidad. Málaga. Ardales. Sierra del Almorchón. 30SUF4087. Orientación: O. Inclinación: $0^{\circ}$. Área: $25 \mathrm{~m}^{2}$. Litología: calcarenitas. Altitud: $650 \mathrm{~m}$. Altura vegetación: $90 \mathrm{~cm}$. Cobertura vegetación: $20 \%$. Características de comunidad: Cistus monspeliensis 2, Cistus ladanifer + . Característica de unidades superiores: Lavandula stoechas +. Compañeras: Anthyllis cytisoides 2, Sideritis reverchonii + , Ulex parviflorus + , Rosmarinus officinalis + , Teucrium similatum + , Phlomis purpurea 1 .

40. Genisto speciosae-Ulicetum parviflorii Rivas Goday \& Rivas-Martínez ex Pérez Latorre \& Cabezudo, 2009 nom. inv. propos. [Tabla 12]

\section{ulicetosum parviflorii}

var. de Bupleurum spinosum

lavanduletosum lanatae Rivas Goday \& Rivas Martínez ex Pérez Latorre, CasimiroSoriguer \& Cabezudo 2014

(Ulici parviflorii-Genistetum speciosae lavanduletosum lanatae Rivas Goday \& Rivas-Martínez 1968)

[Lectotypus: inv. 8 tab. 29 in Rivas Goday \& Rivas Martínez in Anales Inst. Bot. Cavanilles 25: 136-138 (1968) designado aquí]
Tabla 11

35. Helictotricho arundani-Festucetum capillifoliae (Pérez Latorre \& Cabezudo) Pérez Latorre, Casimiro-Soriguer \& Cabezudo stat. nov.

(Festucion scariosae, Lygeo sparti-Stipetalia tenacissimae, Lygeo sparti-Stipetea tenacissimae)

\begin{tabular}{lccc}
\hline INVENTARIO $\mathrm{N}^{\mathrm{O}}$ & 1 & 2 & 3 \\
Orientación & $\mathrm{N}$ & $\mathrm{N}$ & $\mathrm{N}$ \\
Inclinación $\left(^{\circ}\right)$ & 60 & 70 & 45 \\
Área $\left(\mathrm{m}^{2}\right)$ & 100 & 120 & 50 \\
Litología & $\mathrm{Cad}$ & $\mathrm{Cad}$ & $\mathrm{Cal}$ \\
Altitud $(\mathrm{m})$ & 800 & 1050 & 1100 \\
Altura vegetación $(\mathrm{cm})$ & 70 & 50 & 100 \\
Cobertura vegetación $(\%)$ & 50 & 50 & 40
\end{tabular}

Características y diferenciales de asociación Helictotrichon filifolium

$\begin{array}{llll}\text { subsp. arundanum } & 3 & 3 & 2 \\ \text { Festuca capillifolia } & 1 & + & 1\end{array}$

\section{Características de unidades superiores}

Celtica gigantea

Dactylis glomerata

subsp. hispanica

\section{Compañeras}

Cerastium boissieri

Melica minuta

Scabiosa turolensis

Galium lucidum subsp. lucidum

Ptilostemon hispanicus

Teucrium similatum

Otras compañeras. En 1: Anthyllis vulneraria + , Arisarum vulgare +, Ballota hirsuta 2, Ferula communis subsp. catalaunica + , Jasminum fruticans ,+ Phlomis purpurea 1, Ranunculus blepharicarpos + , Rhamnus myrtifolius + , Tamus communis + . En

2: Conopodium thalictrifolium + , Chaenorhinum villosum 1, Erinacea anthyllis,+ Linaria anticaria ,+ Poa bulbosa + , Ulex parviflorus 1, Viola demetria +. En 3: Biscutella laxa +, Crambe filiformis 1, Dianthus anticarius 1 , Hyoseris radiata + , Lactuca tenerrima + , Ononis minutissima + , Petrorhagia saxifraga + , Silene vulgaris + , Thymus baeticus + .

Localidades. 1. Málaga. Antequera. Sierra del Valle de Abdalajís. Proximidades del "despegue norte". 30SUF4790. 2. Málaga. Antequera. Sierra del Valle de Abdalajís. La Capilla, cara norte. 30SUF4789. 3. Málaga. Antequera. Sierra de Huma. Vertiente norte, entre el Cortijo Campano Chico y la cumbre de Huma. 30SUF4588. Cad: calizas y dolomías. Cal: calizas. 
Tabla 12

40. Genisto speciosae-Ulicetum parviflorii Rivas Goday \& Rivas-Martínez ex Pérez Latorre y Cabezudo 2009 nom. inv. propos.

ulicetosum parviflorii, var. de Bupleurum spinosum

lavanduletosum lanatae Rivas Goday \& Rivas Martínez ex Pérez Latorre, Casimiro-Soriguer y Cabezudo 2014

(Saturejo micranthae-Thymbrion capitati, Rosmarinetalia officinalis, Cisto-Micromerietea julianae)

\begin{tabular}{|c|c|c|c|c|c|c|c|c|c|}
\hline INVENTARIO N ${ }^{\circ}$ & 1 & 2 & 3 & 4 & 5 & 6 & 7 & 8 & 9 \\
\hline Orientación & $\mathrm{N}$ & $\mathrm{O}$ & $\mathrm{S}$ & $\mathrm{N}$ & $\mathrm{O}$ & $\mathrm{O}$ & $\mathrm{NE}$ & $\mathrm{N}$ & - \\
\hline Inclinación $\left({ }^{\circ}\right)$ & 15 & 20 & 25 & 20 & 35 & 40 & 5 & 40 & 0 \\
\hline Área $\left(\mathrm{m}^{2}\right)$ & 150 & 220 & 250 & 300 & 250 & 250 & 200 & 200 & 250 \\
\hline Litología & $\mathrm{Cad}$ & Mac & Mar & Mac & $\mathrm{Cad}$ & $\mathrm{Cad}$ & Arc & Cal & $\mathrm{Cal}$ \\
\hline Altitud (m) & 700 & 787 & 900 & 1050 & 892 & 960 & 980 & 1050 & 950 \\
\hline Altura vegetación(cm) & 70 & 50 & 80 & 55 & 90 & 80 & 80 & 70 & 150 \\
\hline Cobertura vegetac ión $(\%)$ & 90 & 90 & 100 & 60 & 60 & 50 & 80 & 60 & 80 \\
\hline
\end{tabular}

Características y diferenciales de asociación

Ulex parviflorus

Santolina canescens

Genista cinerea

Diferenciales var. orófila

Bupleurum spinosum

Koeleria vallesiana

Teucrium webbianum

Diferenciales de subasociación

Centaurea boissieri

Echium albicans subsp. albicans

Lavandula lanata

Características de unidades superiores

Teucrium similatum

Ptilostemon hispanicus

Thymus baeticus

Thymus zygis

Thymbra capitata

Helianthemum marifolium

Cistus albidus

Helianthemum hirtum

Asperula hirsuta

Rosmarinus officinalis

Fumana thymifolia

Otras características de unidades superiores. En 1: Staehelina dubia +. En 2: Fumana laevipes 1 . En 3: Thymus $x$ arundanus 1. En 9: Helianthemum appeninum + , Hippocrepis bourgaei + , Thymelaea argentata + , Convolvulus lanuginosus + .

\section{Compañeras}

Brachypodium retusum

Phlomis lychnitis

Cerastium boissieri

$\begin{array}{lllllllll}+ & 1 & + & 1 & 2 & 2 & 1 & - & 1 \\ - & + & 1 & 2 & 1 & 1 & 1 & 3 & - \\ - & + & - & 2 & 2 & + & 1 & + & - \\ + & 1 & - & - & - & - & - & - & 1 \\ - & 4 & - & - & + & - & - & - & 3 \\ - & - & - & - & + & - & + & - & + \\ 2 & - & - & - & - & + & - & - & + \\ - & - & + & - & - & - & - & + & + \\ - & - & - & - & + & - & + & + & - \\ + & - & - & - & - & - & - & - & 2 \\ - & - & - & - & + & - & - & - & +\end{array}$


Phlomis purpurea

Dactylis glomerata subsp. hispanica

Helictotrichon filifolium

subsp. arundanum

Melica minuta

Rhamnus myrtifolius

Allium roseum

Biscutella laxa

Carlina hispanica

Crataegus monogyna

Daphne gnidium

Dianthus gaditanus

Juniperus turbinata

Quercus rotundifolia

Rhamnus lycioides

Scabiosa turolensis

Arrhenatherum elatius

subsp. baeticus

Asparagus horridus

Celtica gigantea

Crambe filiformis

Festuca capillifolia

Klasea pinnatifida

Sideritis hirsuta

\begin{tabular}{lllllllll}
3 & 1 & 2 & - & + & - & 3 & - & 1 \\
+ & - & 1 & - & + & - & 2 & - & - \\
& & & & & & & & \\
- & - & - & 1 & 2 & 2 & - & 2 & - \\
+ & - & + & - & - & + & - & 1 & - \\
- & + & + & + & - & - & + & - & - \\
- & + & + & - & - & + & - & - & - \\
+ & - & - & - & - & + & - & + & - \\
1 & 1 & - & - & - & 1 & - & - & - \\
- & - & + & - & - & - & + & 1 & - \\
+ & + & + & - & - & - & - & - & - \\
- & - & - & - & + & + & - & + & - \\
- & - & + & - & - & + & + & - & - \\
- & - & - & + & + & - & + & - & - \\
+ & - & + & - & - & - & - & + & - \\
- & - & - & - & + & + & - & 1 & - \\
& & & & & & & & - \\
- & - & - & - & - & - & 1 & 2 & - \\
- & + & + & - & - & - & - & - & - \\
+ & - & - & - & + & - & - & - & - \\
- & - & + & - & - & + & - & - & - \\
- & - & - & + & - & - & - & 1 & - \\
+ & - & - & - & + & - & - & - & - \\
+ & - & - & - & - & - & - & - & + \\
\hline
\end{tabular}

Otras compañeras. En 1: Cladonia sp. 1, Elaeoselinum foetidum + , Fritillaria lusitanica,+ Linum narbonense + , Musgo acrocárpico 2, Ranunculus blepharicarpos 1, Sanguisorba verrucosa + , Tulipa sylvestris + . En 2: Avenula gervaisii subsp. arundana + , Cuscuta epithymum 1, Nepeta tuberosa 1, Thymus mastichina + , Trachynia distachya +, Urginea maritima + . En 3: Chamaerops humilis 1, Melica magnolii 1, Quercus coccifera + , Verbascum rotundifolium subsp. haenseleri + . En 4: Carduus tenuiflorus 1, Viola demetria 1. En 5: Avenula bromoides + , Leuzea conifera + , Pinus pinaster + , Scorzonera crispatula + . En 6: Eryngium campestre 1. En 7: Andryala integrifolia +, Cynara humilis + , Helychrisum stoechas + , Stachys germanica +, Vicia pubescens +. En 8: Galium lucidum subsp. lucidum 1, Helleborus foetidus +, Paeonia broteroi +, Rubia peregrina 1, Vinca difformis +. En 9: Cistus monspeliensis +, Cistus salviifolius + .

Localidades. 1. Málaga. Antequera. Sierra del Valle de Abdalajís. Proximidades del "despegue norte". 30SUF4790. 2. Málaga. Antequera. Sierra del Valle de Abdalajís. Subida al Cortijo de la Rejanada, proximidades del "despegue de levante". 30SUF4688. 3. Málaga. Antequera. Sierra del Valle de Abdalajís. Vaguada entre el Cortijo de la Rejanada y La Capilla. 30SUF 4789. 4 . Málaga. Antequera. Sierra del Valle de Abdalajís. La Capilla, cara norte. 30SUF 4789. 5 y 6. Málaga. Antequera. Sierra de Huma. Vertiente oeste, entre la pista superior y los tajos de la cumbre. 30SUF4387. 7 y 8. Málaga. Antequera. Sierra de Huma. Vertiente norte, entre el Cortijo Campano Chico y la cumbre de Huma. 30SUF4588. 9. Málaga. Antequera. Sierra Llana. Proximidades del Tajo de Ballesteros. 30SUF4490. Cad: calizo-dolomías. Mac: margocalizas. Mar: margas. Arc: arcillas y calizas. Cal: calizas.

Matorrales ricos en genisteas y aulagas nanofanerofíticas, caracterizados por Genista cinerea y Ulex parviflorus, de distribución en el subsector Torcalense y que generalmente se desarrollan sobre calizas y margocalizas en el piso mesomediterráneo del área de estudio. En zonas cacuminales de la Sierra de Huma, por encima de 1000m., aparece una variante con alguna especie xeroacántica como Bupleurum spinosum y otras especies orófilas como Koeleria vallesiana y Teucrium webbianum. La subasociación lavanduletosum lanatae habita 
sobre suelos dolomíticos, está marcada por L. lanata y otros dolomitófitos como Echium albicans subsp. albicans y hasta el momento no se había encontrado en otras zonas del subsector Torcalense, salvo donde fue descrita (Puerto de los Alazores y alrededores, Granada-Málaga, Rivas Goday \& Rivas Martínez, 1968: 138; Pérez Latorre et al., 2009). La inexistencia de Genista haenseleri Boiss. excluye del área de estudio a otros matorrales con genisteas, como el Coridothymo-Genistetum haenselerii Rivas Goday \& Rivas Martínez 1968 (Rivas Goday \& Rivas Martínez, 1968: 124-126, tab. 26, invs. 1 y 2 ).

\section{Genisto equisetiformis-Cytisetum} fontanesii Rivas Goday \& Rivas-Martínez ex Pérez Latorre, Casimiro-Soriguer \& Cabezudo 2014 [Tabla 13]

(Genisto umbellatae-Chronanthetum biflori Rivas Goday \& Rivas-Martínez 1968)

[Lectotypus: inv. 3 tab. 24 in Rivas Goday \& Rivas Martínez in Anales Inst. Bot. Cavanilles 25: 119-120 (1968) designado aquí]

Matorral-bolinares caracterizados por las genisteas pulviniformes Genista umbellata subsp. equisetiformis y Cytisus fontanesii subsp. fontanesii, acompañadas predominantemente por Rosmarinus officinalis, Cistus monspeliensis y Phlomis purpurea. Se desarrollan sobre suelos erosionados margocalizos, incluso con pequeños afloramientos yesíferos, en la base norte de las sierras del Valle de Abdalajís y Llana (sub. Teucrio-Coridothymetum capitati, Asensi et al., 2005), contactando con la vegetación gipsófita de la zona yesífera de Gobantes (Cabezudo et al., 2013). Aunque existen formaciones de este matorral que presentan esparto (Stipa tenacissima), no se ha observado que esta especie ocupe suficiente extensión ni densidad como para considerar la existencia de espartal (Asensi et al., 2005). Tal y como indicaron Rivas Goday \& Rivas Martínez (1968) este matorral ocupa una posición basal y térmica respecto a Genisto
Tabla 13

41. Genisto equisetiformis-Cytisetum fontanesii Rivas Goday \& Rivas-Martínez 1968 ex Pérez

Latorre, Casimiro-Soriguer \& Cabezudo 2014

(Saturejo micranthae-Thymbrion capitati, Rosmarinetalia officinalis, Cisto-Micromerietea julianae)

\begin{tabular}{lcc}
\hline INVENTARIO N & 1 & 2 \\
Orientación & $\mathrm{NE}$ & $\mathrm{SO}$ \\
Inclinación $\left({ }^{\circ}\right)$ & 20 & 5 \\
Área $\left(\mathrm{m}^{2}\right)$ & 200 & 100 \\
Litología & May & $\mathrm{Mac}$ \\
Altitud $(\mathrm{m})$ & 400 & 420 \\
Altura vegetación $(\mathrm{cm})$ & 100 & 100 \\
Cobertura vegetación $(\%)$ & 90 & 90 \\
Características y diferenciales de asociación & \\
Genista umbellata & & \\
$\quad$ subsp. equisetiformis & + & 2 \\
Cytisus fontanesii & & \\
subsp. fontanesii & - & 1 \\
Características de unidades superiores & \\
Rosmarinus officinalis & 4 & 2 \\
Thymus zygis & 2 & + \\
Fumana thymifolia & 2 & 1
\end{tabular}

Otras características de unidades superiores. En 1: Thymbra capitata 1, Helianthemun hirtum + , Helianthemun marifolium +, Helianthemun syriacum + . En 2: Teucrium lusitanicum + , Cistus albidus + , Asperula hirsuta + , Klasea pinnatifida + .

\section{Compañeras}

Brachypodium retusum

Cistus monspeliensis

Hedysarum spinossisimum

Macrochloa tenacissima

Phlomis purpurea

$\begin{array}{cc}+ & 2 \\ 2 & 3 \\ + & 1 \\ 1 & 1 \\ + & + \\ 1 & 1\end{array}$

Teucrium pseudochamaepitys

Otras compañeras. En 1: Asparagus horridus +, Quercus coccifera 1, Thapsia villosa + , Ophrys speculum +, Oprhys lutea +, Tulipa australis 1, Hippocrepis bourgaei +, En 2: Carex halleriana + , Cladonia sp. 1, Chamaerops humilis + , Dactylis glomerata subsp. hispanica +, Helminthoteca echioides +, Juniperus turbinata 1, Musgo acrocárpico 2, Pistacia lentiscus 1, Hedysarum glomeratum + , Leuzea conifera + , Phlomis lychnitis + , Scorzonera angustifolia + , Ulex parviflorus + .

Localidades. 1. Málaga. Antequera. Bobadilla. Las Salinas.30SUF4199. 2. Málaga. Antequera. Proximidades de la estación de Gobantes. 30SUF4593. May: margocalizas con yeso. Mac: margocalizas. 
cinereae-Ulicetum parviflorii. Dinámicamente constituyen la vegetación serial de encinares de Smilaci mauritanicae-Querco rotundifoliae $S$ y sabinares de Asparago horridi-Junipereto turbinatae $S$.

\section{Comunidad de Erinacea anthyllis BC [Tabla 14]}

Vegetación xeroacántica, almohadillada, camefítica, caracterizada por Erinacea anthyllis y Bupleurum spinosum, que se desarrolla en el piso bioclimático mesomediterráneo en su horizonte medio, en la cumbre y umbría de la Sierra de Huma (unidad de Abdalajís). El piornal se desarrolla en una cumbre alomada y zonas de canchal, donde predominan los litosuelos y la acción del viento es muy potente. Se trata por tanto de una comunidad permanente. En la composición es frecuente Centaurea boissieri subsp. boissieri, coincidiendo con la presencia de dolomías en la zona y Teucrium similatum y Ptilostemon hispanicus, propios del piso mesomediterráneo y superiores. Se puede presentar en mosaico con lastonares de Helictotricho arundaniFestucetum capillifoliae stat. nov. en zonas con suelo intersticial. En este mismo subsector Torcalense, pero en su zona oriental, existe otra comunidad xeroacántica similar, pero ya en el piso supramediterráneo y con bioindicadores con mayor grado de orofilia como Ptilotrichum spinosum (Pérez Latorre et al., 2009).

\section{Asparago horridi-Juniperetum turbinatae}

Díez Garretas, Asensi \& Martín Osorio 1996 [Tabla 15]

\section{juniperetosum turbinatae}

pinetosum halepensis subass. nova [Tab.

15 , holotypus inv. $\mathrm{n}^{\mathrm{o}} 1$ ]

\section{var. de Halimium halimifolium}

El sabinar caudado ocupa grandes extensiones en la zona de estudio y presenta un grado de conservación excepcional. Este sabinar alcanza el piso mesomediterráneo exclusivamente en estas sierras, pero no se
Tabla 14

42. Com. de Erinacea anthyllis $\mathrm{BC}$

(Xeroacantho-Erinaceion anthyllidis, Erinacetalia anthyllidis, Cisto-Micromerietea julianae)

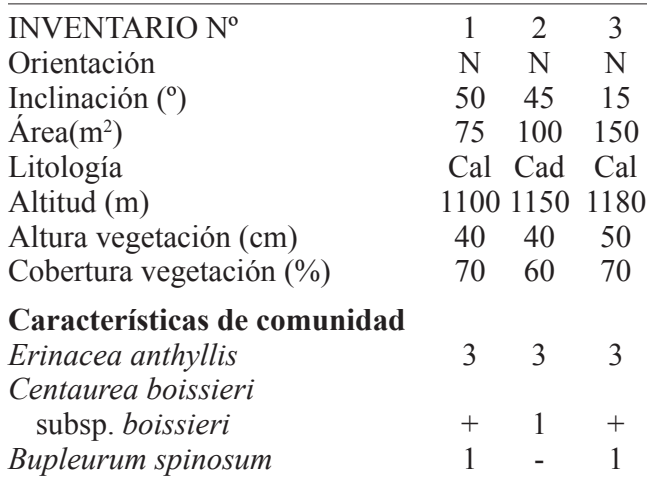

Características de unidades superiores

Ptilostemon hispanicus

Teucrium similatum

Anthyllis vulneraria

Cerastium boissieri

Helianthemun apenninum

Helianthemun origanifolium

Thymus baeticus

\section{Compañeras}

Festuca capillifolia

Helictotrichon filifolium

subsp. arundanum

Santolina canescens

Scabiosa turolensis

Koeleria vallesiana

Melica minuta

$\begin{array}{ccc}2 & 2 & + \\ + & + & 2 \\ - & + & - \\ - & - & + \\ - & + & - \\ - & - & + \\ - & - & 1 \\ & & \\ 2 & 1 & 1 \\ & & \\ + & 1 & 1 \\ 1 & + & + \\ 1 & - & + \\ - & + & + \\ 1 & + & -\end{array}$

Otras compañeras. En 1: Crataegus monogyna 1, Dactylis glomerata subsp. hispanica +, Hymantoglossum hircinum +, Ranunculus blepharicarpos +, Ulex parviflorus +. En 2: Biscutella laxa +, Carlina hispanica 1, Erodium cheilanthifolium + , Ononis minutissima + . En 3: Arrhenatherum elatius subsp. baeticum + , Celtica gigantea +, Cirsium echinatum +, Dianthus anticarius + , Eryngium campestre 1 .

Localidades. 1-3. Málaga. Antequera. Sierra de Huma. Vertiente norte, entre el Cortijo Campano Chico y la cumbre de Huma. 30SUF4588. Cal: calizas. Cad: calizas-dolomías.

observan diferencias florísticas. No se han encontrado inventarios correspondientes a la subasociación ceratonietosum siliquae, 
Tabla 15

48. Asparago-Juniperetum turbinatae Díez Garretas, Asensi \& Martín Osorio 1996 juniperetosum turbinatae

pinetosum halepensis subass. nova, var. de Halimium halimifolium

(Asparago-Rhamnion oleoidis, Pistacio lentisci-Rhamnetalia alaterni, Quercetea ilicis)

$\begin{array}{lcccccccccccccc}\text { INVENTARIO N } & 1 & 2 & 3 & 4 & 5 & 6 & 7 & 8 & 9 & 10 & 11 & 12 & 13 & 14 \\ \text { Orientación } & \mathrm{NE} & \mathrm{SE} & \mathrm{S} & \mathrm{S} & \mathrm{NE} & - & \mathrm{N} & - & \mathrm{S} & \mathrm{SO} & - & - & \mathrm{E} & \mathrm{NO} \\ \text { Inclinación }\left({ }^{\circ}\right) & 20 & 30 & - & - & 30 & - & 50 & - & 45 & 10 & - & - & 30 & 20 \\ \text { Área }\left(\mathrm{m}^{2}\right) & 40 & 40 & 100 & 100 & 350 & 400 & 200 & 150 & 100 & 100 & 250 & 50 & 200 & 100 \\ \text { Litología } & \mathrm{Car} & \mathrm{Car} & \mathrm{Car} & \mathrm{Car} & \mathrm{Cal} & \mathrm{Cal} & \mathrm{Car} & \mathrm{Car} & \mathrm{Car} & \mathrm{Cal} & \mathrm{Cal} & \mathrm{Cal} & \mathrm{Cal} & \mathrm{Cal} \\ \text { Altitud }(\mathrm{m}) & 650 & 660 & 660 & 550 & 936 & 950 & 400 & 420 & 360 & 380 & 520 & 480 & 830 & 400 \\ \text { Altura vegetación }(\mathrm{cm}) & 700 & 600 & 650 & 500 & 200 & 200 & 600 & 500 & 700 & 150 & 200 & 160 & 200 & 700 \\ \text { Cobertura vegetación }(\%) & 90 & 100 & 100 & 100 & 80 & 80 & 200 & 60 & 70 & 80 & 50 & 100 & 60 & 100\end{array}$

Características y diferenciales de asociación

$\begin{array}{lllllllllllllll}\text { Juniperus turbinata } & 3 & 4 & 4 & 4 & 4 & 4 & 2 & 3 & 3 & 4 & 3 & 4 & 3 & 4 \\ \text { Juniperus oxycedrus } & + & 1 & 2 & + & - & - & + & - & + & 1 & - & - & - & 4\end{array}$ Asparagus horridus

Diferenciales de subasociación y variante

Pinus halepensis $\quad 4 \quad 4 \quad 4 \quad 4 \quad 4$

Halimium halimifolium -

Características de unidades superiores

Pistacia lentiscus

Rhamnus lycioides

subsp. oleoides

Chamaerops humilis

Ephedra fragilis

Quercus coccifera

Olea europaea

var. sylvestris

Daphne gnidium

Carex distachya

Phillyrea latifolia

Quercus rotundifolia

Arisarum vulgare

Asparagus albus

Rhamnus alaternus

Jasminum fruticans

Otras características. En 4: Coronilla juncea 3. En 8: Ophrys fusca +. En 14: Asparagus acutifolius 1, Pistacia terebinthus 1, Rubia peregrina 1.

\section{Compañeras}

Rosmarinus officinalis 2

Brachypodium retusum 4

Macrochloa tenacissima +

Cistus albidus

Phlomis purpurea

Anthyllis cytisoides

Cistus monspeliensis

Pinus halepensis

Thymbra capitata 
Thymus zygis Ulex parviflorus Carlina corymbosa Dactylis glomerata subsp. hispanica Phlomis lychnitis Teucrium lusitanicum Thymus mastichina Urginea maritima Cistus ladanifer Cistus salviifolius Gagea elliptica Helianthemun syriacum Narcissus cantabricus Retama sphaerocarpa Teucrium similatum

\begin{tabular}{llllllllllllll}
- & - & - & - & - & + & - & - & - & + & + & - & + & - \\
+ & - & - & - & - & - & + & - & - & - & + & + & 1 & - \\
- & - & - & - & - & - & - & + & + & - & - & - & + & - \\
& & & & & & & & & & & & & \\
- & - & - & - & + & - & - & - & - & 1 & - & + & - & - \\
- & - & - & - & - & - & + & - & - & + & - & - & + & - \\
- & - & - & - & - & - & - & - & 1 & - & + & 1 & - & - \\
- & - & - & - & - & - & - & + & - & - & - & + & + & - \\
- & - & - & - & - & - & - & - & - & + & 1 & - & + & - \\
- & + & + & - & - & - & - & - & - & - & - & - & - & - \\
- & - & - & 1 & - & - & - & - & - & - & - & - & - & 1 \\
- & - & - & - & - & - & + & + & - & - & - & - & - & - \\
- & - & - & - & - & - & + & - & + & - & - & - & - & - \\
- & - & - & - & - & - & + & + & - & - & - & - & - & - \\
- & - & - & - & - & - & - & - & - & + & - & + & - & - \\
- & - & - & - & 1 & 1 & - & - & - & - & - & - & - & - \\
\hline
\end{tabular}

Otras compañeras. En 5: Crambe filiformis 1, Dianthus gaditanus +, Thymus baeticus +. En 6: Helianthemun marifolium 1, Saxifraga reuteriana +. En 7: Muscari neglectum +. En 9: Cistus clusii subsp. clusii + , Sedum album +, Thapsia villosa + . En 10: Foeniculum vulgare +, Genista umbellata + . En 13: Santolina canescens + , Lavandula lanata + . En 14: Colutea hispanica 2, Hyacinthoides hispanica + .

Localidades. 1, 2 y 3. Málaga. Ardales. Sierra del Almorchón. Entre el Pico del Convento y los Altos del Almorchón. 30SUF4087. 4. Málaga. Campillos. Altos de Cerro Pardo. 30SUF4089. 5. Málaga. Antequera. Sierra Llana. Cabecera Ayo. Todos Aires. 30SUF4289. 6. Málaga. Antequera. Sierra Llana. Proximidades del Tajo de Ballesteros. 30SUF4490. 7 y 8. Málaga. Ardales. El Chorro. Cerro Almorchón. 30SUF4087 9. Málaga. Ardales. El Chorro. Cerro Pardo. Casa forestal El Gaitanejo. 30SUF4089. 10. Málaga. Antequera. Sierra de Huma. Cara Norte. Carril a Gobantes. 11. Málaga. Antequera. Sierra Llana. Puerto de Ramos. 30SUF4491 12. Málaga. Antequera. Sierra Llana. 30SUF49. 13. Málaga. Antequera. Sierra de Huma. Puerto Rosalejo. 30SUF4589. 14. Málaga. Campillos. Cerro Pardo. 30SUF4090. Car: calcarenitas. Cal: calizas.

característica del Valle del Guadalhorce y sierras litorales costasoleñas (Hidalgo \& Pérez Latorre, 2013). Los pinares autóctonos de Pinus halepensis de las sierras de Almorchón y Cerro Pardo ya fueron citados por Ceballos y Vicioso (1933). Constituyen una subasociación del sabinar caudado, pinetosum halepensis subass. nova, propia de las calcarenitas y molasas, ya que las representaciones del sabinar sobre calizas (subass. juniperetosum turbinatae) que presenta pino carrasco corresponden a reforestaciones (tabla 15, invs. 10, 11, 12 y 14). En los suelos de textura arenosa se presenta una variante marcada por Halimium halimifolium. Esta asociación constituye la cabecera de la serie Asparago horridi-Junipereto turbinatae $S$, aunque en lugares muy puntuales, en el límite de la zona de estudio, podrían ser interpretados como la etapa preforestal arbustiva de encinares de Smilaci mauritanicaeQuercetum rotundifoliae sobre margocalizas.

En estas sierras, los sabinares caudados constituyen formaciones de gran valor por su desviación ecológica (habitan en sierras interiores) respecto a las demás formaciones mediterráneo-occidentales de sabinar caudado (habitan el litoral y zonas insulares) y por su relictualidad, relacionada con la presencia de paleocostas y paleoislas marinas (Hidalgo et al., 2014). Las formaciones de J. turbinata continúan hacia el norte (Bobadilla-Gobantes, Antequera), ya fuera de la zona de estudio y sobre yesos, transformándose en una comunidad gipsícola de gran singularidad (Cabezudo et al., 2013) y exclusiva también de esta zona biogeográfica antequerana. 


\section{Series de Vegetación}

En la mayor parte del territorio estudiado las etapas climácicas corresponden a vegetación permanente arbustiva, de matorral o rupícola. Las únicas formaciones arbóreas corresponden a reforestaciones con Pinus halepensis o pinaressabinares con dicho Pinus, generalmente en zonopotencialidad de los sabinares de Juniperus turbinata o de los encinares de Quercus rotundifolia. Son observables algunas agrupaciones de $Q$. rotundifolia en los piedemontes con suelos profundos en los límites del área de estudio. En el piso mesomediterráneo es destacable la ausencia de acerales y terebintales y de sus orlas espinosocaducifolias, frecuentes en el resto del subsector Torcalense (Phillyreo latifoliae-Pistacietum terebinthi, Vinco difformis-Quercetum fagineae aceretosum monspessulani, Pérez Latorre et al., 2009; Pavón et al., 2013). Esto se atribuye a la xericidad causada por el mayoritario ombrotipo seco, aunque en algunos biotopos muy restringidos de la umbría elevada de la Sierra de Huma se dan las condiciones zonopotenciales para su desarrollo.

\section{Series climatófilas}

\section{Encinares}

\section{Smilaco mauritanicae-Querco rotundifoliae $S$}

(p.p. Rhamno oleoidis-Querco rotundifoliae $S$ sensu Asensi et al., 2005)

Serie tingitano-onubo-algarviense, bética y mauritánica, termomediterránea, seco-subhúmeda de la encina (Quercus rotundifolia).

1a. faciación basófila seca con encinas quercetoso rotundifoliae $s$

Esta serie es reconocible sucesionalmente solo desde la etapa arbustiva, ya que los encinares han desaparecido y por ello se consideran criptoclimácicos. Dicha fase arbustiva que se desarrolla sobre margocalizas es un espinar de Asparago-Rhamnetum oleoides ceratonietosum, que puede evolucionar a una comunidad de Chamaerops humilis con acebuches (Olea europaea var. sylvestris) debido al uso recurrente de pastoreo y fuego. Estas dos asociaciones pueden formar un complejo topogénico rupícola del que se habla más adelante.

El matorral serial es de Genisto-Cytisetum fontanesii, más frecuente en la cara norte de las sierras Llana y del Valle de Abdalajís y sobre margocalizas.

El pastizal corresponde a la formación graminoide de baja talla de la comunidad de Aegilops geniculata.

\section{Paeonio coriaceae-Querco rotundifoliae $S$}

Serie bética, basófila, mesomediterránea, seco-subhúmeda-húmeda de la encina (Quercus rotundifolia).

2a. Faciación termófila con Pistacia lentiscus

Los encinares cabecera de esta serie no existen a día de hoy en la zona de estudio y por ello se consideran criptoclimácicos. Sí que es posible observar su primera etapa de sustitución: los coscojares de Crataego monogynae-Quercetum cocciferae en su variante más termófila con Pistacia lentiscus.

Los matorrales seriales más representativos son los aulagares de Genisto speciosaeUlicetum parviflorii, sobre calizas, y de su subasociación lavanduletosum lanatae sobre dolomías. En las zonas más elevadas, el matorral se enriquece en especies orófilas como Bupleurum spinosum, marcando el tránsito a la vegetación permanente de la comunidad de Erinacea anthyllis. En zonas con fuerte inclinación, con lapiaces y pedregales, pero con acumulación de suelo intersticial, se desarrollan lastonares de HelictotrichoFestucetum capillifoliae stat. nov. En la cara norte de la Sierra del Valle de Abdalajís son frecuentes los canchales de calizo-dolomías, en 
los que se ha inventariado vegetación glerícola de la comunidad de Centaurea boissieri y Andryala ramossisima. Aunque poco frecuente, existen zonas donde el matorral se ha rozado por labores forestales de modo recurrente, tomando entonces preponderancia los "yesquerales" de Cerastio-Brachypodietum retusi. Existen zonas con suelo margoso en las que la humedad edáfica permanece más tiempo y es aquí donde se ha inventariado la pradera graminoide de la comunidad de Brachypodium phoenicoides.

El pastizal anual oligotrófico sobre margocalizas es de la comunidad de Brachypodium distachyon. En las zonas más elevadas, mesomediterráneas, sobre calizas, y en zonas muy pedregosas y de fuerte inclinación y orientadas al norte se puede encontrar el pastizal de Violo-Jonosidietum prolongoi var. con Campanula cabezudoi. El pastizal anual subnitrófilo sobre margocalizas es de tipo graminoide y de corta talla, correspondiente a la comunidad de Aegylops geniculata. Si el grado de nitrificación aumenta, el pastizal pasa a ser de la comunidad de Leontodon longirrostris y Anthemis arvensis. El pastoreo frecuente de ganado ovino lleva a la instalación de majadales basófilos de la comunidad de Erodium primulaceum. En zonas llanas pero con abundante pedregosidad, sobre suelos muy xéricos y en el piso mesomediterráneo, se pueden encontrar pastizales crasos de Sedetum granatensis-acris var. con Sedum mucizonia.

En las cercanías de las cortijadas y en algunas cuevas y cumbres, con uso ganadero, que produce sobrepastoreo y nitrificación del suelo, se desarrollan cardales de gran tamaño de la asociación Carduo-Sylibetum mariani.

\section{Series edafoxerófilas}

Sabinares

\section{Asparago horridi-Junipereto turbinatae $S$}

Serie relicta, bética occidental y aljíbica, termomediterránea, seco-subhúmeda de la sabina caudada (Juniperus turbinata)

3a. Faciación típica juniperetoso

\section{turbinatate $s$}

Faciación propia de las calizas y dolomías de las Sierras de Huma y Llana en los pisos termomediterráneo y mesomediterráneo inferior. Se trata de sabinares puros de AsparagoJuniperetum turbinatae que se asientan sobre margocalizas con suelos desarrollados en la base de las sierras y sobre todo en los espolones, roquedos, lapiaces y valles encajados sobre litosuelos. El uso del fuego y el pastoreo han transformado parte de estos sabinares, sobre todo en la cara sur de la Sierra de Huma, en espinares de Asparago-Rhamnetum oleoidis ceratonietosum siliquae.

El matorral serial es de GenistoCytisetum fontanesii en margocalizas del piso termomediterráneo, mientras que en zonas mesomediterráneas y ya sobre calizodolomías, son aulagares de Genisto cinereaeUlicetum parviflorii. En mosaico con este matorral, en zonas aclaradas, probablemente por el uso del fuego y por la fuerte pendiente y disgregación de la roca se desarrollan lastonares de Helictotricho-Festucetum capillifoliae stat. nov.

En la umbría de la Sierra de Huma y sobre calizas con fuertes pendientes y gleras se desarrolla el pastizal de Violo-Jonopsidietum prolongoi var. con Campanula cabezudoi. El herbazal de pequeña talla en suelos margocalizos con ligera nitrificación debido al paso de ganado es la comunidad de Leontodon longirrostris y Anthemis arvensis. En zonas donde el ganado se concentra, se incrementa el pisoteo y se acumulan excrementos, se desarrollan cardales hipernitrófilos de Notobasio-Scolymetum maculati.

3a1. Variante dolomitícola

Existe una variante de estos sabinares que aparece sobre dolomías y calizo-dolomías en la zona alta de Sierra de Huma en el piso mesomediterráneo, reconocible a nivel serial 
de matorral y pastizal. Los aulagares de Genisto-Ulicetum parviflorii lavanduletosum lanatae aparecen sobre las dolomías más consistentes. En los canchales con fuerte inclinación existen pequeñas representaciones de la comunidad graminoide de elevada talla de Celtica gigantea. El tomillar dolomitícola es escaso y solo parece en zonas en las que se han formado taludes y pequeñas gleras, donde se desarrolla la comunidad de Centaurea boissieri y Andryala ramosissima. El pastizal anual dolomitícola es de muy pequeña talla y corresponde a la comunidad de Arenaria modesta y Chaenorhinum rubrifolium, y se desarrolla en pequeñas gleras y graveras con suelo arenoso, entre el matorral.

\section{3b. Faciación con pino carrasco pinetoso halepensis $s$}

Faciación propia de las calcarenitas y molasas del distrito Pizarreño. La vegetación climácica se corresponde con sabinares con pinos carrascos y con un buen grado de conservación en el Almorchón y Cerro Pardo. Corresponden a la subasociación AsparagoJuniperetum turbinatae pinetosum halepensis subass. nova y ocupan litosoles y entisoles a veces en fuertes pendientes e incluso roquedos y cantiles. Existen zonas puntuales donde pueden aparecer grupos de encinas (Quercus rotundifolia) en el sabinar, en suelos más profundos y sitios conservados. Los suelos más arenosos quedan indicados por la presencia de la var. con Halimium halimifolium.

El tomillar de calcarenitas se puede incluir en Saturejo-Coridothymetum capitati helianthemetosum almeriense, que puntualmente puede mostrar una variante con Halimium halimifolium en suelos muy arenosos. Los espartales son poco frecuentes y se incluyen en Lavandulo-Stipetum tenacissimae helianthemetosum almeriense. Los taludes con derrubios y suelos arenosos pueden ser el hábitat para la comunidad glerícola de Echium albicans subsp. fruticescens. Las zonas donde las molasas y calcarenitas llevan intercalaciones de cuarzo y por tanto el suelo tiene cierto matíz silíceo está indicado por la aparición de pequeños jarales de la comunidad de Cistus monspeliensis donde aparece además Cistus ladanifer, como una rareza en el Paraje.

Los pastizales se desarrollan sobre litosuelos arenosos y presentan sinfenosucesión. En otoño y en zonas elevadas con suelos compactados se desarrolla el pastizal efemeroide de ScilloRanunculetum bullati. También existen otros dos pastizales anuales oligotróficos: a finales de invierno aparece, aunque poco extendido, el Saxifrago-Hornungietum petraeae, mientras que ya en primavera, aparece el ArenarioLinarietum salzmanii. Las zonas pastoreadas presentan pequeñas extensiones con majadales de la comunidad de Poa bulbosa y Erodium cicutarium, que se encuentran a veces asociadas o en mosaico con nanopastizales de SedoCrassuletum tillaeae poetosum bulbosae.

\section{Series edafohidrófilas}

Fresnedas

\section{Ficario ranunculoidis-Fraxineto angustifoliae $S$}

Serie riparia iberomarroquí-atlántica del fresno (Fraxinus angustifolia)

4a. Faciación aljíbica y bética salicetoso pedicellataes

La fuerte transformación de las riberas de los embalses que atraviesan la zona de estudio sobre calcarenitas hace que la vegetación climácica edafohigrófila de bosques de ribera esté muy alterada. Existen algunas formaciones de Fraxinus angustifolia que podrían incluirse en la serie en cuestión (fresnedas criptoclimácicas). Se encuentran en mosaico con adelfares de Rubo-Nerietum oleandri y zarzales de la comunidad de Rubus ulmifolius.

Adelfares

\section{Rubo ulmifolii-Nerieto oleandri S}

Serie riparia ibérica, termo-mesomediterránea inferior de la adelfa (Nerium 
oleander).

La litología porosa de la mayor parte del área de estudio y la inundación de las riberas del río Guadalhorce debido a los embalses no permiten apenas reconocer los adelfares de Rubo-Nerietum oleandri, salvo en algún arroyo en la zona calcarenítica de la unidad Pizarreña.

\section{Complejos topogénicos de vegetación}

Rupícolas termófilos y arbustivos

\section{Asparago-Rhamnetum oloides ceratonietosum: Comunidad de Chamaerops humilis}

La abundancia de hábitats rocosos con grandes grietas permiten la existencia de vegetación arbustiva permanente: el espinar con algarrobos de Asparago-Rhamnetum oleoidis ceratonietosum siliquae en las bases de los grandes cortados y farallones, y la comunidad de Chamaerops humilis en hábitats más pastoreados.

Rupícolas termófilos, espeluncícolas y de gleras

\section{Rupicapnetum decipientis: Parietarietum judaicae}

8. Atamanthetum vayredanae: Comunidad de Hippocrepis tavera-mendozae

9. Comunidad de Delphinium staphisagria y Smyrnium olusatrum

Los frecuentes roquedos con paredes con pendiente superior a $90^{\circ}$ están colonizados tanto en calcarenitas como en calizo-dolomías por el Rupicapnetum decipientis. Si el grado de nitrofilia es muy elevado, lo que se desarrolla es un herbazal rupícola perenne de Parietarietum judaicae. Cuando la pendiente es menor y en siempre en zonas muy térmicas, soleadas y a media-baja altitud, otras dos comunidades ocupan las grietas: el Athamantetum vayredanae en el Cañón del Chorro y la comunidad de Hippocrepis tavera-mendozae en los roquedos más expuestos y a mayor elevación.

Todos estos tipos de roquedos, en umbrías, suelen presentar en la base acúmulos de rocas con nitrificación por el paso de ganado, lo que lleva a la instalación del herbazal escionitrófilo de la comunidad de Delphinium staphisagria y Smyrnium olusatrum.

Rupícolas mesomediterráneos

\section{Biscutello-Saxifragetum reuterianae: Polypodietum serrati: Stachydetum circinatae}

Los roquedos verticales con orientación norte, presentan la comunidad rupícola umbrófila del Biscutello-Saxifragetum reuterianae. En las oquedades de esas mismas grietas, donde se deposita cierta cantidad de materia orgánica, se desarrolla el Stachydetum circinatae. En zonas kársticas o "torcales", las pequeñas grietas de roca horizontal con acúmulos terrosos pueden albergar a la comunidad pteridofítica del Polypodietum serrati.

Topoclimácicos

11. Comunidad de Erinacea anthyllis: Helictotricho arundani-Festucetum capillifoliae stat. nov.

Vegetación xeroacántica almohadillada en mosaico con vegetación graminoide amacollada. Se desarrollan como comunidades permanentes en la cresta alomada de Sierra de Huma, sobre litosuelos calizo-dolomíticos muy xéricos y muy expuestos al viento, en el termotipo mesomediterráneo medio con ombrotipo subhúmedo.

\section{Complejos edafogénicos de vegetación}

Colas de embalses y rezumaderos

\section{Typho-Schoenoplectetum glauci: Comunidad de Carex hispida e Iris pseudacorus}

\section{Trachelio-Adiantetum capilli-veneris}

Vegetación edafohigrófila ligada a las infraestructuras hidrául icas que atraviesan y rodean a la zona de estudio. En las orillas poco profundas y con suelos limosos de los 
pantanos se alternan, en función de la duración del encharcamiento, formaciones de carrizal de Typho-Schoenoplectetum glauci, o de cárices y grandes hierbas de la comunidad de Carex hispida e Iris pseudacorus. En los rezumaderos causados por las fugas de las canalizaciones aparece la asociación Trachelio-Adiantetum capilli-veneris.

Fuentes y vertisoles temporalmente hidromorfos

\section{Holoschoenetum vulgaris: Ranunculo-} Juncetum inflexi: Comunidad de Festuca mediterranea: Comunidad de Juncus bufonius

Vegetación edafohigrófila que se desarrolla en suelos arcillosos sobre vertisoles que sufren encharcamiento temporal pero prolongado. La duración variable del agua en superficie y profundidad hace que se sitúen en mosaico, o incluso de modo sinfenosucesional: los nanojuncales de Juncus bufonius en pequeños regueros que se secan ya en primavera, la comunidad de Festuca mediterranea sobre vertisoles también con secado temprano y los juncales en suelos con hidromorfía en profundidad, que son de Holoschoenetum vulgaris en zonas menos pastoreadas y de Ranunculo-Juncetum inflexi en zonas con paso de ganado.

\section{Zonopotencialidad}

La tabla 16 resume las formaciones y especies climácicas en función de su respectiva zonopotencialidad bioclimática y litológica.

\section{ESQUEMA SINTAXONÓMICO Y ECOFISIONÓMICO}

Se presenta a continuación la clasificación fitosociológica de la vegetación del área de estudio, siguiendo básicamente el esquema propuesto por Rivas Martínez et al. (2002) a nivel de clases y grupos ecofisionómicos. Cada asociación, subasociación, comunidad (o comunidad basal, BC) y variante (todas resaltadas en negrita) se acompañan de una breve descripción con datos fisionómicos, fitoecológicos y/o corológicos para la zona de estudio.

\section{Vegetación dulceacuícola fontinal, anfibia y turfófila}

\section{IIa. Vegetación pionera efímera}

ISOETO-NANOJUNCETEA Br. - Bl. \& Tüxen ex Westhoff, Djik \& Passchier 1946

+ Nanocyperetalia Klika 1935

* Nanocyperion Koch ex Libbert 1932

1. Comunidad de Juncus bufonius BC [Nanojuncales sobre arcillas hidromorfas]

IIb. Vegetación lacustre, fontinal y turfófila

MAGNOCARICI-PHRAGMITETEA Klika in Klika \& Novak 1941 nom. inv.

+ Phragmitetalia W. Koch 1926

* Phragmition communis W. Koch 1926

** Phragmitenion communis

2. Typho-Schoenoplectetum glauci Br.-B1. \& O. Bolòs 1958 [Carrizales con espadañas sobre orillas limosas]

+ Magnocaricetalia Pignatti 1954

* Magnocaricion elatae Koch 1926

3. Comunidad de Carex hispida e Iris pseudacorus [Vegetación basófila de grandes cárices en orillas de embalses]

\section{Vegetación casmofítica, glerícola y epifítica}

\section{IVa. Vegetación casmofítica}

ADIANTETEA Br.-Bl. in Br.-B1., Roussine \& Nègre 1952

+ Adiantetalia capilli-veneris Br.-Bl. ex Horvatic 1934 


\begin{tabular}{|c|c|c|c|}
\hline Litología & Piso bioclimático & Ombrotipo & Zonopotencialidad \\
\hline \multicolumn{4}{|c|}{ Unidad de Abdalajís: Sierras Huma, Llana y Valle de Abdalajís } \\
\hline Calizas & $\begin{array}{l}\text { termomediterráneo } \\
\text { superior y } \\
\text { mesomediterráneo } \\
\text { inferior } \\
\end{array}$ & $\begin{array}{c}\text { seco- } \\
\text { subhúmedo }\end{array}$ & $\begin{array}{l}\text { Sabinares y encinares, } \\
\text { (Juniperus turbinata, } \\
\text { Quercus rotundifolia) }\end{array}$ \\
\hline Dolomías & $\begin{array}{l}\text { termomediterráneo } \\
\text { superior y } \\
\text { mesomediterráneo } \\
\text { inferior }\end{array}$ & $\begin{array}{c}\text { seco- } \\
\text { subhúmedo }\end{array}$ & $\begin{array}{l}\text { sabinares y encinares } \\
\text { (Juniperus turbinata, } \\
\text { Quercus rotundifolia) }\end{array}$ \\
\hline Arcillas, margas & $\begin{array}{l}\text { termomediterráneo } \\
\text { superior y } \\
\text { mesomediterráneo } \\
\text { inferior } \\
\end{array}$ & $\begin{array}{c}\text { seco- } \\
\text { subhúmedo }\end{array}$ & $\begin{array}{l}\text { Sabinares y encinares } \\
\text { (Juniperus turbinata, } \\
\text { Quercus rotundifolia) }\end{array}$ \\
\hline Calizo-Dolomías & $\begin{array}{c}\text { mesomediterráneo } \\
\text { medio }\end{array}$ & subhúmedo & $\begin{array}{c}\text { Piornales } \\
\text { (Erinacea anthyllis) }\end{array}$ \\
\hline Fuentes & $\begin{array}{l}\text { termomediterráneo } \\
\text { superior y } \\
\text { mesomediterráneo } \\
\text { inferior } \\
\end{array}$ & $\begin{array}{c}\text { seco- } \\
\text { subhúmedo }\end{array}$ & $\begin{array}{c}\text { Juncales (Scirpus } \\
\text { holoschoenus, Juncus } \\
\text { inflexus, } \\
\text { Festuca mediterranea) }\end{array}$ \\
\hline \multicolumn{4}{|c|}{ Distrito Pizarreño: El Chorro, Almorchón, Cerro Pardo } \\
\hline Calcarenitas & $\begin{array}{l}\text { termomediterráneo } \\
\text { superior }\end{array}$ & seco & $\begin{array}{c}\text { Sabinares con pinos } \\
\text { carrascos (Juniperus } \\
\text { turbinata, } \\
\text { Pinus halepensis) }\end{array}$ \\
\hline
\end{tabular}

Tabla 16. Formaciones climácicas boscosas, arbustivas y de matorral del territorio según la zonopotencialidad litológica y bioclimática en las dos unidades fitogeográficas. Forests and shrubland vegetation in the study area according to zono-potential lithology and bioclimatology in the phytogeographical units.

*Adiantion capilli-veneris Br.-Bl. ex Horvatic 1934

4. Trachelio coerulei-Adiantetum capilliveneris O. Bolòs 1957 [Vegetación de paredes rezumantes y pozos]

ASPLENIETEA TRICHOMANIS (Br.-B1. in Meier \& Br.-Bl. 1934) Oberdorfer 1977

+ Asplenietalia petrarchae (glandulosi) Br.-B1. in Meier \& Br.-B1. 1934

++ Tinguarrenalia siculae (Daumas, Quèzel \& Santa 1952) Galán de Mera in Pérez Latorre,
Galán de Mera, Deil \& Cabezudo 1996

* Campanulion velutinae Martínez Parras \& Peinado 1990

** Campanulenion velutinae

5. Biscutello frutescentis-Saxifragetum reuterianae Socorro \& Marín Calderón 1983 saxifragetosum reuteranae [Vegetación rupícola ombrófila]

var. con Erodium cheilanthifolium [Variante orófila]

var. con Petrorrhagia saxifraga [Variante local torcalense occidental] 
6. Athamanthetum vayredanae $M$. López \& Esteve in M. López, Marín, Molero \& Esteve 1982 nom. mut. propos. [Vegetación rupícola termófila]

var. con Rupicapnos africana [Variante local torcalense occidental]

7. Comunidad de Hippocrepis tavera-mendozae

[Vegetación rupícola heliófila]

PARIETARIETEA Rivas-Martínez in Rivas Goday 1964

+ Parietarietalia judaicae Rivas-Martínez in Rivas Goday 1964

* Parietario-Galion murale Rivas Martínez ex Rivas Goday 1964

8. Parietarietum judaicae K. Buchwald 1952 [Vegetación rupícola herbácea nitrófila y umbrófila]

9. Stachydetum circinatae Fdez. Casas 1972

[Comunidad de oquedades nitrificadas]

PETROCOPTIDO-SARCOCAPNETEA ENNEAPHYLLAE Rivas-Martínez, Cantó \& Izco in Rivas-Martínez, Díaz, FernándezGonzález, Izco, Loidi, Lousã \& Penas 2002

+ Sarcocapnetalia enneaphyllae Fdez. Casas 1972 em. Deil \& Galán de Mera 1997

* Rupicapnion africanae Br. - Bl. \& Maire 1924 10. Rupicapnetum decipientis Pérez Latorre, Cabezudo \& Nieto 1995 [Vegetación espeluncícola]

IVb. Vegetación casmocomofítica, epifítica y glerícola

ANOMODONTO-POLYPODIETEA RivasMartínez 1975

+ Anomodonto-Polypodietalia O. Bolòs \& Vives in O. Bolòs 1957

* Polypodion serrati Br.-Bl. in Br.-Bl., Roussine \& Nègre 1952

11. Polypodietum serrati $\mathrm{Br}$.-Bl. in $\mathrm{Br}$--B1., Roussine \& Nègre 1952 [Comunidad pteridofítica umbrófila vivaz de repisas terrosas] * Anogrammion leptophyllae Bellot \& Casaseca in Bellot 1967

12. Selaginello-Anogrammetum leptophyllae R. Molinier 1937 [Pastizal pteridofítico de taludes terrosos sombreados]

PHAGNALO-RUMICETEA INDURATI (Rivas Goday \& Esteve 1972) Rivas-Martínez, Izco \& Costa 1973

+ Phagnalo-Rumicetalia indurati Rivas Goday \& Esteve 1972

* Melico-Phagnalion intermedii Rivas Goday \& Esteve 1972

13. Campanulo mollis-Phagnaletum intermedii Rivas Goday \& Esteve ex Nieto \& Cabezudo 1988 [Comunidad rupícola basófila de grandes grietas y repisas rocosas]

* Andryalo-Crambion filiformis (Rivas Goday \& esteve 1972) Rivas Martínez, Izco \& Costa 1973

14. Comunidad de Centaurea boissieri y Andryala ramosissima [Pastizal vivaz sobre arena dolomítica]

15. Comunidad de Echium albicans subsp. fruticescens [Pastizal vivaz de taludes y roquedos calcareníticos]

\section{Vegetación antropógena, de lindero de bosque y megafórbica.}

\section{Va. Vegetación antropógena}

ARTEMISIETEA VULGARIS Lohmeyer, Preising \& Tüxen in Tüxen 1950 ampl. RivasMartínez, Báscones, T.E. Díaz, Fernández González \& Loidi 1991

+ Carthametalia lanati Brullo in Brullo \& Marceno 1985

* Onopordion castellani Br.-B1. \& O. Bolòs 1958 corr. Rivas-Martínez, T.E. Díaz, FernándezGonzález, Izco, Loidi, Lousã \& Penas 2002

16. Notobasio syriacae-Scolymetum maculati Rivas Goday ex Ladero, Socorro, Molero, M. López, Zafra, Marín, Hurtado \& Pérez-Raya 1981 [Cardales de suelos vérticos, estivales] 
* Sylibion mariani Rivas Martínez 1987

17. Carduo bourgaeani-Sylibetum mariani Rivas Martínez ex Rivas Martínez, Costa \& Loidi 1992 [Cardales primaverales]

STELLARIETEA MEDIAE Tüxen, Lohmeyer \& Preising ex von Rochow 1951

Stellarienea mediae

+Thero-Brometalia (Rivas Goday \& Rivas-Martínez ex Esteve 1973) O. Bolòs 1975

*Taeniathero-Aegylopion geniculatae Rivas-Martínez \& Izco 1977

18. Comunidad de Aegilops geniculata [Pastizal anual graminoide, primaveral, basófilo, subnitrófilo]

Vb. Vegetación de lindero de bosque y megafórbica

GALIO-URTICETEA Passarge ex Kopecky 1969

+ Galio aparines-Alliarietalia petiolatae Gors \& Muller 1969 em. Rivas Martínez 1987

* Galio-Alliarion petiolatae Oberdorter \& Lohmeyer in Oberdorfer. Gérs, Korneck, Lohmeyer, Mtiller. Philippi \& Seiben 1967

19. Comunidad de Delphinium staphisagria y Smyrnium olusatrum sensu Pérez Latorre, Caballero, Casimiro-Soriguer, Gavira \& Cabezudo 2008 [Vegetación suribérica de base de cantiles calizos umbríos termomediterráneos]

\section{Vegetación pratense y pascícola}

\section{VIIa. Pastizales terofíticos}

HELIANTHEMETEA GUTTATI (Br.-Bl. in Br.-Bl., Roussine \& Nègre 1952) Rivas Goday \& Rivas-Martínez 1963 em. Rivas-Martínez 1978

+ Trachynietalia distachyae Rivas-Martínez 1978

* Omphalodion commutatae Rivas Martínez, Izco \& Costa in Izco 1973 corr. Pérez Raya 1988
20. Arenario arundanae-Linarietum salzmannii Asensi, Díez-Garretas \& Esteve 1979 corr. Rivas-Martínez, Asensi, Molero \& F. Valle 1991 [Nanopastizal efímero sobre calcarenitas]

21. Comunidad de Arenaria modesta y Chaenorhinum rubrifolium [Nanopastizal dolomitícola en suelos arenosos]

* Trachynion distachyae Rivas-Martínez 1978 22. Comunidad de Brachypodium distachyon sensu Pérez Latorre, Caballero, CasimiroSoriguer, Gavira \& Cabezudo 2008 [Pastizal terofítico basófilo graminoide]

23. Sedo caespitosii-Crassuletum tillaeae Rivas Goday 1958

poetosum bulbosae Pérez Latorre \& Cabezudo in Pérez Latorre, Caballero, Casimiro-Soriguer, Gavira \& Cabezudo 2008 [Pastizal crasifolio pastoreado]

24. Violo demetriae-Jonopsidietum prolongoi Asensi, Díez-Garretas \& Esteve 1979

jonopsidetosum [Pastizal anual fugaz de litosuelos calizos]

Var. con Campanula cabezudoi sensu Pérez Latorre, Casimiro-Soriguer, Gavira \& Cabezudo 2012 [Variante local]

25. Saxifrago tridactylitae-Hornungietum petraeae Izco 1974 [Pastizal anual subrupícola tardoinvernal]

26. Comunidad de Leontodon longirostris y Anthemis arvensis [Pastizal anual sobre litosuelos, subnitrófilo]

* Ranunculion bullati Pérez Latorre \& Cabezudo in Pérez Latorre, Caballero, Casimiro-Soriguer, Gavira \& Cabezudo 2008

27. Scillo autumnalis-Ranunculetum bullati Pérez Latorre \& Cabezudo in Pérez Latorre, Caballero, Casimiro-Soriguer, Gavira \& Cabezudo 2008 [Pastizal geófito otoñal]

VIIb. Pastizales y prados vivaces xerofíticos y mesofíticos

FESTUCO-BROMETEA Br. - Bl. \& Tüxen ex Br. - Bl. 1949 
+ Brachypodietalia phoenicoides (Br. - B1. 1931) Molinier 1934

28. Comunidad de Brachypodium phoenicoides BC [Herbazales de suelos margosos húmedos hasta final de primavera]

POETEA BULBOSAE Rivas Goday \& Rivas-Martínez in Rivas-Martínez 1978

+ Poetalia bulbosae Rivas Goday \& Rivas-Martínez in Rivas Goday \& Ladero 1970 * Plantaginion serrariae Galán de Mera, Morales \& Vicente Orellana 2000

29. Comunidad de Erodium primulaceum BC sensu Pérez Latorre, Caballero, CasimiroSoriguer, Gavira y Cabezudo 2009 [Majadales sobre margocalizas]

30. Comunidad de Poa bulbosa y Erodium cicutarium [Majadales sobre calcarenitas]

SEDO-SCLERANTHETEA Br. - B1. 1955 em. Th. Muller 1961

+ Alysso-Sedetalia Moravec 1967

* Alysso-Sedion albi Oberdorfer \& Müller in Müller 1961

31. Sedetum granatensis-acris Pérez Latorre \& Cabezudo in Pérez Latorre, D. Navas, O. Gavira, G. Caballero \& Cabezudo 2004 var. de Sedum mucizonia [Pastizal crasifolio, variante termófila]

\section{LYGEO SPARTI-STIPETEATENACISSIMAE} Rivas-Martínez 1978

+ Lygeo sparti-Stipetalia tenacissimae Br-Bl. \& O. Bolós 1958 em. Rivas-Martínez 1978

* Thero-Brachypodion Br. - Bl. 1925

32. Cerastio gibraltarici-Brachypodietum retusi Díez Garretas \& Asensi in Rivas Martínez et al. 2011

brachypodietosum retusi [Yesquerales xerófilos]

* Stipion tenacissimae Rivas-Martínez 1978

33. Lavandulo multifidae-Stipetum tenacissimae Pérez Latorre \& Cabezudo in Pérez Latorre, Caballero, Casimiro-Soriguer, Gavira \& Cabezudo 2008 helianthemetosum almeriensis Pérez Latorre \& Cabezudo in Pérez Latorre, Caballero, Casimiro-Soriguer, Gavira \& Cabezudo 2008 [Espartales sobre calcarenitas]

34. Comunidad de Celtica gigantea [Espartales de talla elevada sobre calizo-dolomías]

* Festucion scariosae Martínez Parras, Peinado \& Alcaraz 1983

35. Helictotricho arundani-Festucetum capillifoliae (Pérez Latorre \& Cabezudo) Pérez Latorre, Casimiro-Soriguer \& Cabezudo stat. nov. [Lastonares mesomediterráneos]

VIIc. Vegetación de praderas antropizadas de siega y pastoreo

MOLINIO-ARRHENATHERETEA R. Tx. 1937

+ Holoschoenetalia Br.-B1. (1931) 1947

* Molinio-Holoschoenion Br.-Bl. (1931) 1947

36. Holoschoenetum vulgaris $\mathrm{Br}$.-Bl. ex Tchou 1948 [Juncales subnitrófilos de junco churrero] + Plantaginetalia majoris R. Tx. \& Preising in R. Tx. 1950 em Rivas-Martínez 1987

* Mentho-Juncion inflexi De Foucault 1984

37. Ranunculo macrophylli-Juncetum inflexi Pérez Latorre \& Cabezudo in Pérez Latorre, P. Navas, D. Navas, Gil \& Cabezudo 1998 [Juncales nitrófilos de suelos vérticos]

+ Phalaridetalia coerulescentis A. Galán, Deil, Haug \& Vicente Orellana 1997

* Gaudinio fragilis-Hordeion bulbosi A. Galán, Deil, Haug \& Vicente Orellana 1997

38. Comunidad de Festuca mediterranea BC sensu Pérez Latorre Casimiro-Soriguer, Gavira \& Cabezudo 2012 [Praderas graminoides de suelos arcillosos temporalmente húmedos]

\section{Vegetación serial sufruticosa, fruticosa y arbustiva}

VIIIa. Vegetación de brezales y matorrales

CISTO-LAVANDULETEA Br.-Bl. in Br.-Bl., Molinier \& Wagner 1940 
+ Lavanduletalia stoechadis Br.-Bl. in Br.-Bl., Molinier \& Wagner 1940

* Calicotomo-Cistion ladaniferi Br. - Bl. (1931) 1940 em. Rivas Martínez 1979

** Genistenion umbellatae Peinado, Alcaraz \& Martínez Parras 1992

39. Comunidad de Cistus monspeliensis BC [Jaguarzales acidófilos]

CISTO-MICROMERIETEA JULIANAE Oberdorfer 1954

+ Rosmarinetalia officinalis Br.-Bl. ex Molinier 1934

* Saturejo micranthae-Thymbrion capitati Rivas-Goday \& Rivas-Martínez 1969

40. Genisto speciosae-Ulicetum parviflorii Rivas Goday \& Rivas-Martínez ex Pérez Latorre y Cabezudo 2009 nom. inv. propos.

ulicetosum parviflorii [Matorrales calcícolas mesomediterráneos]

var. con Bupleurum spinosum [Variante orófila]

lavanduletosum lanatae Rivas Goday \& Rivas Martínez ex Pérez Latorre, Casimiro-Soriguer \& Cabezudo 2014 [subasociación dolomitícola] 41. Genisto equisetiformis-Cytisetum fontanesii Rivas Goday \& Rivas-Martínez ex Pérez Latorre, Casimiro-Soriguer \& Cabezudo 2014 [Matorrales sobre margocalizas termomediterráneos]

42. Saturejo malacitanae-Coridothymetum capitati Cabezudo \& Pérez Latorre 2001

helianthemetosum almeriense Pérez Latorre \& Cabezudo in Pérez Latorre, Caballero, Casimiro-Soriguer, Gavira \& Cabezudo 2008 [Tomillares sobre calcarenitas]

var. con Halimium halimifolium [Variante de suelos arenosos]

+ Erinacetalia anthyllidis Quézel 1951

* Xeroacantho-Erinaceion anthyllidis (Quézel 1953) O. Bolòs 1967

43. Comunidad de Erinacea anthyllis BC [Piornal xeroacántico mesomediterráneo culminícola]
VIIIb. Vegetación serial arbustiva y de margen de bosque

RHAMNO-PRUNETEA Rivas Goday \& Borja ex Tüxen 1962

+ Prunetalia spinosae Tüxen 1952

* Pruno-Rubion ulmifolii O. Bolòs 1954

** Pruno-Rubenion ulmifolii

44. Comunidad de Rubus ulmifolius BC [Zarzales]

IX. Vegetación potencial forestal (bosques), preforestal (arbustedas), semidesértica y desértica

IXa. Arbustedas y bosques palustres, quionófilos o colonizadores riparios

NERIO-TAMARICETEA Br.-Bl. \& O. Bolòs 1958

+ Tamaricetalia africanae Br.-B1. \& O. Bolòs 1958 em. Izco, Fernández-González \& Molina 1984

* Rubo ulmifolii-Nerion oleandri O. Bolòs 1985

45. Rubo ulmifolii-Nerietum oleandri $O$. Bolòs 1956 [Adelfares]

SALICI-POPULETEA (Rivas-Martínez \& Cantó ex Rivas-Martínez et al. 1991) Rivas-Martínez \& Cantó 2002

+ Populetalia albae Br.-Bl. ex Tchou 1948

* Populion albae Br.-Bl. ex Tchou 1948

** Fraxino angustifoliae-Ulmenion minoris Rivas Martínez 1975

46. Ficario ranunculoidis-Fraxinetum angustifoliae Rivas-Martínez \& Costa in Rivas-Martínez, Costa, Castroviejo y Valdés 1980 [Fresnedas]

salicetosum pedicellatae Díez-Garretas, Cuenca \& Asensi 1986

var. con Nerium oleander sensu Pérez Latorre Casimiro-Soriguer, Gavira \& Cabezudo 2012 [Variante termófila] 
IXb. Vegetación climatófila y edafófila potencial mediterránea y eurosiberiana

QUERCETEA ILICIS Br.-B1. 1947

+ Pistacio lentisci-Rhamnetalia alaterni Rivas-Martínez 1975

* Asparago-Rhamnion oleoidis (Rivas Goday 1964) Rivas Martínez 1975

47. Asparago albi-Rhamnetum oleoidis Rivas Goday in Rivas Goday, Borja, Esteve, Galiano, Rigual \& Rivas-Martínez 1960

ceratonietosum siliquae Galán de Mera in Pérez Latorre, Galán, P. Navas, D. Navas, Gil \& Cabezudo 1999 [Lentiscares termomediterráneos con algarrobos]

var. con Olea sylvestris sensu Hidalgo \& Pérez Latorre 2013 [Variante subrupícola con acebuches]

48. Comunidad de Chamaerops humilis sensu Pérez Latorre, Caballero, Casimiro-Soriguer, Gavira \& Cabezudo 2008 [Palmitares]

49. Asparago horridi-Juniperetum turbinatae Díez Garretas, Asensi \& Martín Osorio 1996

juniperetosum turbinatae [Sabinares caudados sobre calizas y margas]

pinetosum halepensis subass. nova [Sabinares caudados con pinos carrascos sobre calcarenitas] var. de Halimium halimifolium [Variante de suelos arenosos]

* Rhamno lycioidis-Quercion cocciferae Rivas Goday ex Rivas Martínez 1975

50. Crataego monogynae-Quercetum cocciferae Martínez Parras, Peinado \& Alcaraz 1985

quercetosum cocciferae [Coscojares mesomediterráneos basófilos]

var. con Pistacia lentiscus sensu Pérez Latorre Casimiro-Soriguer, Gavira \& Cabezudo 2012 [Variante termófila]

AGRADECIMIENTOS. A los agentes de medio ambiente de la Junta de Andalucía que nos facilitaron el paso a los carriles de acceso limitado. A Noelia Hidalgo Triana por la elaboración del mapa de situación, colaboración en las recolecciones y preparación del material para el herbario.
ANEXO I

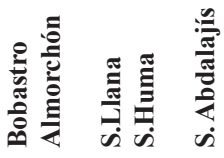

PTERIDOTIFOS

ADIANTACEAE

Adiantum capillus-veneris

ASPLENIACEAE

Asplenium petrarchae

Asplenium trichomanes

Ceterach officinarum

EQUISETACEAE

Equisetum ramosissimum

Equisetum telmateia

HEMIONITIDACEAE

Anogramma leptophylla

Cosentinia vellea

X

SELAGINELLACEAE

Selaginella denticulata

SINOPTERIDACEAE

Cheilanthes acrosticha

GIMNOSPERMAS

CUPRESSACEAE

Juniperus oxycedrus oxycedrus

Juniperus turbinata

EPHEDRACEAE

Ephedra fragilis
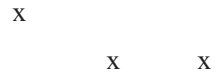

$\mathrm{X}$

$\mathrm{X}$

PINACEAE

Pinus halepensis

Pinus pinaster

ANGIOSPERMAS

AMARYLLIDACEAE

Lapiedra martinezii

Narcissus cantabricus

Narcissus papyraceus

$\mathrm{X}$

ANACARDIACEAE

Pistacia lentiscus

X $\quad \mathrm{X}$

Pistacia terebinthus

X

X

APOCYNACEAE 


\begin{tabular}{|c|c|c|c|c|c|c|c|}
\hline & 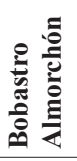 & 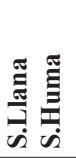 & 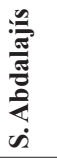 & & 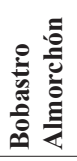 & 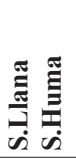 & 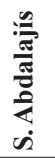 \\
\hline Nerium oleander & $\mathrm{x}$ & & & CAPRIFOLIACEAE & & & \\
\hline Vinca difformis & & $\mathrm{x}$ & & Lonicera periclymenum & $\mathrm{x}$ & & \\
\hline ARACEAE & & & & hispanica & & & \\
\hline Arisarum simorrhinum & & $x$ & & Viburnum tinus & & & $\mathrm{x}$ \\
\hline Arisarum vulgare & $\mathrm{x}$ & $\mathrm{X}$ & $\mathrm{x}$ & CARYOPHYLLACEAE & & & \\
\hline ARALIACEAE & & & & Agrostemma githago & $\mathrm{x}$ & $\mathrm{x}$ & \\
\hline Hedera helix & & $\mathrm{x}$ & & Arenaria arundana & $\mathrm{x}$ & & \\
\hline Hedera hibernica & & & $\mathrm{x}$ & Arenaria hispanica & & & $\mathrm{x}$ \\
\hline ARISTOLOCHIACEAE & & & & Arenaria modesta modesta & $\mathrm{x}$ & $\mathrm{x}$ & $\mathrm{x}$ \\
\hline Aristolochia baetica & $\mathrm{x}$ & $\mathrm{x}$ & $\mathrm{x}$ & $\begin{array}{l}\text { Cerastium gibraltaricum } \\
\text { lanuginosum }\end{array}$ & & $\mathrm{x}$ & $\mathrm{x}$ \\
\hline Aristolochia paucinervis & & $\mathrm{x}$ & $\mathrm{x}$ & Cerastium glomeratum & $\mathrm{x}$ & $\mathrm{x}$ & $\mathrm{x}$ \\
\hline BORAGINACEAE & & & & Cerastium semidecandrum & & $\mathrm{x}$ & $\mathrm{x}$ \\
\hline Alkanna tinctoria & $\mathrm{X}$ & & & Dianthus anticarius & & $\mathrm{x}$ & $\mathrm{x}$ \\
\hline Borago officinalis & & $\mathrm{X}$ & & Dianthus gaditanus & & $\mathrm{x}$ & $\mathrm{x}$ \\
\hline $\begin{array}{l}\text { Cynoglossum cheirifolium } \\
\text { cheirifolium }\end{array}$ & $\mathrm{x}$ & & & Holosteum umbellatum & $\mathrm{x}$ & & \\
\hline $\begin{array}{l}\text { Cynoglossum cheirifolium } \\
\text { heterocarpum }\end{array}$ & & $\mathrm{x}$ & $\mathrm{x}$ & $\begin{array}{l}\text { Minuartia hybrida hybrida } \\
\text { Minuartia mediterranea }\end{array}$ & $\mathrm{x}$ & $\begin{array}{l}\mathrm{x} \\
\mathrm{x}\end{array}$ & $\mathrm{x}$ \\
\hline Echium albicans albicans & & $\mathrm{x}$ & $\mathrm{x}$ & Minuartia montana & & $\mathrm{x}$ & \\
\hline Echium albicans fruticescens & $\mathrm{x}$ & & & Paronychia argentea & $\mathrm{x}$ & $\mathrm{x}$ & $\mathrm{x}$ \\
\hline Echium asperrimum & & $\mathrm{x}$ & & Paronychia suffruticosa hirsuta & $\mathrm{x}$ & & \\
\hline Echium boissieri & & $\mathrm{x}$ & & Paronychia suffruticosa & $\mathrm{x}$ & & \\
\hline Echium creticum coincyanum & $\mathrm{x}$ & $\mathrm{x}$ & & suffruticosa & & & \\
\hline $\begin{array}{l}\text { Myosotis ramosissima } \\
\text { ramosissima }\end{array}$ & & & $\mathrm{x}$ & $\begin{array}{l}\text { Petrorhagia nanteuilii } \\
\text { Petrorhagia saxifraga }\end{array}$ & & $\begin{array}{l}\mathrm{x} \\
\mathrm{x}\end{array}$ & \\
\hline $\begin{array}{l}\text { Neatostema apulum } \\
\text { Omphalodes commutata }\end{array}$ & $\mathrm{x}$ & $\begin{array}{l}\mathrm{x} \\
\mathrm{x}\end{array}$ & $\mathrm{x}$ & $\begin{array}{l}\text { Polycarpon tetraphyllum } \\
\text { tetraphyllum }\end{array}$ & $\mathrm{x}$ & & \\
\hline Omphalodes linifolia & $\mathrm{x}$ & $\mathrm{x}$ & & Silene andryalifolia & & $\mathrm{x}$ & $\mathrm{x}$ \\
\hline CAMPANULACEAE & & & & Silene apetala & $\mathrm{x}$ & & \\
\hline Campanula cabezudoi & & $\mathrm{x}$ & $\mathrm{x}$ & Silene colorata & $\mathrm{x}$ & $\mathrm{x}$ & \\
\hline Campanula dieckii & & $\mathrm{x}$ & & Silene decipiens & $\mathrm{x}$ & & \\
\hline Campanula erinus & $\mathrm{x}$ & $\mathrm{x}$ & & Silene gallica & $\mathrm{x}$ & $\mathrm{x}$ & \\
\hline Campanula mollis & $\mathrm{x}$ & $\mathrm{x}$ & $\mathrm{x}$ & Silene latifolia & & $\mathrm{x}$ & \\
\hline Campanula rapunculus & & & $\mathrm{x}$ & Silene nocturna & & $\mathrm{x}$ & \\
\hline Jasione blepharodon & $\mathrm{x}$ & $\mathrm{x}$ & & Silene secundiflora & $\mathrm{x}$ & $\mathrm{x}$ & $\mathrm{x}$ \\
\hline Legousia scabra & & $\mathrm{x}$ & & Silene tridentata & & $\mathrm{x}$ & \\
\hline Trachelium caeruleum & $\mathrm{x}$ & $\mathrm{X}$ & & Silene vulgaris commutata & & $\mathrm{x}$ & $\mathrm{x}$ \\
\hline
\end{tabular}




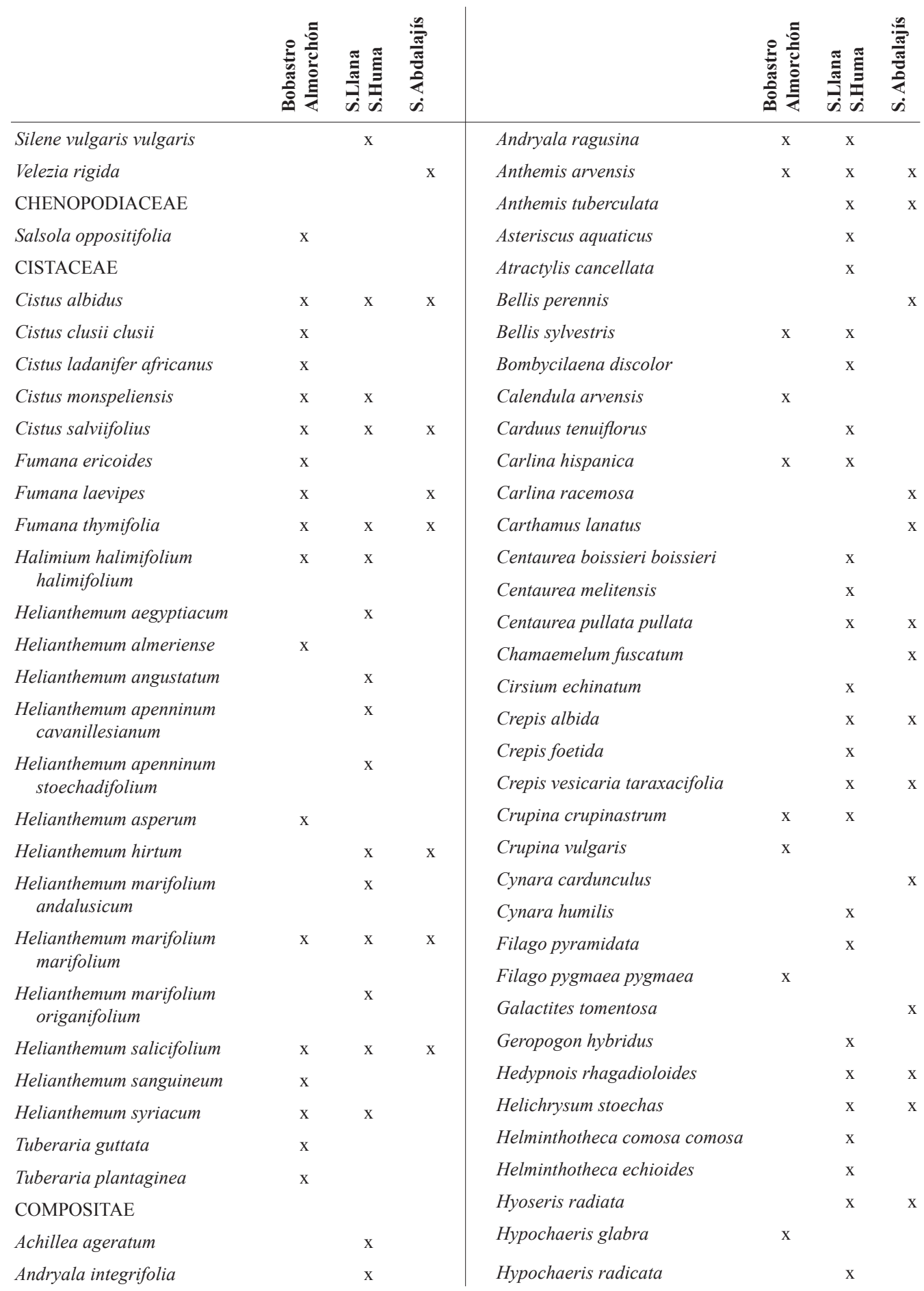




\begin{tabular}{|c|c|c|c|c|c|c|c|}
\hline & 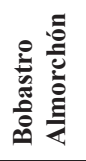 & 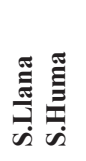 & 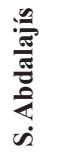 & & 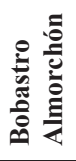 & 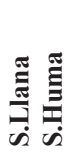 & 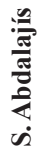 \\
\hline Klasea pinnatifida & & $\mathrm{x}$ & $\mathrm{x}$ & Cuscuta epithymum kotschyi & & & $\mathrm{x}$ \\
\hline Lactuca tenerrima & & $\mathrm{x}$ & $\mathrm{x}$ & CRASSULACEAE & & & \\
\hline Lactuca viminea & & $\mathrm{x}$ & & Crassula tillaea & $\mathrm{x}$ & & \\
\hline Leontodon longirostris & $\mathrm{x}$ & $\mathrm{x}$ & $\mathrm{x}$ & Sedum acre & & $\mathrm{x}$ & \\
\hline Leontodon tuberosus & & $\mathrm{x}$ & $\mathrm{x}$ & Sedum album & $\mathrm{X}$ & & \\
\hline Notobasis syriaca & & $\mathrm{x}$ & & Sedum caespitosum & $\mathrm{x}$ & & \\
\hline Onopordum macracanthum & & $\mathrm{X}$ & & Sedum dasyphyllum & $\mathrm{x}$ & $\mathrm{X}$ & \\
\hline Pallenis spinosa spinosa & & $\mathrm{x}$ & & Sedum mucizonia & $\mathrm{X}$ & $\mathrm{X}$ & $\mathrm{x}$ \\
\hline Phagnalon rupestre & & $\mathrm{x}$ & & Sedum sediforme & $\mathrm{x}$ & $\mathrm{X}$ & \\
\hline Phagnalon saxatile & & $\mathrm{x}$ & & Umbilicus gaditanus & & $\mathrm{x}$ & \\
\hline Phagnalon sordidum & $\mathrm{x}$ & & & Umbilicus rupestris & $\mathrm{x}$ & $\mathrm{x}$ & $\mathrm{x}$ \\
\hline Prolongoa hispanica & $\mathrm{x}$ & & & CRUCIFERAE & & & \\
\hline Ptilostemon hispanicus & & $\mathrm{x}$ & & Alyssum granatense & $\mathrm{x}$ & & \\
\hline Reichardia intermedia & & $\mathrm{x}$ & $\mathrm{x}$ & Alyssum montanum & $\mathrm{x}$ & & \\
\hline Reichardia tingitana & $\mathrm{x}$ & $\mathrm{x}$ & & Alyssum simplex & & & $\mathrm{x}$ \\
\hline Rhagadiolus stellatus & & $\mathrm{x}$ & $\mathrm{x}$ & Arabis auriculata & & $\mathrm{x}$ & \\
\hline Rhaponticum coniferum & & $\mathrm{x}$ & & Arabis verna & $\mathrm{x}$ & & $\mathrm{x}$ \\
\hline Santolina rosmarinifolia & & $\mathrm{x}$ & $\mathrm{x}$ & Biscutella laxa & $\mathrm{x}$ & $\mathrm{x}$ & $\mathrm{x}$ \\
\hline canescens & & & & Biscutella variegata & & & $\mathrm{x}$ \\
\hline Scolymus hispanicus & & $\mathrm{x}$ & & Capsella bursa-pastoris & & & $\mathrm{X}$ \\
\hline Scorzonera angustifolia & & $\mathrm{X}$ & & Cardamine hirsuta & $\mathrm{x}$ & & \\
\hline Scorzonera hispanica crispatula & & $\mathrm{x}$ & & Clypeola jonthlaspi jonthlaspi & $\mathrm{X}$ & $\mathrm{x}$ & \\
\hline Senecio minutus & & $\mathrm{X}$ & $\mathrm{x}$ & Crambe filiformis & $\mathrm{X}$ & $\mathrm{X}$ & $\mathrm{x}$ \\
\hline Silybum marianum & & $\mathrm{X}$ & $\mathrm{x}$ & Erophila verna & $\mathrm{x}$ & & $\mathrm{x}$ \\
\hline Sonchus oleraceus & $\mathrm{X}$ & $\mathrm{x}$ & & Eruca sativa & & $\mathrm{x}$ & \\
\hline Sonchus tenerrimus & $\mathrm{x}$ & $\mathrm{x}$ & & Erucastrum virgatum & $\mathrm{x}$ & & \\
\hline Staehelina dubia & & $\mathrm{x}$ & $\mathrm{x}$ & Hesperis laciniata & & & $\mathrm{x}$ \\
\hline Taraxacum obovatum & & $\mathrm{X}$ & & Hirschfeldia incana & $\mathrm{x}$ & & \\
\hline Tyrimnus leucographus & & $\mathrm{X}$ & & Hornungia petraea & $\mathrm{X}$ & & \\
\hline Urospermum picroides & & $\mathrm{x}$ & & Iberis pectinata & $\mathrm{X}$ & $\mathrm{X}$ & \\
\hline xeranthemum inapertum & & $\mathrm{X}$ & & Jonopsidium prolongoi & & & $\mathrm{x}$ \\
\hline CONVOLVULACEAE & & & & Lepidium calycotrichum & & & $\mathrm{x}$ \\
\hline Convolvulus althaeoides & & & $\mathrm{x}$ & anticarium & & & \\
\hline Convolvulus lanuginosus & & $\mathrm{x}$ & & Lobularia maritima maritima & $\mathrm{x}$ & $\mathrm{x}$ & $\mathrm{x}$ \\
\hline Convolvulus lineatus & & $\mathrm{X}$ & $\mathrm{x}$ & Sinapis alba & & $\mathrm{x}$ & \\
\hline Convolvulus siculus siculus & & $\mathrm{x}$ & & Thlaspi perfoliatum & $\mathrm{x}$ & $\mathrm{X}$ & $\mathrm{X}$ \\
\hline
\end{tabular}




\begin{tabular}{|c|c|c|c|c|c|c|c|}
\hline & 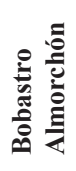 & 嵒 & 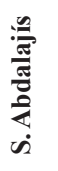 & & 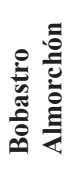 & 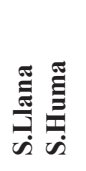 & 递 \\
\hline CUCURBITACEAE & & & & Erodium neuradifolium & $\mathrm{x}$ & & \\
\hline Bryonia dioica & & $\mathrm{x}$ & & Erodium primulaceum & $\mathrm{x}$ & $\mathrm{x}$ & $\mathrm{x}$ \\
\hline CYPERACEAE & & & & Erodium recoderii & & $\mathrm{x}$ & $\mathrm{x}$ \\
\hline Carex distachya & $\mathrm{x}$ & & & Geranium columbinum & & $\mathrm{x}$ & \\
\hline Carex divulsa & & & $\mathrm{x}$ & Geranium dissectum & & $\mathrm{x}$ & \\
\hline Carex flacca & & $\mathrm{x}$ & $\mathrm{x}$ & Geranium lucidum & & & $\mathrm{x}$ \\
\hline Carex halleriana & $\mathrm{x}$ & $\mathrm{x}$ & & Geranium molle & & $\mathrm{x}$ & \\
\hline Carex hispida & $\mathrm{x}$ & & $\mathrm{x}$ & Geranium purpureum & $\mathrm{x}$ & $\mathrm{x}$ & $\mathrm{x}$ \\
\hline Scirpus holoschoenus & $\mathrm{x}$ & & & Geranium rotundifolium & & $\mathrm{x}$ & $\mathrm{x}$ \\
\hline DIOSCOREACEAE & & & & GLOBULARIACEAE & & & \\
\hline Tamus communis & & & $\mathrm{x}$ & Globularia alypum & $\mathrm{x}$ & & \\
\hline DIPSACACEAE & & & & GRAMINEAE & & & \\
\hline Lomelosia stellata & $\mathrm{x}$ & $\mathrm{x}$ & $\mathrm{x}$ & Aegilops geniculata & & $\mathrm{x}$ & \\
\hline Scabiosa turolensis grosii & & $\mathrm{x}$ & $\mathrm{x}$ & Aegilops triuncialis & & $\mathrm{x}$ & \\
\hline EUPHORBIACEAE & & & & Aegilops ventricosa & & $\mathrm{x}$ & \\
\hline Euphorbia exigua exigua & $\mathrm{x}$ & $\mathrm{x}$ & $\mathrm{x}$ & Alopecurus arundinaceus & & $\mathrm{x}$ & \\
\hline Euphorbia peplus & $\mathrm{x}$ & & & Anthoxanthum aristatum & & $\mathrm{x}$ & \\
\hline Euphorbia pterococca & & $\mathrm{x}$ & & Arrhenatherum album & & $\mathrm{x}$ & \\
\hline Euphorbia segetalis & & $\mathrm{x}$ & & Arrhenatherum elatius baeticum & & $\mathrm{x}$ & $\mathrm{x}$ \\
\hline Mercurialis ambigua & & $\mathrm{x}$ & & Avena barbata & $\mathrm{x}$ & $\mathrm{x}$ & $\mathrm{x}$ \\
\hline Mercurialis tomentosa & & $\mathrm{x}$ & & Avenula bromoides bromoides & & $\mathrm{x}$ & $\mathrm{x}$ \\
\hline FAGACEAE & & & & Avenula gervaisii arundana & & $\mathrm{x}$ & $\mathrm{x}$ \\
\hline Quercus coccifera & $\mathrm{x}$ & $\mathrm{x}$ & $\mathrm{x}$ & Avenula gervaisii gervaisii & & $\mathrm{x}$ & $\mathrm{x}$ \\
\hline Quercus rotundifolia & $\mathrm{x}$ & $\mathrm{x}$ & $\mathrm{x}$ & Brachypodium phoenicoides & & $\mathrm{x}$ & \\
\hline GENTIANACEAE & & & & Brachypodium retusum & $\mathrm{x}$ & $\mathrm{x}$ & \\
\hline Blackstonia perfoliata & & $\mathrm{x}$ & & Briza maxima & & & $\mathrm{x}$ \\
\hline Centaurium majus majus & & $\mathrm{x}$ & & Bromus fasciculatus & & & $\mathrm{x}$ \\
\hline GERANIACEAE & & & & Bromus hordeaceus & & $\mathrm{x}$ & \\
\hline Erodium aethiopicum & & $\mathrm{x}$ & & Bromus lanceolatus & & $\mathrm{x}$ & \\
\hline aethiopicum & & & & Bromus rubens & $\mathrm{x}$ & $\mathrm{x}$ & $\mathrm{x}$ \\
\hline Erodium aethiopicum pilosum & $\mathrm{x}$ & & & Catapodium rigidum rigidum & $\mathrm{x}$ & $\mathrm{x}$ & $\mathrm{x}$ \\
\hline Erodium cheilanthifolium & & $\mathrm{x}$ & & Celtica gigantea gigantea & & $\mathrm{x}$ & $\mathrm{x}$ \\
\hline Erodium chium & & $\mathrm{x}$ & & Cynosurus echinatus & & $\mathrm{x}$ & \\
\hline Erodium cicutarium & $\mathrm{x}$ & $\mathrm{x}$ & $\mathrm{x}$ & Dactylis glomerata hispanica & $\mathrm{x}$ & $\mathrm{x}$ & $\mathrm{x}$ \\
\hline Erodium laciniatum & $\mathrm{x}$ & & & Echinaria capitata & & $\mathrm{x}$ & \\
\hline Erodium malacoides & & & $\mathrm{x}$ & Elymus repens repens & & $\mathrm{x}$ & \\
\hline Erodium moschatum & & $\mathrm{x}$ & & Festuca ampla & & $\mathrm{x}$ & \\
\hline
\end{tabular}




\begin{tabular}{|c|c|c|c|c|c|c|c|}
\hline & 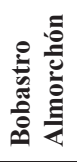 & 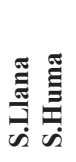 & 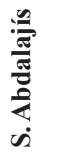 & & 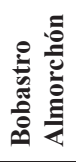 & 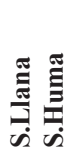 & 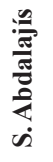 \\
\hline Festuca capillifolia & & $\mathrm{x}$ & $\mathrm{X}$ & Iris planifolia & $\mathrm{x}$ & & \\
\hline Festuca interrupta & & $\mathrm{x}$ & & Iris pseudacorus & $\mathrm{x}$ & & \\
\hline Festuca mediterranea & & & $\mathrm{x}$ & Romulea columnae & $\mathrm{x}$ & & \\
\hline Festuca patula & & $\mathrm{x}$ & & JUNCACEAE & & & \\
\hline Gastridium phleoides & & $\mathrm{x}$ & & Juncus acutiflorus & & $\mathrm{x}$ & $\mathrm{x}$ \\
\hline Gastridium ventricosum & & $\mathrm{x}$ & & Juncus acutus & & $\mathrm{X}$ & \\
\hline Gaudinia fragilis & & & $\mathrm{x}$ & Juncus articulatus articulatus & & $\mathrm{X}$ & $\mathrm{x}$ \\
\hline Helictotrichon filifolium & & $\mathrm{x}$ & $\mathrm{x}$ & Juncus bufonius & & $\mathrm{x}$ & $\mathrm{x}$ \\
\hline arundanum & & & & Juncus hybridus & & $\mathrm{X}$ & \\
\hline Holcus lanatus & & $\mathrm{x}$ & & Juncus inflexus & & $\mathrm{x}$ & \\
\hline Hordeum bulbosum & & & $\mathrm{x}$ & Juncus maritimus & & $\mathrm{x}$ & \\
\hline Hordeum leporinum & & $\mathrm{x}$ & & LABIATAE & & & \\
\hline Koeleria vallesiana & & $\mathrm{X}$ & & Acinos alpinus & & $\mathrm{X}$ & \\
\hline Lagurus ovatus & & $\mathrm{x}$ & & Ballota hirsuta & & $\mathrm{x}$ & \\
\hline Lamarckia aurea & & & $\mathrm{x}$ & Calamintha sylvatica & & & $\mathrm{x}$ \\
\hline Lolium perenne & & & $\mathrm{x}$ & Cleonia lusitanica & & $\mathrm{X}$ & \\
\hline Lolium rigidum & & $\mathrm{x}$ & & Lavandula lanata & & $\mathrm{X}$ & $\mathrm{X}$ \\
\hline Macrochloa tenacissima & $\mathrm{x}$ & $\mathrm{x}$ & & Lavandula stoechas stoechas & $\mathrm{x}$ & $\mathrm{X}$ & \\
\hline Melica magnolii & & $\mathrm{X}$ & $\mathrm{x}$ & Marrubium supinum & & $\mathrm{x}$ & \\
\hline Melica minuta & $\mathrm{x}$ & $\mathrm{X}$ & $\mathrm{x}$ & Marrubium vulgare & & $\mathrm{X}$ & $\mathrm{X}$ \\
\hline Narduroides salzmannii & $\mathrm{x}$ & $\mathrm{x}$ & $\mathrm{x}$ & Mentha pulegium & & & $\mathrm{x}$ \\
\hline Paspalum distichum & & $\mathrm{x}$ & & Micromeria graeca graeca & & $\mathrm{x}$ & $\mathrm{x}$ \\
\hline Phalaris coerulescens & & $\mathrm{x}$ & $\mathrm{x}$ & Nepeta nepetella murcica & & & $\mathrm{x}$ \\
\hline Phragmites australis & $\mathrm{x}$ & & & Nepeta tuberosa & & $\mathrm{x}$ & $\mathrm{x}$ \\
\hline Piptatherum miliaceum & & $\mathrm{X}$ & & Phlomis lychnitis & $\mathrm{X}$ & $\mathrm{X}$ & $\mathrm{X}$ \\
\hline Poa bulbosa & $\mathrm{X}$ & $\mathrm{x}$ & $\mathrm{x}$ & Phlomis purpurea & $\mathrm{X}$ & $\mathrm{X}$ & $\mathrm{X}$ \\
\hline Stipa bufensis & & $\mathrm{x}$ & & Rosmarinus officinalis & $\mathrm{X}$ & $\mathrm{X}$ & $\mathrm{X}$ \\
\hline Stipa capensis & $\mathrm{x}$ & $\mathrm{X}$ & & Salvia argentea & & & $\mathrm{x}$ \\
\hline Trachynia distachya & & $\mathrm{X}$ & $\mathrm{x}$ & Salvia verbenaca & $\mathrm{X}$ & & \\
\hline Vulpia ciliata ciliata & $\mathrm{x}$ & $\mathrm{x}$ & & Salvia viridis & & $\mathrm{X}$ & \\
\hline Vulpia unilateralis & & $\mathrm{x}$ & $\mathrm{x}$ & Sideritis hirsuta & & $\mathrm{X}$ & $\mathrm{x}$ \\
\hline GUTTIFERAE & & & & Sideritis reverchonii & $\mathrm{x}$ & $\mathrm{X}$ & $\mathrm{x}$ \\
\hline Hypericum perforatum & & & $\mathrm{x}$ & Stachys circinata & & $\mathrm{x}$ & $\mathrm{x}$ \\
\hline Hypericum tomentosum & & & $\mathrm{X}$ & Stachys germanica & & $\mathrm{x}$ & \\
\hline IRIDACEAE & & & & Teucrium capitatum & & $\mathrm{X}$ & $\mathrm{x}$ \\
\hline Gynandriris sisyrinchium & & & $\mathrm{x}$ & Teucrium fruticans & & & $\mathrm{X}$ \\
\hline
\end{tabular}




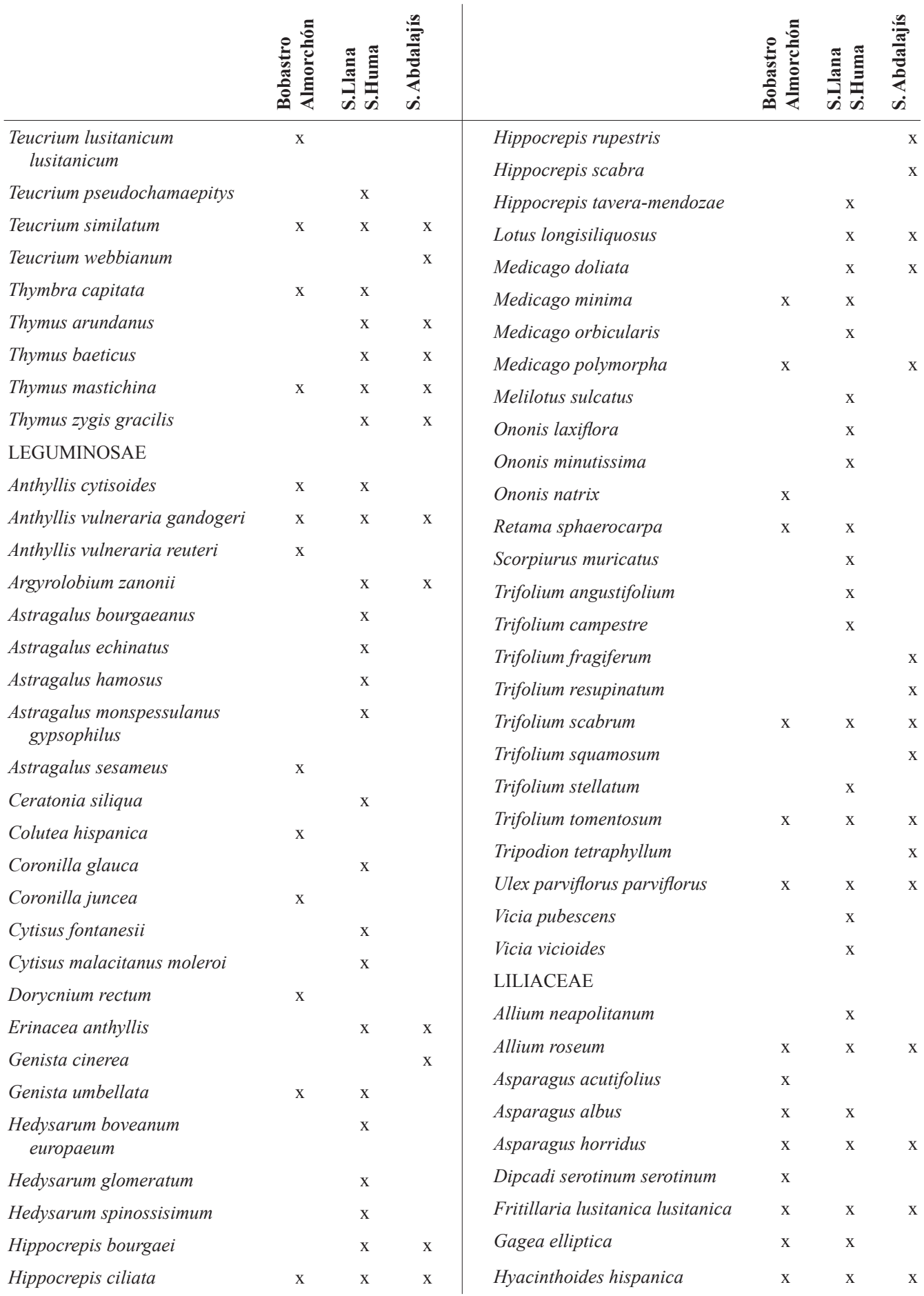




\begin{tabular}{|c|c|c|c|c|c|c|c|}
\hline & 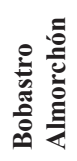 & 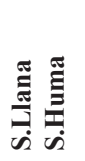 & 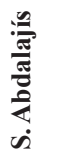 & & 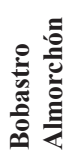 & 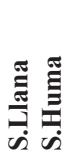 & 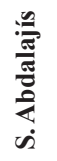 \\
\hline Muscari atlanticum & $\mathrm{x}$ & $\mathrm{x}$ & $\mathrm{x}$ & Neotinea maculata & $\mathrm{x}$ & & \\
\hline Muscari comosum & $\mathrm{x}$ & & & Ophrys fusca & $\mathrm{x}$ & $\mathrm{x}$ & \\
\hline Muscari neglectum & $\mathrm{x}$ & $\mathrm{x}$ & & Ophrys lutea & & $\mathrm{x}$ & \\
\hline Muscari olivetorum & $\mathrm{x}$ & & & Ophrys speculum & $\mathrm{x}$ & $\mathrm{x}$ & \\
\hline $\begin{array}{l}\text { Ornithogalum algeriense } \\
\quad \text { baeticum }\end{array}$ & & $\mathrm{x}$ & $\mathrm{x}$ & $\begin{array}{l}\text { Ophrys tenthredinifera } \\
\text { Orchis collina }\end{array}$ & $\mathrm{x}$ & $\begin{array}{l}\mathrm{x} \\
\mathrm{x}\end{array}$ & $\mathrm{x}$ \\
\hline Ornithogalum narbonense & & $\mathrm{x}$ & $\mathrm{x}$ & Orchis langei & & & $\mathrm{x}$ \\
\hline Scilla autumnalis & $\mathrm{x}$ & & & Orchis mascula & & $\mathrm{x}$ & \\
\hline Scilla peruviana & & & $\mathrm{x}$ & Serapias lingua & & & $\mathrm{x}$ \\
\hline Tulipa sylvestris australis & & & $\mathrm{x}$ & OROBANCHACEAE & & & \\
\hline Urginea maritima & $\mathrm{x}$ & $\mathrm{x}$ & & Orobanche austrohispanica & $\mathrm{x}$ & $\mathrm{x}$ & \\
\hline LINACEAE & & & & Orobanche ballotae & & $\mathrm{x}$ & \\
\hline Linum bienne & & & $\mathrm{x}$ & Orobanche foetida & $\mathrm{x}$ & & \\
\hline Linum narbonense & & & $\mathrm{x}$ & Orobanche nana & $\mathrm{X}$ & & \\
\hline Linum setaceum & & $\mathrm{x}$ & $\mathrm{x}$ & PAEONIACEAE & & & \\
\hline Linum strictum & & $\mathrm{x}$ & & Paeonia broteri & & $\mathrm{x}$ & $\mathrm{x}$ \\
\hline Linum tenue & & $\mathrm{x}$ & & PALMAE & & & \\
\hline LYTHRACEAE & & & & Chamaerops humilis & $\mathrm{x}$ & $\mathrm{x}$ & \\
\hline Lythrum salicaria & $\mathrm{x}$ & & & PAPAVERACEAE & & & \\
\hline $\begin{array}{l}\text { Lythrum thymifolia } \\
\text { MALVACEAE }\end{array}$ & & $\mathrm{x}$ & & $\begin{array}{l}\text { Fumaria macrosepala } \\
\text { macrosepala }\end{array}$ & $\mathrm{x}$ & $\mathrm{x}$ & $\mathrm{x}$ \\
\hline Lavatera cretica & & $\mathrm{x}$ & & Fumaria petteri calcarata & & $\mathrm{x}$ & \\
\hline Lavatera maritima & $\mathrm{x}$ & $\mathrm{x}$ & & Fumaria rupestris rupestris & $\mathrm{x}$ & $\mathrm{x}$ & $\mathrm{x}$ \\
\hline Malva sylvestris & & $\mathrm{x}$ & & Papaver hybridum & & $\mathrm{x}$ & \\
\hline MORACEAE & & & & Papaver rhoeas & & $\mathrm{x}$ & \\
\hline $\begin{array}{l}\text { Ficus carica } \\
\text { MYRTACEAE }\end{array}$ & $\mathrm{x}$ & $\mathrm{x}$ & & $\begin{array}{l}\text { Papaver somniferum } \\
\text { somniferum }\end{array}$ & & $\mathrm{x}$ & \\
\hline Eucalyptus camaldulensis & $\mathrm{x}$ & & & Roemeria argemone & & $\mathrm{x}$ & \\
\hline OLEACEAE & & & & Rupicapnos africana decipiens & $\mathrm{x}$ & $\mathrm{x}$ & \\
\hline Fraxinus angustifolia & $\mathrm{x}$ & & & PLANTAGINACEAE & & & \\
\hline Jasminum fruticans & & $\mathrm{x}$ & & Plantago bellardii & $\mathrm{x}$ & & \\
\hline Olea europaea sylvestris & $\mathrm{x}$ & $\mathrm{x}$ & & Plantago coronopus & $\mathrm{x}$ & & \\
\hline Phillyrea latifolia & & $\mathrm{x}$ & & $\begin{array}{l}\text { Plantago lagopus } \\
\text { Plantago lanceolata }\end{array}$ & $\mathrm{x}$ & $\begin{array}{l}\mathrm{x} \\
\mathrm{x}\end{array}$ & \\
\hline URСНIDACEAE & & & & Plantago serraria & $\mathrm{x}$ & $\mathrm{x}$ & $\mathrm{x}$ \\
\hline Aceras antropophorum & & $\mathrm{x}$ & & PLUMBAGINACEAE & & & \\
\hline Himantoglossum hircinum & & $\mathrm{x}$ & & Armeria villosa longiaristata & & $\mathrm{x}$ & \\
\hline
\end{tabular}




\begin{tabular}{|c|c|c|c|c|c|c|c|}
\hline & 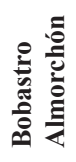 & 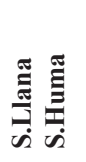 & 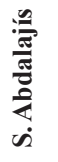 & & 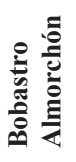 & 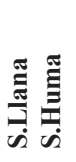 & 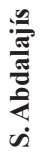 \\
\hline Limonium echioides & $\mathrm{x}$ & & & Reseda barrelieri sessiliflora & $\mathrm{x}$ & & \\
\hline POLYGALACEAE & & & & Reseda lutea & & $\mathrm{x}$ & $\mathrm{x}$ \\
\hline Polygala monspeliaca & & $\mathrm{x}$ & & RHAMNACEAE & & & \\
\hline Polygala rupestris & $\mathrm{x}$ & $\mathrm{x}$ & & Rhamnus alaternus & $\mathrm{x}$ & & $\mathrm{x}$ \\
\hline POLYGONACEAE & & & & Rhamnus lycioides oleoides & $\mathrm{X}$ & $\mathrm{x}$ & $\mathrm{x}$ \\
\hline $\begin{array}{l}\text { Rumex bucephalophorus } \\
\quad \text { gallicus }\end{array}$ & $\mathrm{x}$ & $\mathrm{x}$ & $\mathrm{x}$ & $\begin{array}{l}\text { Rhamnus myrtifolia } \\
\text { ROSACEAE }\end{array}$ & $\mathrm{x}$ & $\mathrm{x}$ & $\mathrm{x}$ \\
\hline Rumex crispus & & & $\mathrm{X}$ & Crataegus monogyna & $\mathrm{X}$ & $\mathrm{X}$ & $\mathrm{x}$ \\
\hline Rumex induratus & $\mathrm{X}$ & & & Potentilla reptans & & $\mathrm{x}$ & \\
\hline Rumex intermedius & & $\mathrm{x}$ & $\mathrm{X}$ & Rosa agrestis & & & $\mathrm{x}$ \\
\hline Rumex scutatus & & $\mathrm{x}$ & & Rubus ulmifolius & $\mathrm{x}$ & & \\
\hline POLYPODIACEAE & & & & Sanguisorba verrucosa & & $\mathrm{X}$ & $\mathrm{x}$ \\
\hline Polypodium cambricum & & $\mathrm{x}$ & $\mathrm{X}$ & RUBIACEAE & & & \\
\hline Polypodium interjectum & & $\mathrm{x}$ & & Asperula hirsuta & & $\mathrm{x}$ & $\mathrm{x}$ \\
\hline POTAMOGETONACEAE & & & & Callipeltis cucullaria & $\mathrm{X}$ & & \\
\hline Potamogeton pectinatus & & $\mathrm{x}$ & & Crucianella angustifolia & & $\mathrm{x}$ & \\
\hline PRIMULACEAE & & & & Galium aparine & & $\mathrm{x}$ & \\
\hline Anagallis arvensis & & $\mathrm{x}$ & & Galium lucidum lucidum & & $\mathrm{x}$ & $\mathrm{x}$ \\
\hline Asterolinon linum-stellatum & $\mathrm{x}$ & $\mathrm{x}$ & $\mathrm{X}$ & Galium minutulum & & $\mathrm{x}$ & \\
\hline Samolus valerandi & $\mathrm{x}$ & & & Galium setaceum & $\mathrm{x}$ & & \\
\hline RANUNCULACEAE & & & & Galium verticillatum & $\mathrm{x}$ & & \\
\hline Anemone palmata & $\mathrm{x}$ & & & Galium verum & & $\mathrm{X}$ & \\
\hline Delphinium gracile & & $\mathrm{x}$ & $\mathrm{x}$ & Putoria calabrica & $\mathrm{X}$ & $\mathrm{X}$ & \\
\hline Delphinium pentagynum & & $\mathrm{x}$ & & Rubia peregrina & $\mathrm{X}$ & $\mathrm{x}$ & \\
\hline Delphinium staphisagria & $\mathrm{x}$ & $\mathrm{x}$ & $\mathrm{x}$ & Sherardia arvensis & $\mathrm{X}$ & & $\mathrm{x}$ \\
\hline Helleborus foetidus & & $\mathrm{x}$ & & Valantia hispida & $\mathrm{X}$ & $\mathrm{X}$ & \\
\hline Nigella damascena & & $\mathrm{x}$ & & Valantia muralis & & $\mathrm{x}$ & \\
\hline Ranunculus bullatus & $\mathrm{x}$ & & & RUTACEAE & & & \\
\hline Ranunculus ficaria ficaria & & $\mathrm{X}$ & $\mathrm{x}$ & Ruta angustifolia & & $\mathrm{X}$ & \\
\hline Ranunculus gramineus & & & $\mathrm{x}$ & SANTALACEAE & & & \\
\hline Ranunculus macrophyllus & & $\mathrm{x}$ & $\mathrm{X}$ & Osyris alba & & & $\mathrm{X}$ \\
\hline Ranunculus muricatus & $\mathrm{X}$ & & & Osyris lanceolata & & $\mathrm{X}$ & \\
\hline Ranunculus paludosus & $\mathrm{x}$ & $\mathrm{X}$ & $\mathrm{x}$ & Thesium humifusum & & $\mathrm{X}$ & \\
\hline $\begin{array}{c}\text { Ranunculus spicatus } \\
\text { blepharicarpos }\end{array}$ & $\mathrm{x}$ & $\mathrm{x}$ & $\mathrm{X}$ & Thesium humile & $\mathrm{x}$ & & \\
\hline RESEDACEAE & & & & SAXIFRAGACEAE & & & \\
\hline Reseda alba & & $\mathrm{x}$ & & Saxifraga globulifera & & $\mathrm{x}$ & \\
\hline
\end{tabular}




\begin{tabular}{|c|c|c|c|c|c|c|c|}
\hline & 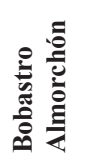 & 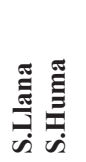 & 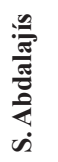 & & 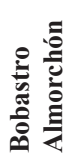 & 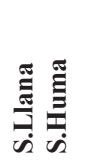 & 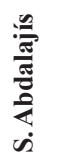 \\
\hline Saxifraga reuteriana & & $\mathrm{x}$ & $\mathrm{x}$ & Apium nodiflorum & & & $\mathrm{x}$ \\
\hline Saxifraga tridactylites & $\mathrm{x}$ & $\mathrm{x}$ & $\mathrm{x}$ & Athamanta vayredana & & $\mathrm{x}$ & \\
\hline SCROPHULARIACEAE & & & & Bunium macuса тасиса & & $\mathrm{x}$ & \\
\hline Antirrhinum barrelieri & & $\mathrm{x}$ & & Bupleurum gibraltaricum & $\mathrm{x}$ & & \\
\hline Antirrhinum controversum & & & $\mathrm{x}$ & Bupleurum spinosum & & $\mathrm{x}$ & \\
\hline Chaenorhinum rubrifolium & & $\mathrm{x}$ & $\mathrm{x}$ & Conium maculatum & & $\mathrm{x}$ & \\
\hline rubrifolium & & & & Conopodium thalictrifolium & & $\mathrm{x}$ & $\mathrm{x}$ \\
\hline $\begin{array}{l}\text { Chaenorhinum villosum } \\
\text { granatense }\end{array}$ & $\mathrm{x}$ & $\mathrm{x}$ & & Daucus carota & & $\mathrm{x}$ & \\
\hline $\begin{array}{l}\text { Chaenorhinum villosum } \\
\text { villosum }\end{array}$ & $\mathrm{x}$ & $\mathrm{x}$ & $\mathrm{x}$ & $\begin{array}{l}\text { Elaeoselinum foetidum } \\
\text { Eryngium campestre }\end{array}$ & & $\mathrm{x}$ & $\mathrm{x}$ \\
\hline Linaria oblongifolia haenseleri & & $\mathrm{x}$ & & Ferula communis catalaunica & & & $\mathrm{x}$ \\
\hline $\begin{array}{l}\text { Linaria oblongifolia } \\
\text { oblongifolia }\end{array}$ & & $\mathrm{x}$ & $\mathrm{x}$ & $\begin{array}{l}\text { Foeniculum vulgare } \\
\text { Lagoecia cuminoides }\end{array}$ & & $\begin{array}{l}\mathrm{x} \\
\mathrm{x}\end{array}$ & \\
\hline Linaria salzmannii & $\mathrm{x}$ & $\mathrm{x}$ & & Oenanthe globulosa & & & $\mathrm{x}$ \\
\hline Linaria tristis & & $\mathrm{x}$ & & Orlaya daucoides & & $\mathrm{x}$ & \\
\hline Linaria verticillata anticaria & & $\mathrm{x}$ & $\mathrm{x}$ & Scandix australis australis & & & $\mathrm{x}$ \\
\hline Misopates orontium & $\mathrm{x}$ & $\mathrm{x}$ & & Scandix pecten-veneris & & $\mathrm{x}$ & $\mathrm{x}$ \\
\hline Parentucellia latifolia & $\mathrm{x}$ & $\mathrm{x}$ & & Scandix stellata & & $\mathrm{x}$ & \\
\hline Scrophularia peregrina & & $\mathrm{x}$ & & Smyrnium olusatrum & $\mathrm{x}$ & $\mathrm{x}$ & $\mathrm{x}$ \\
\hline Scrophularia viciosoi & & $\mathrm{x}$ & & Stoibrax dichotomum & & $\mathrm{x}$ & \\
\hline Verbascum erosum & & & $\mathrm{x}$ & Thapsia villosa & $\mathrm{x}$ & & $\mathrm{x}$ \\
\hline $\begin{array}{l}\text { Verbascum rotundifolium } \\
\text { haenseleri }\end{array}$ & & $\mathrm{x}$ & $\mathrm{x}$ & $\begin{array}{l}\text { Torilis arvensis } \\
\text { Torilis leptophylla }\end{array}$ & $\mathrm{x}$ & $\mathrm{x}$ & $\mathrm{x}$ \\
\hline Verbascum sinuatum & & $\mathrm{x}$ & & URTICACEAE & & & \\
\hline Veronica anagallis-aquatica & & $\mathrm{x}$ & & Parietaria judaica & $\mathrm{x}$ & $\mathrm{x}$ & \\
\hline Veronica cymbalaria & & $\mathrm{x}$ & $\mathrm{x}$ & Parietaria lusitanica & & $\mathrm{x}$ & \\
\hline $\begin{array}{l}\text { SMILACACEAE } \\
\text { Smilax aspera }\end{array}$ & $\mathrm{x}$ & & & Parietaria mauritanica & & $\mathrm{x}$ & \\
\hline $\begin{array}{l}\text { Smilax aspera } \\
\text { THELIGONACEAE }\end{array}$ & & & & Urtica dioica & & $\mathrm{x}$ & \\
\hline Theligonum cynocrambe & & $\mathrm{x}$ & $\mathrm{x}$ & Urtica membranacea & & $\mathrm{x}$ & $\mathrm{x}$ \\
\hline THYMELAEACEAE & & & & $\begin{array}{l}\text { Urtica urens } \\
\text { VAIFRIANACFAF }\end{array}$ & & $\mathrm{x}$ & \\
\hline Daphne gnidium & $\mathrm{x}$ & $\mathrm{x}$ & & VALEKTANACEAГ & & & \\
\hline Thymelaea argentata & & $\mathrm{x}$ & $\mathrm{x}$ & Centranthus macrosiphon & & $\mathrm{x}$ & \\
\hline TYPHACEAE & & & & Fedia cornucopiae & & $\mathrm{x}$ & \\
\hline Typha domingensis & & $\mathrm{x}$ & & Valeriana tuberosa & & $\mathrm{x}$ & \\
\hline UMBELLIFERAE & & & & VIOLACEAE & & & \\
\hline Anthriscus caucalis & & & $\mathrm{x}$ & Viola demetria & & $\mathrm{x}$ & $\mathrm{x}$ \\
\hline
\end{tabular}




\section{BIBLIOGRAFÍA}

ASENSI, A. \& J. M. NIETO CALDERA -1981Vegetación acuática, halófila y halonitrófila de la provincia de Málaga. Trabajos y Monografías del Departamento de Botánica de Málaga 2: 105-122.

ASENSI A., B. DÍEZ GARRETAS \& J. M. NIETO -2005- Torcal de Antequera-Desfiladero de Los

Gaitanes. Guía Geobotánica. XX Jornadas de Fitosociología. Málaga. 87 pp.

BALSERA MEDINA, J. -1989- Mapa de suelos de Andalucía. CSIC-IARA. Madrid.

BLANCA, G., B. CABEZUDO, M. CUETO, C. MORALES TORRES \& C. SALAZAR (eds.) -2011- Flora Vascular de Andalucía Oriental ( $2^{a}$ edición corregida y aumentada). Consejería de Medio Ambiente. Junta de Andalucía. Sevilla.

BRAUN-BLANQUET, J. -1979-. Fitosociología. Ed. Blume. Madrid.

CABEZUdo, B., A. V. PÉREZ LATORRE, P. NAVAS FERNÁNDEZ, Y. GIL JIMÉNEZ \& D. NAVAS FERNÁNDEZ -1998- Paraje Matural de los Reales de Sierra Bermeja. Cartografía y evaluación de la flora y vegetación. Memoria de investigación. Departamento de Biología Vegetal. Universidad de Málaga.

CABEZUDO, B., A.V. PÉREZ LATORRE \& F. CASIMIRO-SORIGUER SOLANAS -2013Vegetación gipsícola del sector Antequerano (provincia Bética, Andalucía). Acta Bot. Malacitana 38: 193-217.

CEBALLOS, L. \& C. VICIOSO. -1933- Estudio sobre la vegetación y flora forestal de la provincia de Málaga. Inst. Forestal de Invest. y Exp. Madrid.

CASTROVIEJO, S. et al. (coord.) -1986-2014Flora iberica. Real Jardín Botánico. CSIC. Madrid.

DE LEÓN LLAMAZARES, A. -1989-. Caracterización agroclimática de la provincia de Málaga. M. A. P. A.

DIERSCHKE, H. -1993- Grundlagen und Methoden der Planzensoziologie. Ulmer. Stuttgart.

FOCAULT, B. -1981-Réflexions su l'apprauvrissement des syntaxons aux limites chorologiques des unités phytosociologiques supérieurs et quelques unes de leurs consequences. Lazaroa 3: 75-100.

GALÁN DE MERA, A., A. V. PÉREZ LATORRE y
J.A. VICENTE ORELLANA -2003- Relaciones fitogeográficas entre el suroccidente de la Península Ibérica y el noroeste de África. Una propuesta de sectorización. Lagascalia 23: 27-52.

GEHÙ, J. M. y S. RIVAS-MARTÍNEZ -1981Notions fondamentales de phytosociologie. In H. Dierschke (ed.). Syntaxonomie, Ber. Int. Symp. Int. Vereinigung Vegetationsk. pp. 5-33. J. Cramer, Vaduz.

GÓMEZ MERCADO, F.J. MOTA, J. PEÑAS, J. CABELLO \& F. VALLE (1994). Vegetación de la Subbética Cordobesa pp. 184-285. Universidad de Almería y Universidad de Granada. Junta de Andalucía.

GUERRA, J. -1982- Catálogo de la flora vascular de la sierra del Torcal de Antequera (Málaga). Homenaje almeriense al botánico Rufino Sagredo. Almería. pp. 105-119.

HIDALGO TRIANA, N. \& A. V. PÉREZ LATORRE -2013-Vegetación y flora de la Sierra de Cártama (Valle del Guadalhorce, Málaga, España). Acta Bot. Malacitana 38: 119-149.

HIDALGO TRIANA N., A. V. PÉREZ LATORRE, \& B. CABEZUDO -2014- Las poblaciones de Juniperus turbinata en el valle del río Guadalhorce (Málaga, España) como indicadoras de territorios relictos paleobiogeográficos. In: Cámara, R., B. Rodríguez \& J. L. Muriel (eds.). Biogeografía de Sistemas Litorales. Dinámica y Conservación. pp. 377-380. Sevilla.

IGME -1978- Mapa Geológico de Ardales a escala 1:50.0000. Hoja 1052. Segunda serie, Primera edición. Madrid.

LÓPEZ GUADALUPE M., G. MARIN, J. MOLERO \& F. ESTEVE -1982- Contribución al estudio de la Asplenietea rupestria en Andalucía Oriental I: Seselietum vayredani López Guadalupe y Esteve Chueca (as. nova). Trab. del Departamento de Botánica (Granada) 7: 5-10.

MÉDAIL, F. \& P. QUÉZEL -1999- Biodiversity Hotspots in the Mediterranean Basin: setting global conservation priorities. Conserv. Biol. 13: $1510-1513$.

MOTA, J.F., J.M. MEDINA-CAZORLA, F.B NAVARRO, F.J. PÉREZ-GARCÍA, A.V., PÉREZ-LATORRE, P. SÁNCHEZ-GÓMEZ, , J.A. TORRES, A. BENAVENTE, G. BLANCA, C. GIL, J. LORITE, M.E. MERLO -2008- 
Dolomite flora of the Baetic Ranges glades (South Spain). Flora 203(5): 359-375.

NIETO CALDERA, J. M., A. V. PÉREZ LATORRE y B. CABEZUDO -1991-. Biogeografía y series de vegetación de la provincia de Málaga (España). Acta Bot. Malacitana 16(2): 417-436. PAVÓN NÚÑEZ, M., N. HIDALGO TRIANA \& A. V. PÉREZ LATORRE -2013- Aportaciones al conocimiento de las comunidades de Pistacia terebinthus L. y de Acer monspessulanum L. en el sur de la Península Ibérica. Lagascalia 33: 299-311.

PÉREZ LATORRE, A. V. -2010- Vegetación terrestre de la provincia de Málaga. Jábega 101: 28-44.

PÉREZ LATORRE A. V., P. NAVAS, D. NAVAS, Y. GIL \& B. CABEZUDO -1998-. Datos sobre la Flora y Vegetación de la Serranía de Ronda (Málaga, España). Acta Bot. Malacitana 23:149-191.

PÉREZ LATORRE A. V. \& B. CABEZUDO -2002-

La flora y el paisaje vegetal de la provincia de Málaga: importancia y conservación. Jábega 90: 25-39.

PÉREZ LATORREA. V., D. NAVAS FERNÁNDEZ, O. GAVIRA, G. CABALLERO \& B. CABEZUDO -2004- Vegetación del P. N. de las Sierras Tejeda, Almijara y Alhama. Acta Bot. Malacitana 29: 117-190.

PÉREZ LATORRE A. V., G. CABALLERO, F. CASIMIRO-SORIGUER SOLANAS, O. GAVIRA y B. CABEZUDO -2008- Vegetación del sector Malacitano-Axarquiense (comarca de la Axarquía, Montes de Málaga). Acta Bot. Malacitana 33: 215- 270.

PÉREZ LATORRE A. V., G. CABALLERO, F. CASIMIRO-SORIGUER SOLANAS, O. GAVIRA \& B. CABEZUDO -2009- Vegetación de la Cordillera Antequerana Oriental (subsector Torcalense). Málaga-Granada (España). Acta Bot. Malacitana 34: 144-173.

PÉREZ LATORRE A. V., F. CASIMIRO-
SORIGUER SOLANAS, O.GAVIRA \& B. CABEZUDO -2012- Vegetación de la Reserva de la Biosfera Sierra de las Nieves: Río Grande y Sierras Prieta y Blanquilla (Málaga, España). Acta Bot. Malacitana 37: 103 -140.

PLAZA ARREGUI, L., A. LORA GONZÁLEZ \& A. J. PUJADAS SALVÁ -2001- Propuesta de ampliación del Paraje Natural del Desfiladero de los Gaitanes (Málaga, España) sobre la base de criterios florísticos. Libro de Actas, tomo I. III Congreso Forestal Español. Granada.

RIVAS GODAY S. \& S. RIVAS MARTÍNEZ -1968- Matorrales y tomillares de la Península Ibérica comprendidos en la clase OnonidoRosmarinetea. Anales Inst. Bot. Cavanilles 25: 5-197.

RIVAS MARTINEZ, S. -1987- Memoria y mapa de las series de vegetación de España (1: 400.000). ICONA. Madrid.

RIVAS MARTÍNEZ, S., T. E. DÍAZ, F. FERNÁNDEZ GONZÁLEZ, J. IZCO, J. LOIDI y A. PENAS -2002-Vascular plant communities of Spain and Portugal. Itinera Geobotanica 15(1, 2): 5-432.

RIVAS MARTÍNEZ, S. -2007- Mapa de series, geoseries y geopermaseries de vegetación de España. Memoria del Mapa de Vegetación Potencial de España. Parte II. Itinera Geobot. 17: 1-436.

RIVAS MARTÍNEZ, S. -2011- Mapa de series, geoseries y geopermaseries de vegetación de España. Memoria del Mapa de Vegetación Potencial de España. Parte II. Itinera Geobot. 18(1): 5-424.

SCHUHWERK, F. -1990- Relikte und Endemiten in Pflanzengesellschaften Bayerns- eine vorlaufige Ubersicht. Ber. Bayer. Bot. Ges. 61: 303-323.

VIGO, J. -1998- Some reflections on geobotany and vegetation mapping. Acta Bot. Barc. 45: 535-566.

WEBER, H. E., J. MORAVEC \& J. P. THEURILLAT -2000- International Code of Phytosociological Nomenclature. J. Veg. Sci. 11: 739-768. 
